\title{
Advanced Hot Gas Filter Development
}

\author{
Topical Report \\ December 1996 - August 1998
}

\author{
By \\ Matthew R. June
}

Work Performed Under Contract No.: DE-AC21-95MC31215

For

U.S. Department of Energy

Office of Fossil Energy

Federal Energy Technology Center P.O. Box 880

Morgantown, West Virginia 26507-0880

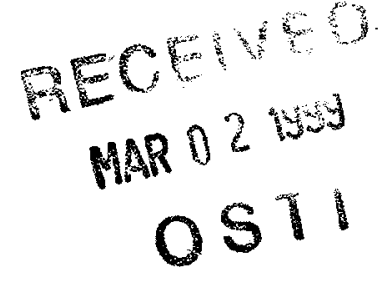

By

Pall Aeropower Corporation 6301 49th Street North

Pinellas Park, Florida 34665-5789 


\section{Disclaimer}

This report was prepared as an account of work sponsored by an agency of the United States Government. Neither the United States Government nor any agency thereof, nor any of their employees, makes any warranty, express or implied, or assumes any legal liability or responsibility for the accuracy, completeness, or usefulness of any information, apparatus, product, or process disclosed, or represents that its use would not infringe privately owed rights. Reference herein to any specific commercial product, process, or service by trade name, trademark, manufacturer, or otherwise does not necessarily constitute or imply its endorsement, recommendation, or favoring by the United States Government or any agency thereof. The views and opinions of authors expressed herein do not necessarily state or reflect those of the United States Government or any agency thereof.

\section{RECEIVED \\ MAR 02 2999 \\ OSTI}




\section{DISCLAIMER}

Portions of this document may be illegible in electronic image products. Images are produced from the best available original document. 


\begin{abstract}
Porous iron aluminide was evaluated for use as a particulate filter for integrated gasification combined cycles (IGCC) with a long term corrosion test. Two alloy compositions were tested: $\mathrm{Fe}_{3} \mathrm{Al} 5 \%$ chromium (FAL) and $\mathrm{Fe}_{3} \mathrm{Al} 2 \%$ chromium (FAS). The samples were preoxidized prior to exposure. The test conditions simulated air blown (Tampa Electric) and oxygen blown (Sierra Pacific) gasifiers with one test gas composition. Testing was conducted at $925^{\circ} \mathrm{F}$ with $78,300 \mathrm{ppm}$ hydrogen sulfide for 1,500 hours. The iron aluminide was found capable of withstanding the proposed operating conditions and capable of giving years of service.
\end{abstract}




\section{Acknowledgments}

The authors acknowledge the advice and encouragement of our METC Project Manager Ted McMahon. Special thanks are due to several individuals at Pall including Steve Geibel (PED) for guidance, to Joe Puzo (MMD) for help in the spinning and vacuum sintering of seamless cylinders and to Keith Rekczis (PED), a team member, for running experiments and for help in upgrading the exposure apparatus. Special thanks are due as well to several staff members at Oak Ridge National Laboratory; these include Peter Tortorelli and Jack de Van (Ret.) for calculating equilibrium atmospheres. 


\section{Table of Contents}

\subsection{EXECUTIVE SUMMARY_ 1}

2.0 INTRODUCTION

3.0 PROCEDURE _ 3

3.1 "Long Term" Exposure Testing ___ 3

3.1.1 Corrosion Test Apparatus ___ 3

3.1.2 Blowback Testing _ 4

3.1.3 Test Atmosphere Components ____ 4

$3.2 \quad$ Non-Destructive Testing __ 5

3.2.1 Mass _______ 5

3.2.2 Pressure Drop ___________ 5

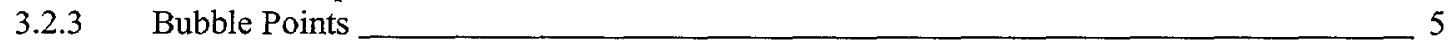

3.2.4 Visual Inspection ____ 6

3.3 Destructive Testing _ 6

3.3.1 Carbon/Sulfur _ 6

3.3.2 Oxygen/Nitrogen___ 6

3.3.3 Ring Burst Test__ 6

3.3.4 Ductility 6

3.3.5 Pore Distribution___ 7

3.3.6 Surface Area __________ 7

3.3.7 Scanning Electron Microscope Examination ___ 7

\subsection{Results \& Discussion__ 7}

4.1 Non-Destructive Test Results and Discussion ___ 7

4.1.1 Mass

4.1.2 Pressure Drop — 9

4.1.3 Bubble Points 9

4.1.4 Visual Inspection ___ 10

4.2 Destructive Test Results and Discussion __ 10

4.2.1 Carbon/Sulfur _ 10

4.2.2 Oxygen/Nitrogen___ 11

4.2.3 Ring Burst Test__ 11

4.2.4 Ductility _ 11

4.2.5 Pore Distribution__ 11

4.2.6 Surface Area _ 12

4.2.7 Scanning Electron Microscope Examination _____ 12

5.0 CONCLUSIONS_ 15

RECOMMENDATION__ 15

APPENDLXI_ 16

APPENDIXII__ 20

APPENDIXIII — 26

APPENDIXIV_ 35

APPENDIXIIV__ 87 


\section{List of Tables}

Table 1: Representative IGCC Atmospheres and a Simulated Atmosphere for Exposure Testing__ 18

Table 2: Percentage Change in Non-Destructive Test Data, Before and After Cleaning _ 19

Table 3: Mechanical and Chemical Data for Controls and Exposure Samples _ 19

Table 4: Mass of Iron Aluminide Filters (Raw Data)_____ 88

Table 5: Pressure Drop of Iron Aluminide Filters (Raw Data) ___ 88

Table 6: First Bubble Point of Iron Aluminide Filters (Raw Data) __ 89

Table 7: Tenth Bubble Point of Iron Aluminide Filters (Raw Data) __ 89

Table 8: Open Bubble Point of Iron Aluminide Filter (Raw Data) __ 90

\section{List of Figures}

Figure 1: Schematic of Process Tube and Test Jig for Long Term Exposure __ 17

Figure 2: Ring Burst Test ___ 17

Figure 3: Change in mass of the iron aluminide samples exposed to $7.83 \mathrm{vol.} \% \mathrm{H}_{2} \mathrm{~S}$ at $925^{\circ} \mathrm{F}$._ 21

Figure 4: Mass gain extrapolations for FAS sample \#3.

Figure 5: Mass gain extrapolations for FAS sample \#3.

Figure 6: Change in pressure drop of the iron aluminide samples ___ 22

Figure 7: Change in first bubble point of the iron aluminide samples__ 23

Figure 8: Change in tenth bubble point of the iron aluminide samples _ 23

Figure 9: Change in open bubble point of the iron aluminide samples _ 24

Figure 10: Change in carbon content of the iron aluminide with exposure time. __ 24

Figure 11: Change in the sulfur content of the iron aluminide alloys.___ 25

Figure 12: Change in strength of the iron aluminide samples after exposure.

Figure 13: Porosimetry of as-sintered FAS media. __ 28

Figure 14: Porosimetry of preoxidized FAS media. 28

Figure 15: Porosimerty of FAS media exposed for 500 hours __ 29

Figure 16: Porosimerty of FAS media exposed for 1000 hours. ___ 29

Figure 17: Porosimerty of FAS media exposed for 1500 hours___ 30

Figure 18: Porosimetry of as-sintered FAL media ___ 32

Figure 19: Porosimetry of preoxidized FAL media

Figure 20: Porosimerty of FAL media exposed for 500 hours. ___ 33

Figure 21: Porosimerty of FAL media exposed for 1000 hours. ___ 33

Figure 22: Porosimerty of FAL media exposed for 1500 hours. __ 34

Figure 23: Cross-section of FAS control sample. Preoxidized for seven hours at $800^{\circ} \mathrm{C}$.

Figure 24: Cross-section of FAS control sample. Preoxidized for seven hours at $800^{\circ} \mathrm{C} \longrightarrow 37$

Figure 25: Partial field spectrum of base metal in Figure 24. Typical iron aluminide signature. __ 38

Figure 26: Partial field of upstream surface of Figure 24.

Figure 27: Upstream surface of FAS control sample. Preoxidized for seven hours at $800^{\circ} \mathrm{C}$. 39

Figure 28: Upstream surface of FAS control sample. Preoxidized for seven hours at $800^{\circ} \mathrm{C}$. 39

Figure 29: Full screen spectrum of Figure 28.

Figure 30: Fracture surface of FAS control sample. Preoxidized for seven hours at $800^{\circ} \mathrm{C}$ —_ 40

Figure 31: Fracture surface of FAS control sample. Preoxidized for seven hours at $800^{\circ} \mathrm{C}$.

Figure 32: Full screen spectrum of Figure 31.

Figure 33: FAS cross-section. Top edge of the sample is the upstream surface. Exposed for 500 hours. 43

Figure 34: FAS cross-section. Top edge of the sample is the upstream surface. Exposed for 500 hours. 43

Figure 35: Spectrum of base metal of Figure 34. Typical iron aluminide signature. _ 44

Figure 36: Spectrum of upstream edge of Figure 34. High sulfur peak with iron. ___ 44

Figure 37: FAS upstream surface. Exposed for 500 hours.

Figure 38: FAS upstream surface. Exposed for 500 hours. Iron sulfide crystals shown.__ 45 
Figure 39: Full screen spectrum of Figure 38. Upstream surface of FAS sample exposed for 500 hours. 46 Figure 40: Spot spectrum of crystal structure on surface of Figure 38. Figure 41: FAS fracture surface. Clean, minimal reaction. Exposed for 500 hours.__ 47 Figure 42: FAS fracture surface. Appears to be a typical iron aluminide surface. Exposed for 500 hours. 47 Figure 43: Full screen spectrum of Figure 42. No sulfur present.

Figure 44: FAS cross-section. Upstream edge shown. Exposed for 1000 hours.___ 50

Figure 45: FAS cross-section. Upstream edge shown. Exposed for 1000 hours._ 50

Figure 46: Partial field of base metal in Figure 45. Typical iron aluminide signature ___ 51

Figure 47: Partial field of upstream edge of Figure 45. High sulfur and iron.

Figure 48: FAS upstream surface. Exposed for 1000 hours. Covered in iron sulfide crystals. ___ 52

Figure 49: FAS upstream surface. Exposed for 1000 hours.

Figure 50: Full screen spectrum of Figure 49. High sulfur and iron. Strong indication of iron sulfide._ 53

Figure 51: FAS fracture surface. Exposed for 1000 hours. ___ 53

Figure 52: FAS fracture surface. Exposed for 1000 hours. __ 54

Figure 53: Full screen spectrum of Figure 52.

Figure 54: FAS cross-section. Upstream edge shown. Exposed for 1500 hours ___ 56

Figure 55: FAS cross-section. Upstream edge shown. Exposed for 1500 hours.. __ 56

Figure 56: Spectrum of base metal on Figure 55. Typical iron aluminide signature. __ 57

Figure 57: Spectrum of upstream edge of Figure 55._ 57

Figure 58: FAS upstream surface. Exposed for 1500 hours. Covered in iron sulfide crystals. ___ 58

Figure 59: FAS upstream surface. Exposed for 1500 hours. ___ 58

Figure 60: Full screen spectrum of Figure 59. High sulfur and iron. Strong indication of iron sulfides. _ 59

Figure 61: FAS fracture surface. Exposed for 1500 hours. _ 59

Figure 62: FAS fracture surface. Exposed for 1500 hours __ 60

Figure 63: Full screen spectrum of Figure 62. Typical iron aluminide signature. 60

Figure 64: Cross-section of FAL control sample. Preoxidized for seven hours at $800^{\circ} \mathrm{C}$ — 62

Figure 65: Cross-section of FAL control sample. Preoxidized for seven hours at $800^{\circ} \mathrm{C}$. — 62

Figure 66: Partial field spectrum of base metal of Figure 65. High carbon is from carbon flashing. — 63

Figure 67: Upstream surface of FAL control sample. Preoxidized for seven hours at $800^{\circ} \mathrm{C}$.

Figure 68: Upstream surface of FAL control sample. Preoxidized for seven hours at $800^{\circ} \mathrm{C}$.

Figure 69: Full screen spectrum of Figure 68. Typical iron aluminide signature.

Figure 70: Fracture surface of FAL control sample. Preoxidized for seven hours at $800^{\circ} \mathrm{C}$ - 65

Figure 71: Fracture surface of FAL control sample. Preoxidized for seven hours at $800^{\circ} \mathrm{C}$ _ 65

Figure 72: Full screen spectrum of Figure 71. Typical iron aluminide signature.

Figure 73: FAL cross-section. Upstream edge shown. Exposed for 500 hours. _ 68

Figure 74: FAL cross-section. Upstream edge shown. Exposed for 500 hours.

Figure 75: Spectrum of the base metal of Figure 74. Typical iron aluminide signature. __ 69

Figure 76: Spectrum of the upstream edge of Figure 74. High sulfur and iron.

Figure 77: FAL upstream surface. Exposed for 500 hours.__ 70

Figure 78: FAL upstream surface. Exposed for 500 hours.

Figure 79: Full screen spectrum of Figure 78. Upstream surface of FAL sample exposed for 500 hours. 71

Figure 80: FAL fracture surface. Exposed for 500 hours.

Figure 81: FAL fracture surface. Exposed for 500 hours.__ 72

Figure 82: Full screen spectrum of Figure 81__ 72

Figure 83: Spot spectrum of bright nodules (1) on Figure 81.____ 73

Figure 84: Spot spectrum of dark clusters (2) on Figure 81.__ 73

Figure 85: FAL cross-section. Upstream edge shown. Exposed for 1000 hours. __ 75

Figure 86: FAL cross-section. Upstream edge shown. Exposed for 1000 hours.

Figure 87: Partial field spectrum of base metal in Figure 86. Typical iron aluminide spectrum.___ 76

Figure 88: Partial field spectrum of upstream edge in Figure 86. High sulfur and iron. ___ 76

Figure 89: Upstream surface of $F A L$ sample exposed for 1000 hours. _- 77

Figure 90: Upstream surface of FAL sample exposed for 1000 hours.

Figure 91: Full screen spectra of Figure 90.

Figure 92: Fracture surface of FAL sample exposed for 1000 hours.___ 78

Figure 93: Fracture surface of FAL sample exposed for 1000 hours.. ___ 79 
Figure 94: Full screen spectrum of Figure 93. Typical iron aluminide signature. 79

Figure 95: FAL cross-section. Upstream edge shown. Exposed for 1500 hours.

Figure 96: FAL cross-section. Upstream edge shown. Exposed for 1500 hours.

Figure 97: Partial field spectrum of the base metal of Figure 96. Typical iron aluminide signature.

Figure 98: Upstream edge of the filter media of Figure 96. High sulfur and iron. 82

Figure 99: Spot spectrum of dark inclusions (1) in Figure 96.

Figure 100: Spot spectrum of light inclusion (2) of Figure 96. Appears to be a zirconia inclusion. 83

Figure 101: FAL upstream surface. Exposed for 1500 hours. Covered in a layer of crystals. 83

Figure 102: FAL upstream surface. Exposed for 1500 hours. 84

Figure 103: Full screen spectrum of Figure 102. 84

Figure 104: FAL fracture surface. Exposed for 1500 hours.

Figure 105: FAL fracture surface. Exposed for 1500 hours. 85

Figure 106: Full screen spectrum of Figure 105. 85 


\subsection{EXECUTIVE SUMMARY}

The overall objective of this project is to commercialize weldable, crack resistant metal filters which will provide several years service in advanced power generation processes. These filters will be used to remove particulates from the gas stream prior to entering a turbine.

The objectives of the current phase are to demonstrate long term corrosion stability for two iron aluminide candidates. The compositions of $\mathrm{Fe}_{3} \mathrm{Al}$ (FAS modification) with $2 \%$ chromium and $\mathrm{Fe}_{3} \mathrm{Al}$ (FAL modification) with $5 \%$ chromium were chosen based on prior short term testing conducted in Task Three of this project. Both of these alloys were preoxidized to form a continuous alumina $\left(\mathrm{Al}_{2} \mathrm{O}_{3}\right)$ layer before placing them in the exposure test stand. Testing was conducted at $496^{\circ} \mathrm{C}\left(925^{\circ} \mathrm{F}\right)$ with 7.83 vol\% $\mathrm{H}_{2} \mathrm{~S}$ at one atmosphere.

Both of the alloys were evaluated for ductility, strength and corrosion resistance. It was found that the alloys experienced an increase in mass for the first five-hundred hours due to the sulfidation of free iron on the exterior surface of the formed alumina layer. Once the iron was sulfidized the rate of mass gain markedly slowed. Both of the alloys demonstrated excellent corrosion resistance. The FAS and FAL alloy ductilities were unaffected by the exposure conditions. The FAS alloy retained most of its strength while the FAL alloy had a decrease. The FAS alloy is favored for most IGCC applications because of its retention of strength. The FAL version should be considered for applications where aqueous corrosion is a concern. The higher chromium content may increase its survivability over the FAS version. 


\subsection{INTRODUCTION}

The development of advanced, coal fired, power generation systems such as pressurized fluid-bed combustion (PFBC) and integrated gasification combined cycles (IGCC) is an important part of the future energy picture for the United States and the world. These technologies can provide economical power generation with minimal environmental emissions and high efficiency. These advanced power generation projects are, however, dependent on the development of durable, economical high temperature filter systems.

Currently high temperature filter systems are in the demonstration phase with the first commercial-scale hot filter systems installed on IGCC units and demonstration units of PBFC systems. These filters are mostly ceramic tubes or candles. Ceramic filter durability has not been high. Failure is usually attributed to mechanical or thermal shock.

For IGCC, the major problem associated with the use of ceramic filters is their lack of resistance to cracking due to mechanical loads. One possible solution to this problem is the development of sintered metal filters (which are more resistant to cracking than ceramic filters) which can withstand the hydrogen sulfide-laden, high temperature gases of these systems. The purpose of this project is to develop crack resistant, corrosion resistant, sintered metal filters of iron aluminide suitable for application in advanced power processes. The goal is to develop filters which will provide several years of service in advanced power gasification applications without a substantial temperature penalty. 


\subsection{PROCEDURE}

Corrosion testing was accomplished by exposing the samples to the simulated IGCC atmosphere at increasing time intervals. This allowed the samples' progress to be monitored. The qualification of the iron aluminide porous media samples was done using both non-destructive and destructive testing. The samples were non-destructively tested during each shutdown of the cyclic testing. At the conclusion of the exposure run and after the last non-destructive tests, the filters were cut into samples for destructive testing as described in section 3.3.

\section{1 "Long Term" Exposure Testing}

Long term corrosion testing of the FAS and FAL preoxidized alloys was performed in a simulated IGCC atmosphere (see Table 1, Appendix I). The samples were preoxidized at $800^{\circ} \mathrm{C}$ for seven hours to form a continuous alumina layer. Prior short term testing has shown that it is beneficial. The long term testing was used to identify trends in alloy performance for the estimation of filter life.

\subsubsection{Corrosion Test Apparatus}

A three zone, $11 \mathrm{kw}, 4.0$ inch diameter, 36 inch long solid tube furnace was used for the elevated temperature exposure testing. This furnace was linked to a second, $5.3 \mathrm{kw}, 3.0$ inch inside diameter, 24 inch tube furnace for preheating the simulated IGCC atmosphere.

The muffles for the furnaces were made of Alonized stainless steel, a preferred containment material for atmospheres that have hydrogen sulfide as a constituent. Both furnaces were operated horizontally. Temperature uniformity was favored by this positioning. The length of the uniform zone in the 4.0 inch diameter furnace was maximized to contain the four test filter elements. The tube that spanned the gap between the two furnaces, containing the simulated atmosphere, was insulated to reduce the loss of heat.

The four filter samples were held between 310 stainless steel hardware by tightening the assembly with a tie rod. Figure 1 (Appendix I) shows a schematic of the assembled filter string. This method allows the removal of the 310 stainless steel hardware for weighing the iron aluminide media. The filter samples were rotated in the filter string, as is common practice in corrosion testing.

For temperature monitoring, two thermocouples were placed in the center of the hot zone length. One was inside the filter string while the other was on the outside. The thermocouples were connected to a strip chart recorder providing a continuous record of temperature versus time. 


\subsubsection{Blowback Testing}

Thermal pulsing was added to the exposure test to check the FAS and FAL candidates for susceptibility to spalling the oxide scale. The thermal pulsing was controlled by timed solenoid valves. The following pulse parameters were chosen to simulate typical service conditions during blowback of filters:

$$
\begin{aligned}
& \text { Pulse Duration }=0.75 \mathrm{~s} \\
& \text { Pulse Frequency }=\text { every } 15 \mathrm{~min} \\
& \text { Velocity }=18 \mathrm{ft} / \text { min } \\
& \text { Pulse gas }=\text { Nitrogen } \\
& \text { Pulse Temperature }=\text { Room Temperature }
\end{aligned}
$$

\subsubsection{Test Atmosphere Components}

The atmosphere consisted of a mixture of hydrogen, carbon monoxide, methane, hydrogen sulfide and steam with sodium chloride, potassium chloride and hydrochloric acid. Table I (Appendix I) lists the operating conditions for representative oxygen blown (Tampa Electric) and air blown (Sierra Pacific) IGCC atmospheres at system pressure. This table also lists the test atmosphere (without nitrogen) that was used, at approximately one atmosphere, to simulate both the oxygen blown and the air blown installations. The composition for this simulation atmosphere was determined by Oak Ridge National Laboratory. The face velocity chosen was 0.5 feet per minute in forward flow. During thermal pulsing, the velocity was 18 feet per minute. The furnace atmosphere flowed from the outside to the inside of the test filters which simulated use. The simulation gas was mixed in the process tube, flowed through the filters and then exited the furnace.

Hydrogen, carbon monoxide, carbon dioxide and methane were dispensed from individual pressurized cylinders. A reservoir filled with DI water plus $\mathrm{NaCl}, \mathrm{KCl}$, and $\mathrm{HCl}$ supplied the water and chlorides to the test stand. Hydrogen sulfide was dispensed from a tank (liquid phase). Provisions were made to measure the hydrogen sulfide levels before and after the gas passed through the filter string. Each day the $\mathrm{H}_{2} \mathrm{~S}$ level was monitored at the inlet and at the outlet of the furnace tube. To measure the $\mathrm{H}_{2} \mathrm{~S}$ levels a Toxic Gas Detector Model 8014KA (Matheson-Kitagawa) was used. The $\mathrm{H}_{2} \mathrm{~S}$ inlet and outlet ports were connected in a tee, this allowed the gas to be flowing while the $\mathrm{H}_{2} \mathrm{~S}$ was being measured. The hydrogen sulfide level outlet was kept within $15 \%$ of the target level. 


\subsection{Non-Destructive Testing}

\subsubsection{Mass}

The mass of the filters was determined to \pm 0.0001 grams using a Mettler AE200 scale.

\subsubsection{Pressure Drop}

The pressure drop in inches $\mathrm{H}_{2} \mathrm{O}$ across the filter media was recorded at a flow of $28 \mathrm{acfm} / \mathrm{ft}^{2}$.

\subsubsection{Bubble Points}

The samples were wet in Filmex-B (denatured ethyl alcohol) and submerged approximately half inch below the surface prior to testing. Stoppers were placed in the open ends of the samples. Air pressure inside the element was gradually increased. The pressures at which the first and tenth bubbles occurred were recorded. The first bubble point is the pressure at which a bubble of air escapes from the largest pore in the sample: it can be correlated to the absolute filter efficiency. The tenth bubble point can be compared against the first bubble point to judge the uniformity of the pore size.

The open bubble point was also recorded. The open bubble point is an indication of the pressure required to pass a specified quantity of air (1 $\mathrm{scfm} / \mathrm{ft}^{2}$ ) with the element wet in Filmex and relates by experience to the average pore size. Below the equations for calculating the pore size are provided.

$$
\begin{aligned}
& d=\frac{4 \gamma}{\Delta p} \\
& \Delta p=p_{0}-p_{1} \\
& p_{1}=9.81 \times \rho_{1} \times h
\end{aligned}
$$

$d=$ pore throat diameter in meters

$\gamma=$ surface tension of liquid. (Filmex-B $=0.0234 \mathrm{~N} / \mathrm{m}$ )

$p_{0}=$ gas pressure in Pascals. $(1$ inch of water $=248.84 \mathrm{~Pa}$ )

$p_{1}=$ pressure of the liquid at the level of bubble formation.

$\rho_{l}=$ density of the test liquid. $\left(\sim 780-850 \mathrm{~kg} / \mathrm{m}^{3}\right)$

It should be noted that the pore size calculated from these equations is only a rough estimate used for quality control. The exposure conditions could potentially alter the surface interaction of the Filmex and media causing 
unaccountable variations of the bubble points over the exposure conditions.

\subsubsection{Visual Inspection}

During each stage of testing the filters were examined visually. Any abnormalities or changes in filter appearance were recorded.

\subsection{Destructive Testing}

\subsubsection{Carbon/Sulfur}

A calibrated (NIST traceable standards) LECO Model CS444 Carbon/Sulfur Determinator was used to measure the carbon and sulfur contents of the samples.

\subsubsection{Oxygen/Nitrogen}

A LECO TC-436 determinator was used to measure the oxygen and nitrogen contents of the samples. Tested in accordance with ASTM E 1019-94.

\subsubsection{Ring Burst Test}

The ring burst test (Figure 2, Appendix I)) places the one-inch tall sample under tension, until failure, by internally compressing a putty. This test removes any alignment and ductility factors that are associated with the Dring tensile test, the typical method of measuring the strength of a cylindrical specimen.

$$
\begin{aligned}
\sigma= & P \frac{r_{1}^{2}+r_{0}^{2}}{r_{1}^{2}-r_{0}^{2}} \\
\sigma & =\text { Modulus of rupture } \\
P & =\text { Pressure on putty at fracture } \\
r_{I} & =\text { outer radius of test ring } \\
r_{0} & =\text { inner radius of test ring }
\end{aligned}
$$

\subsubsection{Ductility}

The ductility of each sample was determined using a ring crush test. The ring crush test was performed using a vise and a 0.50 inch tall ring cut from the element. The ring was placed in the vise bringing the jaws barely in contact with the test ring. The separation of the jaws was measured, with no deformation of the ring at this point. The vise was slowly closed until the ring exhibited gross cracking. The separation of the vise jaws was 
then re-measured. The ratio of the change in the separation of the vise jaws to the original distance is the ductility.

\subsubsection{Pore Distribution}

The pore size distribution was determined using mercury porosimetry. Autoscan-25 and Autoscan-60 mercury porosimeters were used. This will give the overall pore distribution qualitatively. Changes in the pore distributions can be easily seen with this technique.

\subsubsection{Surface Area}

The multipoint BET surface areas are determined on an Autosorb-I sorptometer.

\subsubsection{Scanning Electron Microscope Examination}

Sections of media (as-preoxidized and after exposure to corrosive gases) were examined with an Amray 1830T digital scanning electron microscope (SEM) and a Princeton Gamma-Tech x-ray spectrometer with digital image processing. Cross-sections were mounted in black epoxy fine powder and carbon-flashed to improve conduction. Fracture samples were mounted in the SEM with alligator clips. Robinson backscatter mode of the SEM was used. Qualitative analysis of the samples was done using energy dispersive spectroscopy. (EDS) Quantitative analysis of the samples was not performed because the material did not satisfy the requirements for bulk samples.

\subsection{RESULTS \& DISCUSSION}

\subsection{Non-Destructive Test Results and Discussion}

Plots of the non-destructive test results are in Appendix II as Figure 3 - Figure 9. The raw data that was used to generate the plots is contained in Appendix IIV.

\subsubsection{Mass}

All of the iron aluminide samples had an increase in mass. The plot of the mass gains (Figure 3) demonstrates that the FAS and FAL alloys perform similarly. FAL sample \#1 has a marked increase after thirty-one hours of testing. This was due to a plastic spacer, used to align the filter samples in the test jig, accidentally being left in the jig during testing. If the mass gain due to the plastic is normalized to the mass gain of the other three samples, the rest of the curve would follow the other three. 
The FAS and FAL sample \#3 had a marked increase in mass until 500 hours testing had been completed. This increase in mass is due to the formation of iron sulfides on the upstream surface. The iron sulfides are not believed to be from the base metal, see section 4.2.7. Once all of the material available for sulfidation had reacted with the gas stream the mass gain rate significantly decreased. The total percentage mass gain for the iron aluminide samples exposed for 1,500 hours were $0.39 \%$ and $0.38 \%$ for the FAS and FAL alloys, respectively. After the filter samples were cleaned they had a total mass gain for $0.31 \%$ and $0.29 \%$ for the FAS and FAL alloys, respectively. This is a remarkably low mass gain for a porous metal filter with a total surface area between 5.6 and $6.9 \mathrm{~m}^{2}$, see section 4.2.6. The reduction in mass after the ultrasonic cleaning is due to the removal of soot.

Sample \#2 of the FAS and FAL alloys did not show the same rate of mass gain as the other samples. These samples are from a different sintering and preoxidation batch. There are probably slight differences in the sintering and preoxidation of the media that may alter the continuous alumina layer or the amount of free iron on the exterior of the oxide scale available for sulfidation. These samples have not reached the same percentage of mass gain as the others when there was a noticeable decrease in mass gain rate. It is believed that FAS and FAL and samples \#2 would mimic the same trend as the others alloys and have a decreasing rate of mass gain after another two-hundred and fifty hours, approximately.

The total mass gain of the filter samples exposed for 24,000 hours (using FAS samples \#3), the desired life of the elements, has been projected between $1.6 \%$ and $2.4 \%$ (Figure 4 and Figure 5) using two extrapolation techniques. Extrapolations assume that there is no drastic change in the corrosion mechanism acting upon the alloys. The extrapolations did not take into account the reduction in overall mass gain of the samples after cleaning. This would lower the projected mass gain, however, it is not possible to know if this mass gain, from soot deposition, was linear or parabolic.

The linear extrapolation done for the projected mass gain, after 24,000 hours of exposure, was done using a best fit of the points forming the plateau (500 - 1,500 hours) after the initial mass gain (Figure 4). This would be a crude method to use for a solid material. For a porous material that has demonstrated a marked increase in mass upon the first portion of the exposure, this type of extrapolation can be useful. The linear fit gave a mass gain of $2.4 \%$ after 24,000 hours.

A parabolic fit was done on the entire curve that allows a more traditional estimation of the mass gain of the porous alloy. This fit is in close 
agreement with the final three points of FAS sample \#3. This gave a final mass gain of $1.6 \%$ after 24,000 hours.

\subsubsection{Pressure Drop}

The press drop increase of the samples mimicked the mass gain of the samples (Figure 6). The marked increase on the pressure drop of FAL sample \#1 was from the plastic spacer. FAS and FAL samples \#2 had a lower rate of pressure drop increase. This could be related to slight differences in sintering and preoxidation.

The samples exposed for 500 hours (samples \#1) had pressure drop increases of $62 \%$ and $76 \%$ for the FAS and FAL alloys, respectively. Once they were cleaned, they had increases of $38 \%$ for the FAS and $46 \%$ for the FAL. The FAL sample had and retained a higher pressure drop from the plastic spacer.

Samples \#2 (1000 hours of exposure) had increases of $48 \%$ and $39 \%$ in pressure drop for the FAS and FAL alloys, respectively. These are much lower than the increase seen from the samples exposed for only fivehundred hours. After ultrasonic cleaning, the samples had an overall increase of 3\% for the FAS and $8 \%$ for the FAL. Most of the pressure drop increase for these samples was caused by the deposition of soot in the pores.

The FAS and FAL samples exposed for 1,500 hours (samples \#3) had a total pressure drop increase of $115 \%$. This is an acceptable pressure drop increase. After the samples were ultrasonically cleaned, they had an overall pressure drop increase of $35 \%$. The soot was constricting some of the pores and increasing the pressure drop. Comparing the cleaned pressure drops of samples \#1 and \#3, the pressure drop increases beyond five-hundred hours was caused mainly by soot deposition.

\subsubsection{Bubble Points}

The plots of the first and tenth bubble points do not indicate any trends (Figure 7 and Figure 8). For materials that are not affected by the exposure atmosphere, the bubble points do not offer much insight to the overall effect on the media. The simulated IGCC atmosphere does not affect the iron aluminide media significantly enough for the first and tenth bubble points to be useful.

The open bubble point plot (Figure 9) show a general increase indicating a decrease in the average pore size of the samples. This trend seems to approximate the same behavior seen with the mass and pressure drop increases. There may be an initial decrease of the outer pores of the media, 
due to sulfidation of the free iron (see section 4.2.7) that does not increase after the first five-hundred hours.

The open bubble points of the FAS and FAL samples \#2 were not affected until after seven-hundred and fifty hours of the exposure time. This is a different response than the other four samples. It may be caused by slight variations in sample preparation and the formation of the continuous alumina scale.

\subsubsection{Visual Inspection}

The as-sintered media was a dark grey color. After preoxidation, the media color is a varied "oil slick" color. This is because of variations in the thickness of the thin oxide film causing different levels of interference. After each exposure cycle, the samples would be covered in a black soot. This soot could be smeared but remained on the filter after bubble pointing in Filmex. FAL sample \#1 had a black charred section where the plastic had been during the testing. This effectively blinded the media in this area.

\subsection{Destructive Test Results and Discussion}

Plots of the destructive test results are contained in Appendix II as Figure 10 Figure 12 and Appendix III as Figure 13 - Figure 22. The results for the mechanical and chemical properties are contained in Table 3.

\subsubsection{Carbon/Sulfur}

The carbon content of all the iron aluminide samples did not exceed the typical carbon range. The porous iron aluminide is produced with carbon between $0.08 \%$ and $0.17 \%$. There is no indication of carburization. The change in the carbon content of the samples is plotted as Figure 10. Carbonization and metal dusting in a hydrogen sulfide containing environment is not thermodynamically possible ${ }^{1}$.

All of the samples had an increase in sulfur content (Figure 11). This increase is due to the formation of iron sulfides on the upstream surface of the porous media (see section 4.2.7). The FAS samples had a lower sulfur increase than the FAL samples. Some reasons for the differences are proposed in section 4.2.7. FAS and FAL samples \#2 had a minor percentage increase in sulfur when compared to the other test specimens. This is from the samples having an initially higher sulfur content than the other specimens.

\footnotetext{
${ }^{1}$ J. H. DeVan, P. F. Tortorelli, R. R. Judkins, and I. G. Wright, "Carbon Formation and Metal Dusting in Advanced Coal Gasifiaction Processes", ORNL/TM-13014, Oak Ridge National Lab, February 1997
} 


\subsubsection{Oxygen/Nitrogen}

There was no significant change in the nitrogen content of the iron aluminide. This is expected because of the lack of nitrogen in the simulated atmosphere.

The oxygen contents of the alloys increase upon preoxidation. This is the desired effect of the heat treatment. The oxygen content of the alloys continues to increase during the exposure testing. The alumina scale continues to slowly grow, even in the reducing conditions. Extremely low amounts of oxygen are needed for the alumina scale to grow.

\subsubsection{Ring Burst Test}

The strength of the FAS media was not affected by the exposure in the simulated IGCC conditions. There was a measured decrease in strength of approximately $8 \%$ (Figure 12). This decrease is within the error of the ring burst test. Strength loss of the media does not seem to be a limiting factor in FAS element's life expectancy.

The FAL sample had a marked decrease in strength after five-hundred hours of exposure (Figure 12). The rate of decrease remained constant, within the error of the burst test, for the entire exposure test. This indicates that the decrease in strength occurs in the first five-hundred hours and does not measurably continue. The reason for the decrease in strength of the FAL and not the FAS is not currently known. It is not possible to project the failure of the FAL media based on this data.

\subsubsection{Ductility}

Both of the iron aluminide alloys retained some ductility throughout the exposure testing. After 1,500 hours of testing the samples had a change of ductility of $10 \%$ and $-17 \%$ for the FAS and FAL samples, respectively. These are minor changes considering the low ductility of the iron aluminide alloys. There were no clear trends on the behavior of the ductility of the iron aluminide samples.

\subsubsection{Pore Distribution}

The graphs of the pore distributions (Appendix II) show that there are no major changes in the average pore size of the media during the exposure testing. The pore size is decreased slightly during the preoxidation of the alloys. The growth of the alumina scale slightly reduces the pores of the iron aluminide media. The changes seen on the plots of the pore distribution are difficult to quantify and comparisons can have errors. 
The pore distributions for the FAS media show that the pore size decreases slightly with time. This is probably from the formation of the iron sulfides on the upstream surface of the samples (see section 4.2.7). The FAL media's pore distribution shows increasing pore size with time.

\subsubsection{Surface Area}

The preoxidized control samples had surface areas of 0.05 and $0.04 \mathrm{~m}^{2} / \mathrm{g}$ for the FAS and FAL samples, respectively. The FAS samples had a decrease in surface area for the first one-thousand hours of exposure. After 1,500 hours, the FAS samples had returned to the $0.05 \mathrm{~m}^{2} / \mathrm{g}$. It is unclear why there was a decrease in surface area.

The FAL samples experienced an increase in surface area over the entire exposure testing. After 1,500 hours of the exposure the FAL sample had a surface area of $0.09 \mathrm{~m}^{2} / \mathrm{g}$. The increase in surface area is probably due to the formation of crystals on the upstream surface of the media.

\subsubsection{Scanning Electron Microscope Examination}

All of the SEM images are contained in Appendix IV. The images are subdivided into alloy type within the appendix.

\subsubsection{Control samples}

The control images for the FAS and FAL samples (Figure 23 - Figure 32 and Figure 64 - Figure 72) are typical for preoxidized iron aluminide samples. The dark inclusions seen on the cross-sections are alumina. Light inclusions have been determined to be mainly zirconia. Both types of inclusions are from the water atomization of the alloy.

The upstream surfaces of the controls are covered with small light nodules composed mainly of zirconium. It is presumed that these are actually zirconia. Previous qualification of the iron aluminide powder has not found zirconium, in significant amounts, on the particle surface. The zirconium is diffusing to the surface of the metal particles during sintering. There are occasionally some darker spots on the surface of the particles. These are mainly composed of alumina. None of these sites were documented during this investigation.

The fracture surfaces of the control samples show some of the broken sinter bonds. These are clean transgranular brittle fractures. Most of the fractures occur at the sinter bonds. There appears to be some porosity in the bonds. The FAL alloy has a higher level of porosity in the sinter bonds. The increased amount of porosity in the sinter bonds of the FAL samples 
probably has a strong influence on the inferior mechanical properties compared to the FAS.

\subsubsection{Samples exposed for $\mathbf{5 0 0}$ hours.}

The cross-sections of the FAS and FAL media (Figure 33 - Figure 36 and Figure 73 - Figure 76) show a layer of crystals on the upstream surface of the media. This layer does not continue into the depth of the media. A partial field spectrum of the layer reveals that it is composed primarily of iron and sulfur. These crystals are believed to be iron sulfides. The base metal has not been affected. The layer of iron sulfides and the base metal are believed to be separated by a thin alumina layer formed during preoxidation. This acts as a diffusion barrier preventing the rapid transport of either sulfur into the base metal or iron out.

The iron sulfides are believed to be forming from free iron on the surface. The free iron was available on the outer surface of the alumina scale because of transient oxidation ${ }^{2}$. This occurs during the preoxidation step when the mixture of iron, chromium and aluminum oxides formed from initial adsorption are separated from the base metal by a continuous film of alumina. The alumina layer then thickens to become a protective oxide. It is believed that the current method of preoxidation forms a gammaalumina, based on the $800^{\circ} \mathrm{C}$ process temperature.

The upstream surface of both alloys was covered in crystals (Figure 37 Figure 40 and Figure 77 - Figure 79). A full screen spectrum of each alloy had a substantial peak for iron and sulfur, it is believed that this is from iron sulfides. The upstream pores do not appear constricted from the formation of the iron sulfides. The fracture samples appear to be similar to the control samples. Full screen spectra revealed only small amounts of sulfur. No iron sulfide crystals were found.

\subsubsection{Samples exposed for $\mathbf{1 0 0 0}$ hours.}

The upstream edge of the sample cross-sections for the FAS and FAL alloys appear to be covered with approximately the same amount of iron sulfides as the samples exposed for five-hundred hours (Figure 44 - Figure 47 and Figure 85 - Figure 88). These samples are from a different sintering and preoxidation lot than the others. This could cause differences in the formation of the oxide scale and the amount of iron left on the external surface of the alumina scale. The base metal of both alloys was not affected by the exposure conditions. The upstream surfaces of both alloys (Figure 48 - Figure 50 and Figure 89 - Figure 91) appear to be covered

\footnotetext{
${ }^{2}$ G. C. Wood and F. H. Scott, "Oxidation of alloys", Materials Science and Technology, Vol.3 July 1987
} 
with the same amount of iron sulfide crystals as the samples exposed for five-hundred hours.

The fracture samples for both alloys (Figure 51 - Figure 53 and Figure 92 Figure 94) did not have any iron sulfide crystals on the metal particle surface. These images were collected towards the center of the media thickness. Both alloys demonstrated the typical clean transgranular brittle fracture that is found on most iron aluminide. The full screen spectrum of both samples was a typical preoxidized iron aluminide spectrum. The oxygen peaks are from the alumina layer formed during preoxidation.

\subsubsection{SamplesP exposed for 1500 hours.}

The cross-sections of the FAS and FAL alloys (Figure 54 - Figure 57 and Figure 95 - Figure 100) were very similar to those of the samples exposed for five-hundred hours. There did not appear to be any significant increase in the formation of iron sulfides on the upstream surface of the media. There were no indications of attack of the base metal or grain boundaries. The partial field spectra of the base metal close to the upstream surface did not contain any sulfur.

The upstream surfaces of the samples (Figure 58 - Figure 60 and Figure 101 - Figure 103) were covered in iron sulfide crystals. These appear to have the same morphology as those seen on the samples exposed for fivehundred hours. The upstream surface maintains open pores that are not significantly obstructed by the formation of the sulfides.

The fracture samples for both alloys (Figure 61 - Figure 63, Figure 104 Figure 106) were similar to the control images. The fracture surfaces had some porosity and were clean and transgranular. Full screen spectra revealed no sulfur for the FAS and nearly undetectable sulfur for the FAL. 


\subsection{CONCLUSIONS}

1. Both the FAS and FAL iron aluminide media experience an initial mass gain from the sulfidation of the free iron present of the upstream surface of the continuous alumina layer from transient oxidation. The rate of the mass gain decreased to an acceptable level for a metal media for use in IGCC installations.

2. The FAS alloy should be capable of providing an operating lifetime of 24,000 hours in similar conditions. The predicted mass gain for the media is between 1.6 and $2.4 \%$.

3. The FAL alloy may be used in IGCC applications where downtime corrosion is a critical concern. The alloy demonstrated a loss in strength upon the first five-hundred hours of the testing. The strength is needed for an iron aluminide element to function in an IGCC installation is not known.

\section{RECOMMENDATION}

A mixture of FAS and FAL elements should be produced under Task Five. This would allow the evaluation of each alloy in a number of industrial installations. 
APPENDIX I

\section{Drawings and Tables}




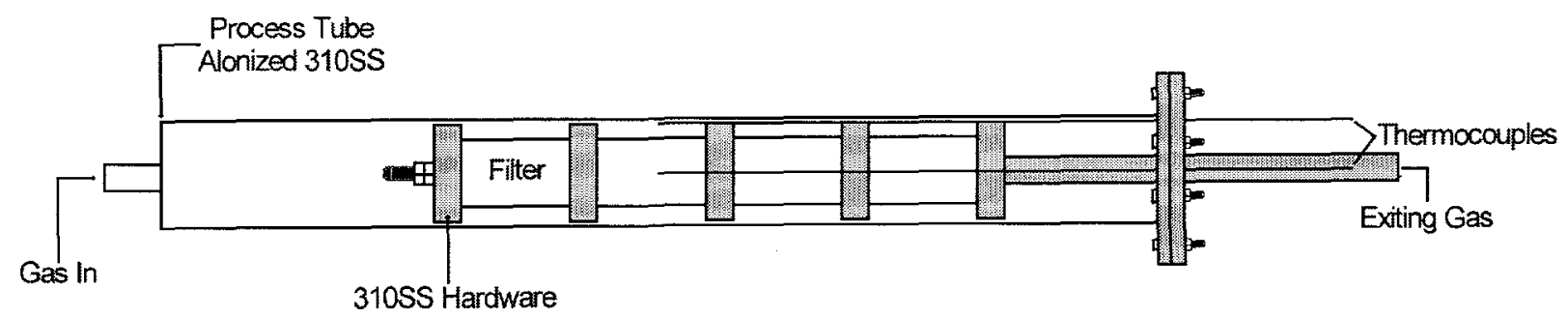

Figure 1: Schematic of Process Tube and Test Jig for Long Term Exposure

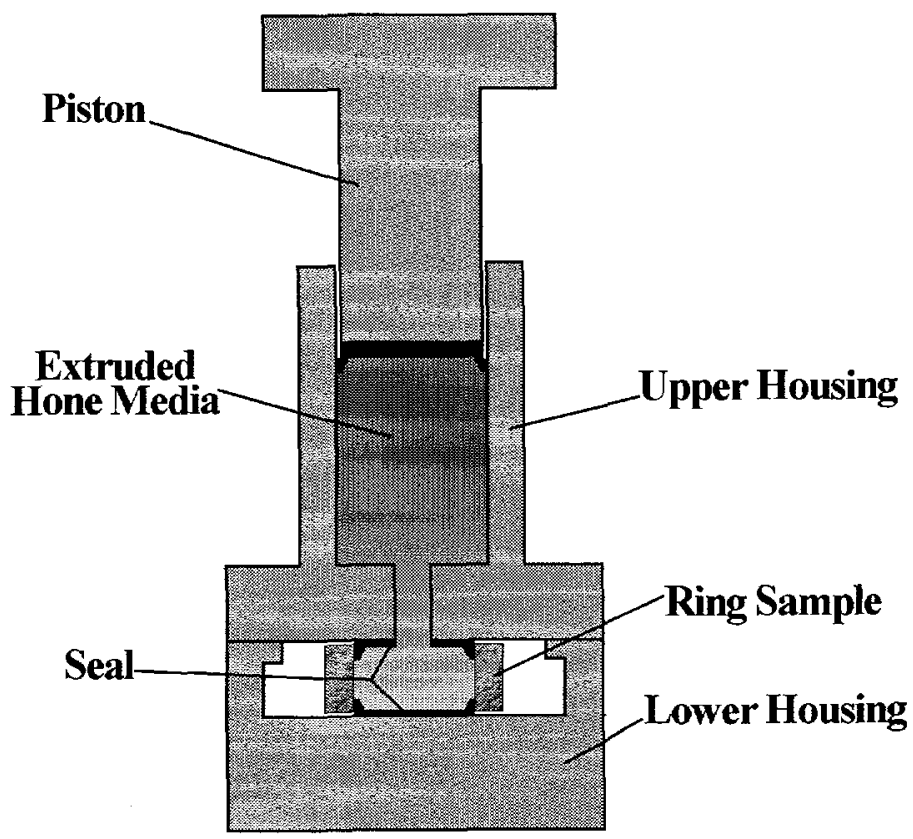

Figure 2: Ring Burst Test 
Table 1: Representative IGCC Atmospheres and a Simulated Atmosphere for Exposure Testing

\begin{tabular}{|c|c|c|c|}
\hline $\begin{array}{c}\text { Types of } \\
\text { Atmosphere }\end{array}$ & $\begin{array}{l}\text { Oxygen Blown } \\
\text { (Tampa Electric) }\end{array}$ & $\begin{array}{c}\text { Air Blown } \\
\text { (Sierra Pacific) }\end{array}$ & $\begin{array}{c}\text { Simulated* } \\
\text { Atmosphere } \\
\text { (w/o Nitrogen } \\
\text { w/ Chlorides) }\end{array}$ \\
\hline Temperature ${ }^{\circ} \mathrm{F}$ & $900-925$ & $1000-1050$ & 925 \\
\hline Pressure & $\begin{array}{l}400 \mathrm{psia} \\
26.1 \mathrm{~atm}\end{array}$ & $272-275$ psia & $\sim 1 \mathrm{~atm}$ \\
\hline Component & Mole \% & Mole \% & Mole \% \\
\hline $\mathrm{CO}$ & 40.36 & 28.89 & 34.1 \\
\hline $\mathrm{H}_{2}$ & 28.20 & 14.57 & 31.4 \\
\hline $\mathrm{CO}_{2}$ & 10.34 & 5.44 & 15.7 \\
\hline $\mathrm{H}_{2} \mathrm{O}$ & 14.16 & 5.50 & 9.2 \\
\hline $\mathrm{CH}_{4}$ & 0.15 & -- & 0.92 \\
\hline $\mathrm{Ar}$ & 0.94 & 0.60 & -- \\
\hline $\mathrm{N}_{2}$ & 5.13 & 48.65 & -- \\
\hline $\cos$ & 0.02 & -- & -- \\
\hline $\mathrm{O}_{2}$ & 0.00 & 0.00 & 0.00 \\
\hline $\mathrm{H}_{2} \mathrm{~S}$ & $0.63^{* *}$ & $0.03 * *$ & 7.83 \\
\hline $\mathrm{HCl}$ & NA & NA & $80 \mathrm{ppm}$ \\
\hline $\mathrm{NaCl}$ & NA & NA & $2 \mathrm{x}^{* * *} 2 \mathrm{ppm}$ \\
\hline $\mathrm{KCl}$ & NA & NA & $2 \mathrm{x}^{* * *} 5.5 \mathrm{ppm}$ \\
\hline
\end{tabular}

Comparison of Test Atmosphere and Actual Atmosphere ${ }^{* * *}$

\begin{tabular}{|c|c|}
\hline $\begin{array}{c}\mathrm{H}_{2} \mathrm{~S} \text { Level for Long Term Exposure Test at } \\
1 \text { atmosphere }\end{array}$ & $\begin{array}{c}\text { Equivalent } \mathrm{H}_{2} \mathrm{~S} \text { Level in Oxygen Blown } \\
\text { Gasifier at 26.1 atmospheres }\end{array}$ \\
\hline $7.83 \mathrm{vol} \%$ & $0.72 \mathrm{~mol} \%$ \\
\hline
\end{tabular}

* Corresponds with oxygen blown Tampa Electric, equilibrated at $1300^{\circ} \mathrm{F}$, at 1 bar with no nitrogen.

** Upstream of final desulfurization which is expected to lower $\mathrm{H}_{2} \mathrm{~S}$ to $0.003 \%$ (30 ppm)

*** Amount added

**** Calculated by Peter Tortorelli of Oak Ridge National Laboratory

Note: Temperatures and pressures supplied by FETC (Morgantown). 
Table 2: Percentage Change in Non-Destructive Test Data, Before and After Cleaning

\begin{tabular}{|c|c|c|c|c|c|c|c|c|c|c|}
\hline \multirow{2}{*}{$\begin{array}{c}\text { Sample } \\
\text { ID }\end{array}$} & \multicolumn{2}{|c|}{ Mass } & \multicolumn{2}{|c|}{ Pressure Drop } & \multicolumn{2}{|c|}{ First Bubble Point } & \multicolumn{2}{|c|}{ Tenth Bubble Point } & \multicolumn{2}{|c|}{ Open Bubble Point } \\
\hline & Before & After & Before & After & Before & After & Before & After & Before & After \\
\hline FAS \#1 & 0.29 & 0.16 & 63 & 38 & -40 & -5 & 13 & 5 & 29 & 13 \\
\hline FAS \#2 & 0.27 & (a) & 48 & 3 & -77 & -11 & -6 & -12 & 17 & -10 \\
\hline FAS \#3 & 0.39 & 0.31 & 115 & 35 & -57 & -14 & 3 & -7 & 56 & 6 \\
\hline FAL \#1 & 0.41 & 0.30 & 76 & 46 & -11 & 2 & 10 & 7 & 40 & 27 \\
\hline FAL \#2 & 0.28 & (a) & 39 & 8 & -65 & -78 & -9 & -4 & 27 & -5 \\
\hline FAL \#3 & 0.38 & 0.29 & 115 & 35 & -4 & -1 & 12 & 2 & 32 & 14 \\
\hline
\end{tabular}

(a) Data not available

Table 3: Mechanical and Chemical Data for Controls and Exposure Samples

\begin{tabular}{|l|l|c|c|c|c|c|c|c|c|}
\hline Sample ID & \multicolumn{1}{|c|}{ Filter ID } & $\begin{array}{c}\text { Exposure } \\
\text { (hours) }\end{array}$ & $\begin{array}{c}\text { Carbon } \\
(\mathrm{wt} \%)\end{array}$ & $\begin{array}{c}\text { Sulfur } \\
(\mathrm{wt} \%)\end{array}$ & $\begin{array}{c}\text { Oxygen } \\
(\mathrm{wt} \%)\end{array}$ & $\begin{array}{c}\text { Nitrogen } \\
(\mathrm{wt} \%)\end{array}$ & $\begin{array}{c}\text { Ductility } \\
(\%)\end{array}$ & $\begin{array}{c}\text { Burst Test } \\
\mathrm{MOR}(\mathrm{psi})\end{array}$ & $\begin{array}{c}\text { Surface Area } \\
\left(\mathrm{m}^{2} / \mathrm{g}\right)\end{array}$ \\
\hline & T-260-C-Con & 0 & 0.126 & 0.009 & 0.170 & 0.006 & 6.1 & 12800 & 0.05 \\
& IA-66-C-Con & 0 & 0.113 & 0.049 & 0.260 & 0.004 & 5.6 & 12600 & 0.05 \\
FAS \#1 & T-260-C-1 & 500 & 0.120 & 0.067 & 0.210 & 0.002 & 4.4 & 13000 & 0.04 \\
FAS \#2 & IA-66-C & 1000 & 0.108 & 0.074 & 0.850 & 0.004 & 5.9 & 11000 & 0.03 \\
FAS \#3 & T-260-C-2 & 1500 & 0.105 & 0.139 & 0.620 & 0.012 & 6.7 & 11900 & 0.05 \\
& T-261-B-Con & 0 & 0.156 & 0.006 & 0.530 & 0.005 & 4.7 & 11400 & 0.04 \\
& IA-75-B-Con & 0 & 0.123 & 0.066 & 0.710 & 0.004 & 4.4 & 14700 & 0.04 \\
FAL \#1 & T-261-B-1 & 500 & 0.150 & 0.105 & 0.600 & 0.002 & 5.3 & 6900 & 0.05 \\
FAL \#2 & IA-75-B & 1000 & 0.110 & 0.109 & 0.590 & 0.004 & 4.5 & 6400 & 0.06 \\
FAL \#3 & T-261-B-2 & 1500 & 0.140 & 0.156 & 0.600 & 0.005 & 3.9 & 6100 & 0.09 \\
\hline
\end{tabular}


APPENDIX II

\section{GRAPHS of DATA}




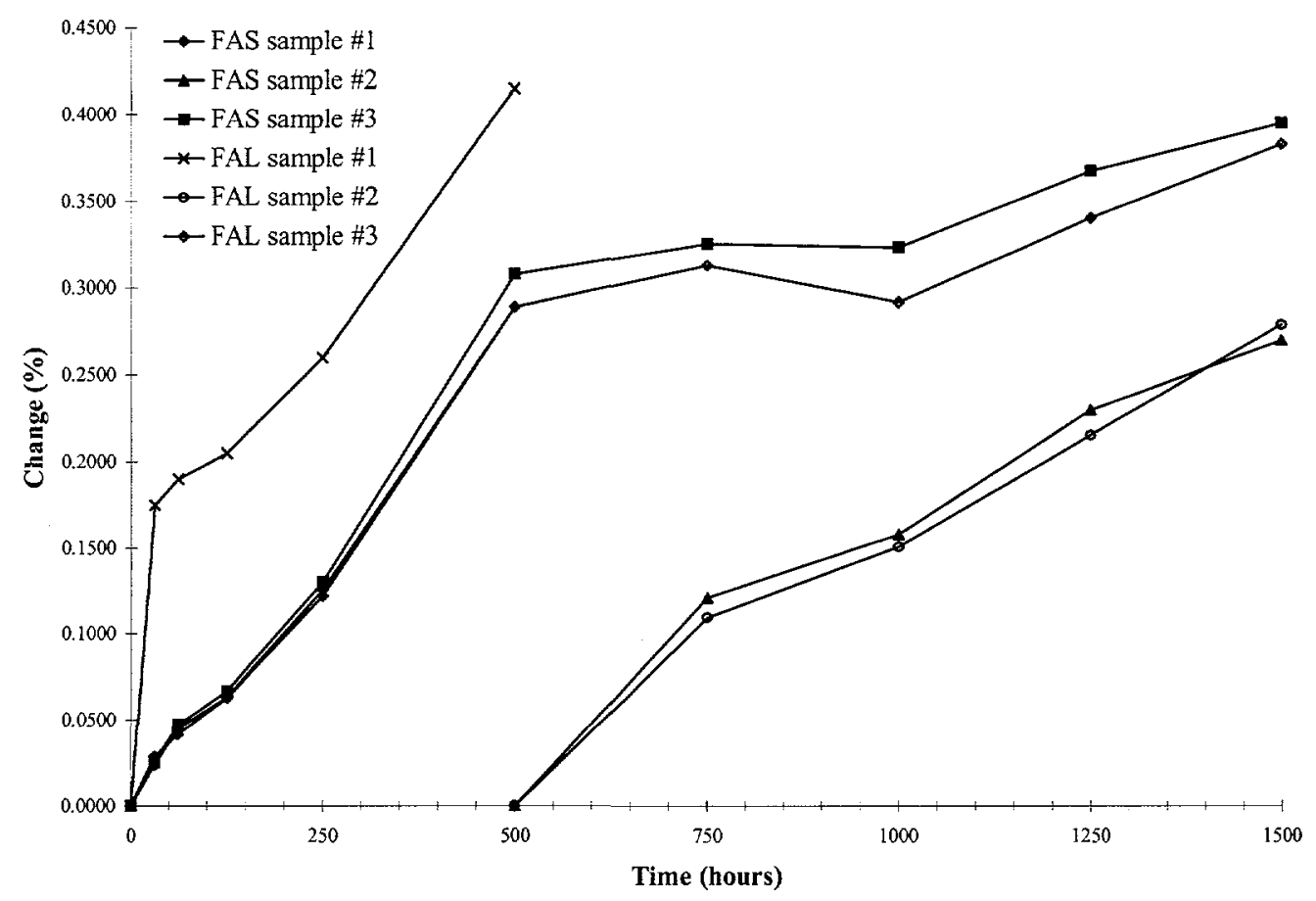

Figure 3: Change in mass of the iron aluminide samples exposed to 7.83 vol. $\% \mathrm{H}_{2} \mathrm{~S}$ at $925^{\circ} \mathrm{F}$. These are low mass gains for a porous sample having a total surface area between 5.6 and $6.9 \mathrm{~m}^{2}$

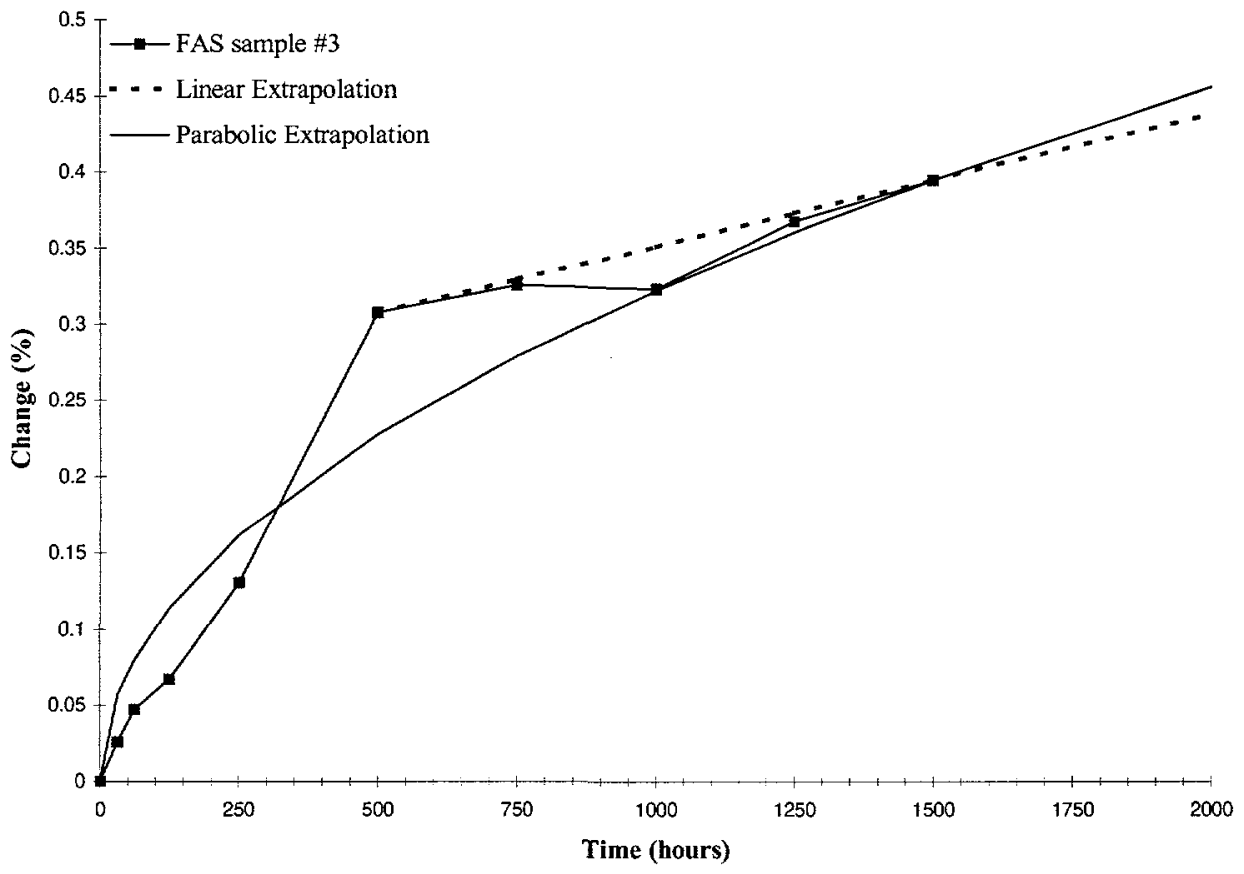

Figure 4: Mass gain extrapolations for FAS sample \#3. Both the linear and parabolic fits are shown. Linear fit was done after five-hundred hours of testing. 


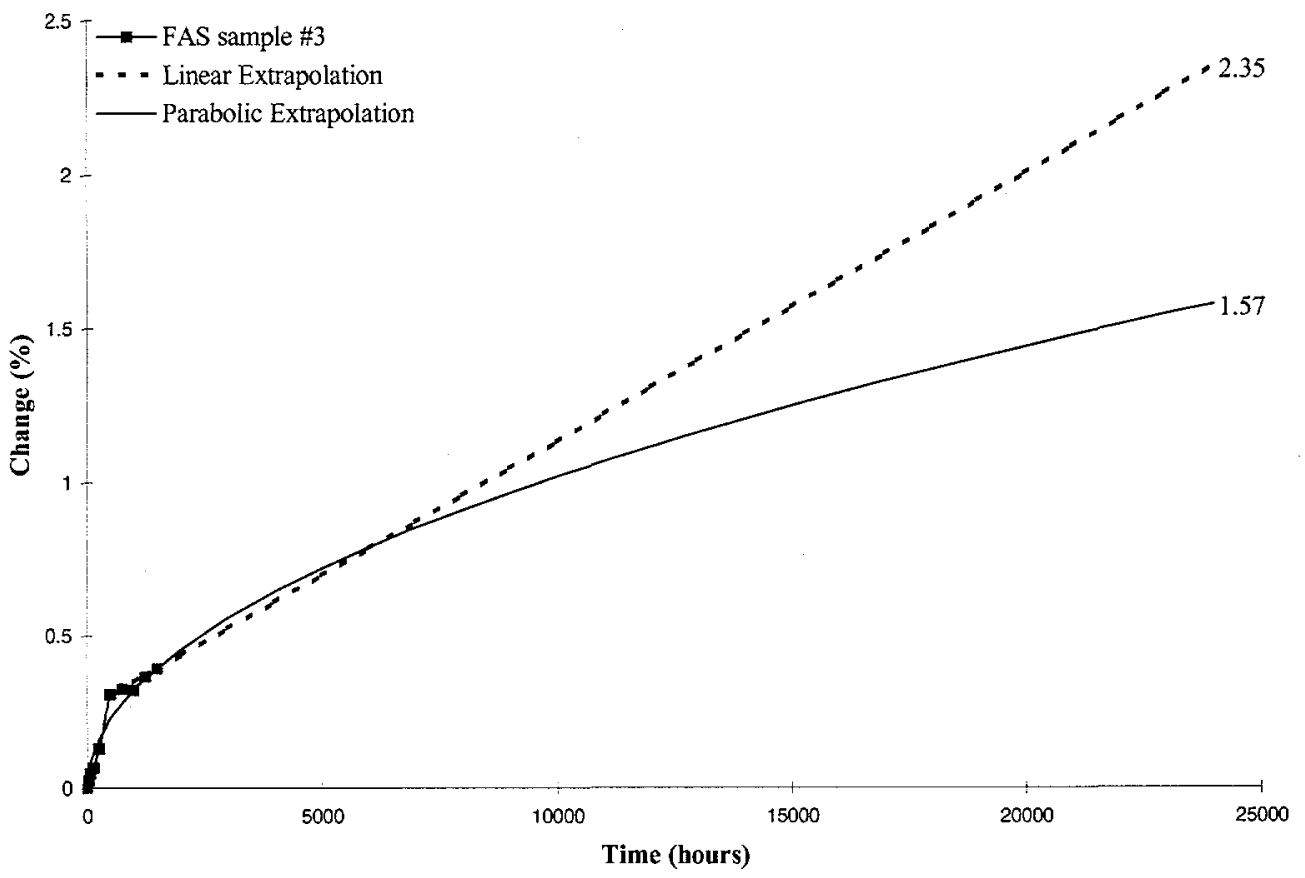

Figure 5: Mass gain extrapolations for FAS sample \#3. Both the linear and parabolic fits are shown. The approximated range of mass gains is between 1.57 and $2.35 \%$.

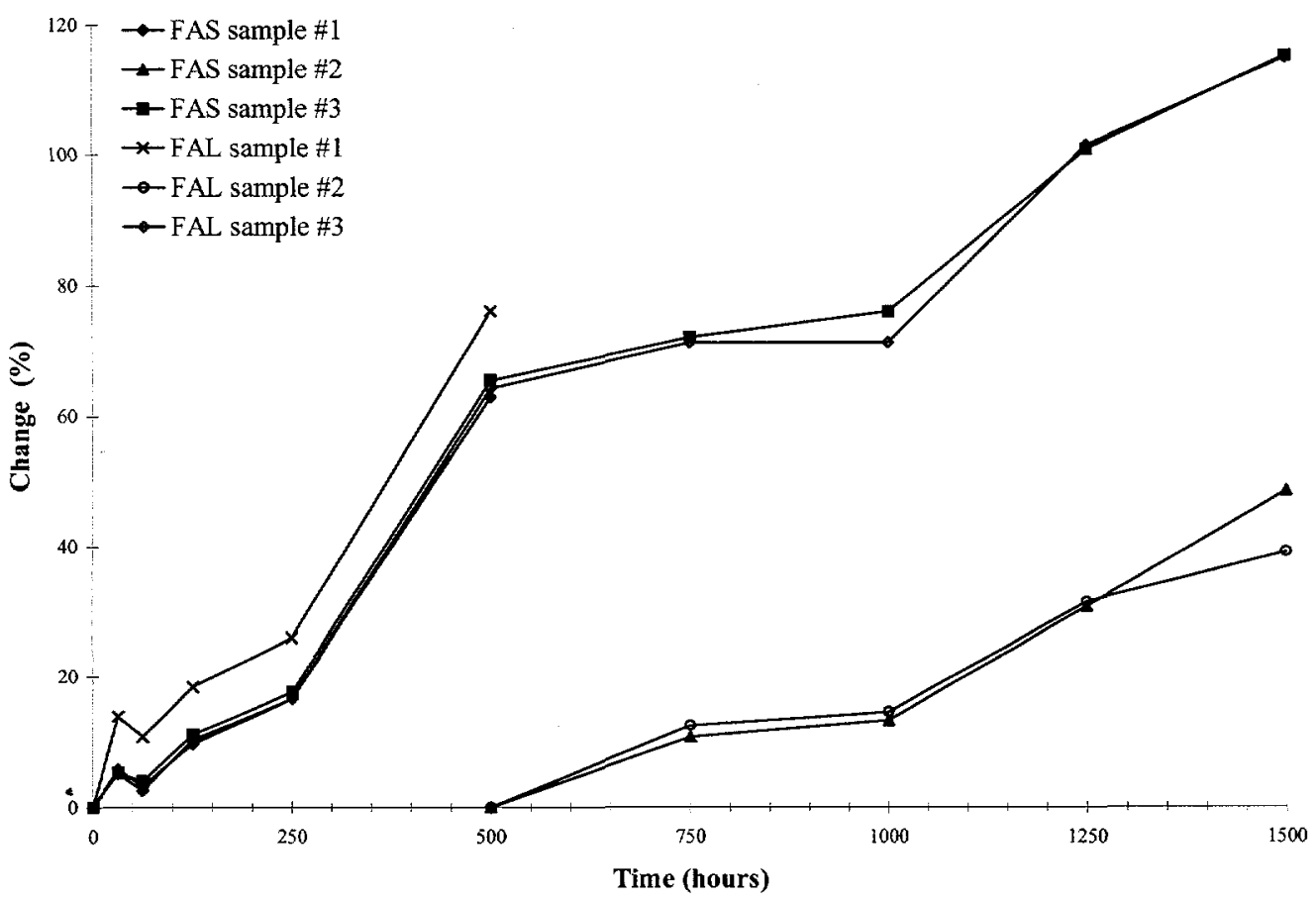

Figure 6: Change in pressure drop of the iron aluminide samples exposed to 7.83 vol. $\% \mathrm{H}_{2} \mathrm{~S}$ at $925^{\circ} \mathrm{F}$. These are insignificant increases for a hot gas filter. A permanent ash cake will cause an increase far higher than these. 


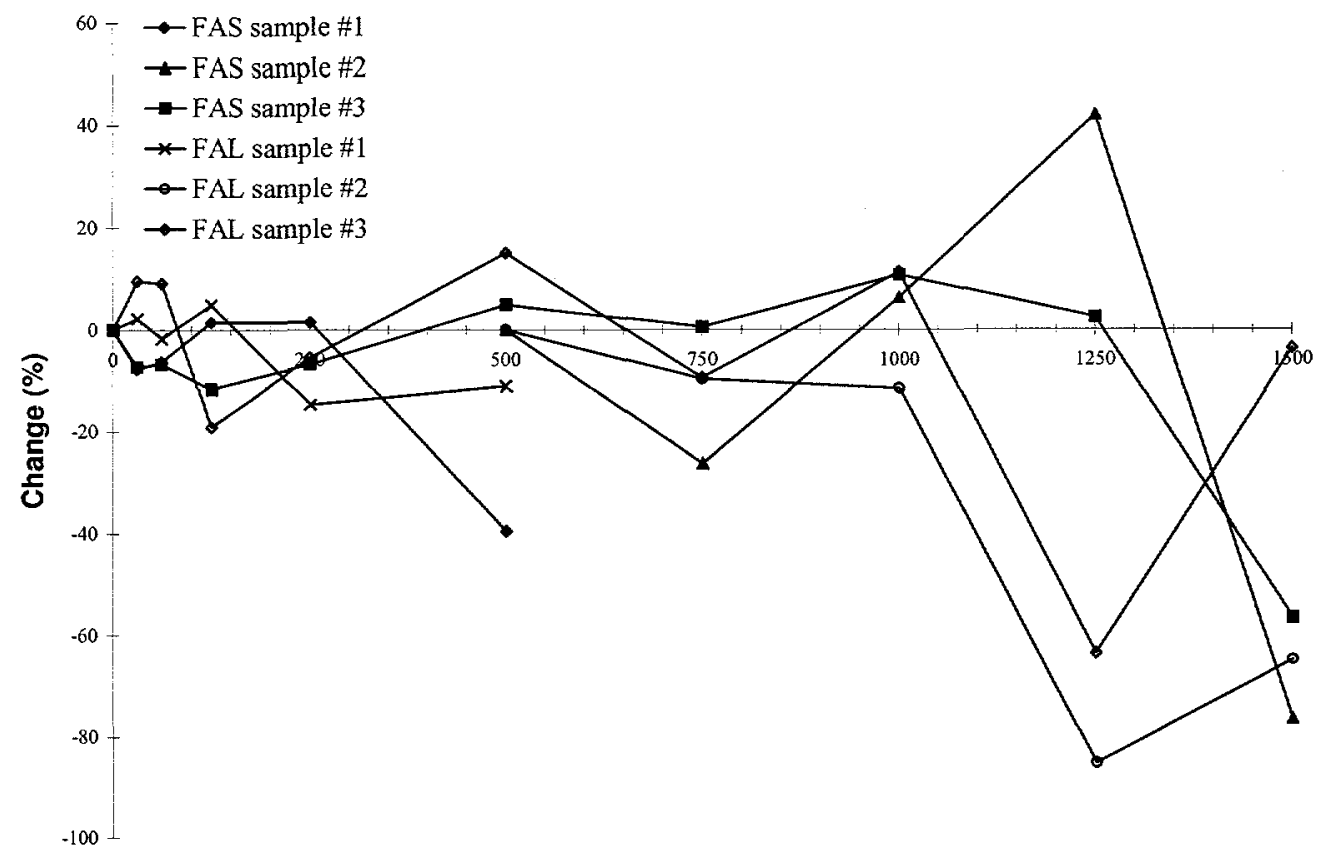

Time (hours)

Figure 7: Change in first bubble point of the iron aluminide samples exposed to 7.83 vol. $\% \mathrm{H}_{2} \mathrm{~S}$ at $925^{\circ} \mathrm{F}$. These results are inconclusive. Mercury porosimetry provides clearer results.

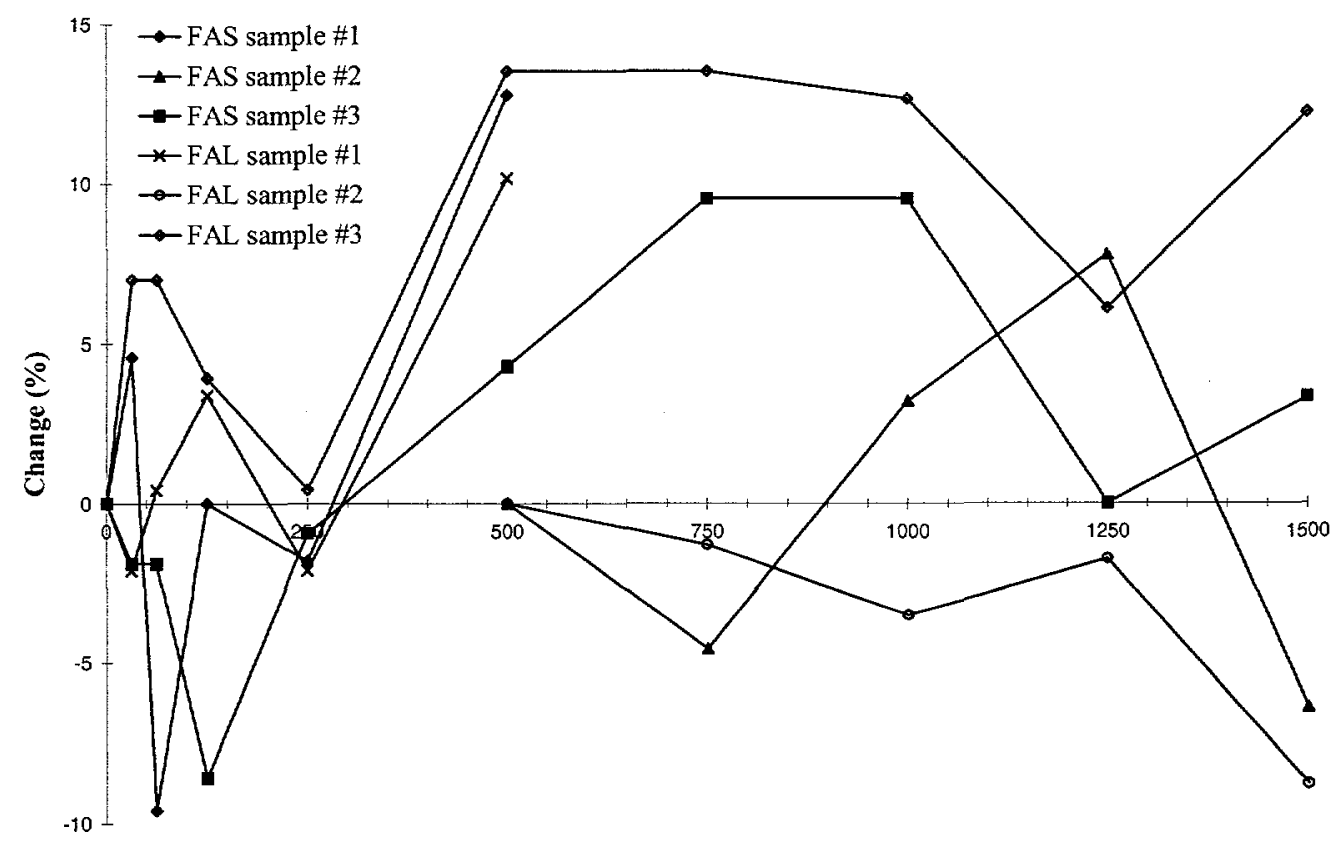

Time (hours)

Figure 8: Change in tenth bubble point of the iron aluminide samples exposed to 7.83 vol. $\% \mathrm{H}_{2} \mathrm{~S}$ at $925^{\circ} \mathrm{F}$. These results are inconclusive. Mercury porosimetry provides clearer results. 


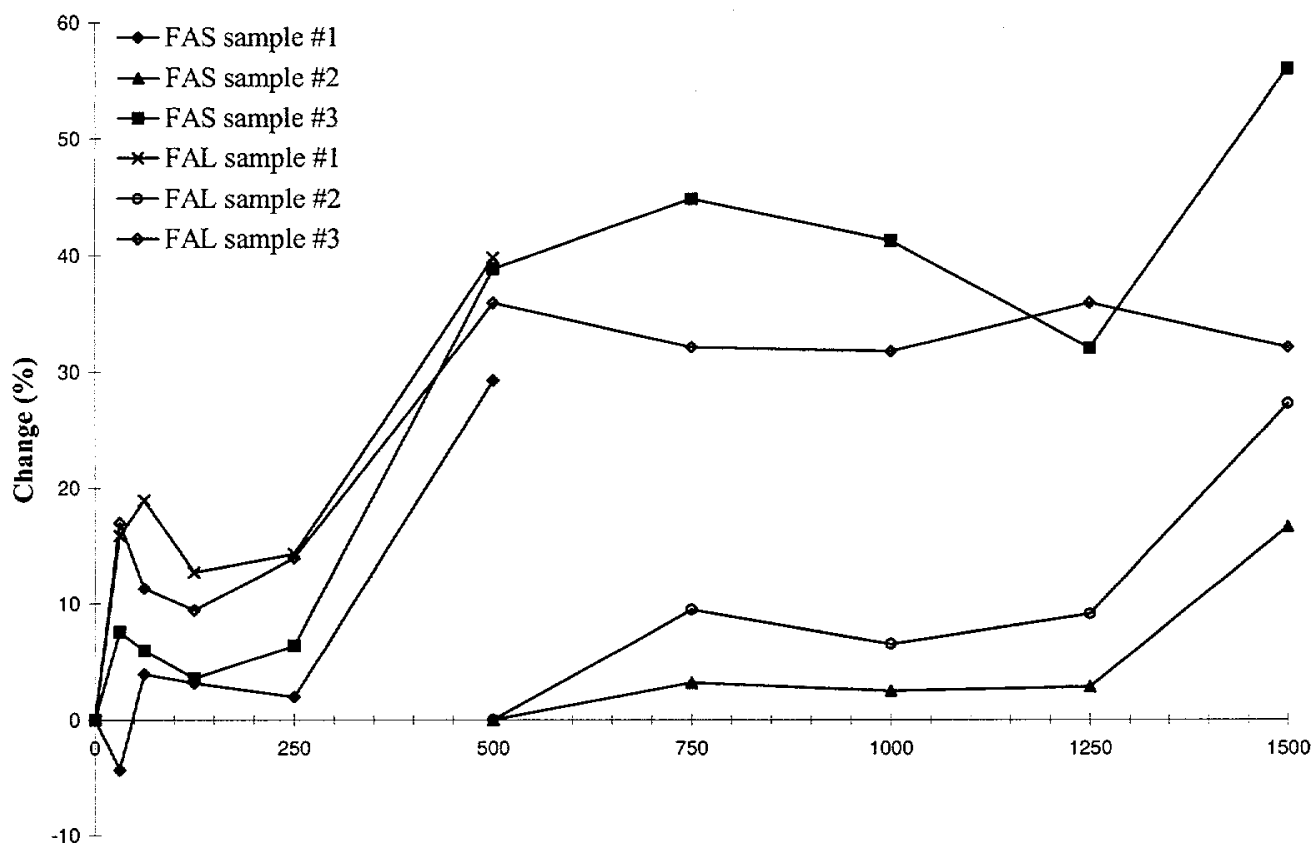

Time (hours)

Figure 9: Change in open bubble point of the iron aluminide samples exposed to 7.83 vol. $\% \mathrm{H}_{2} \mathrm{~S}$ at $925^{\circ} \mathrm{F}$. An increase indicates a general tightening of the average pore size.

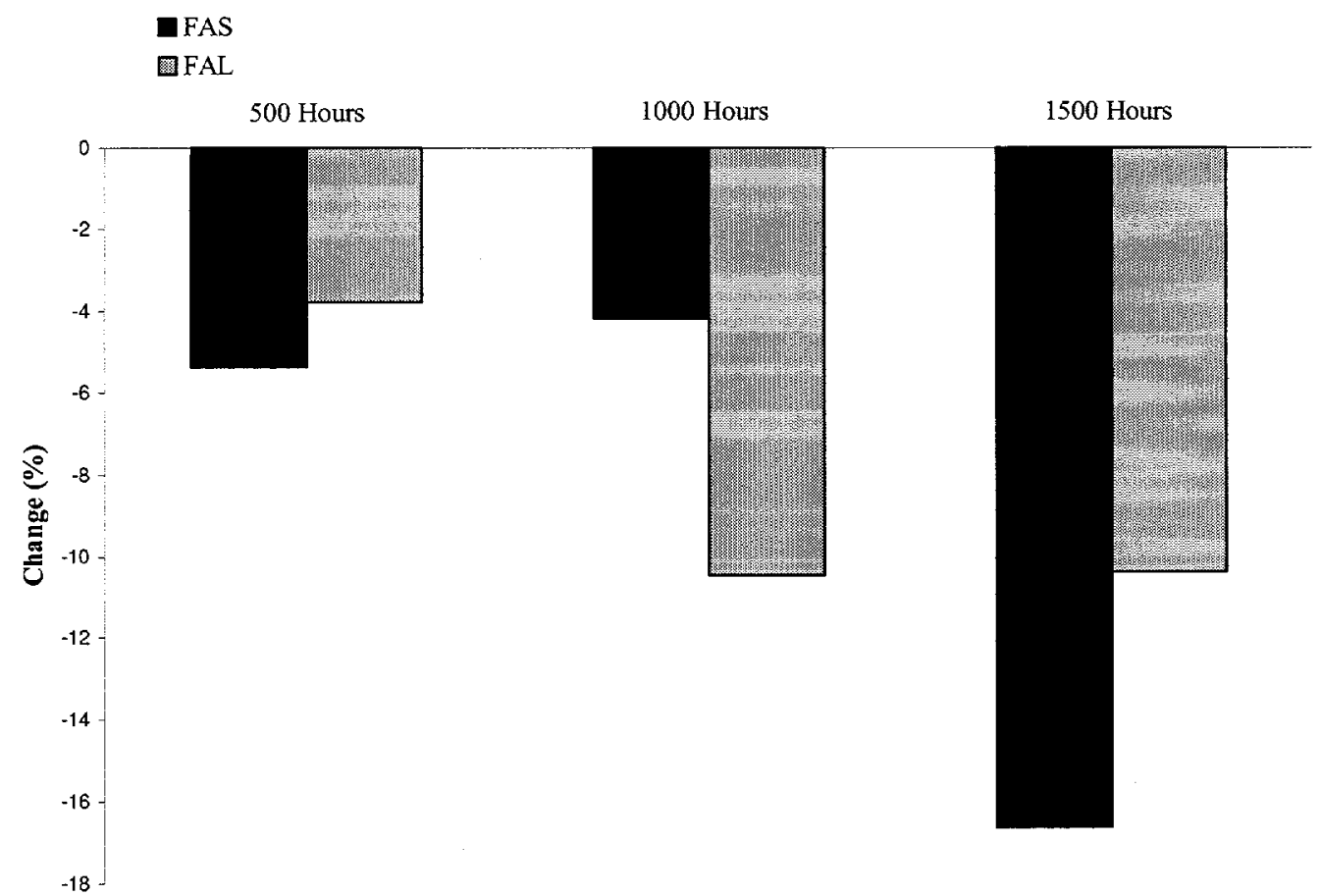

Figure 10: Change in carbon content of the iron aluminide with exposure time. There are only minor changes in the carbon content for both alloys. 


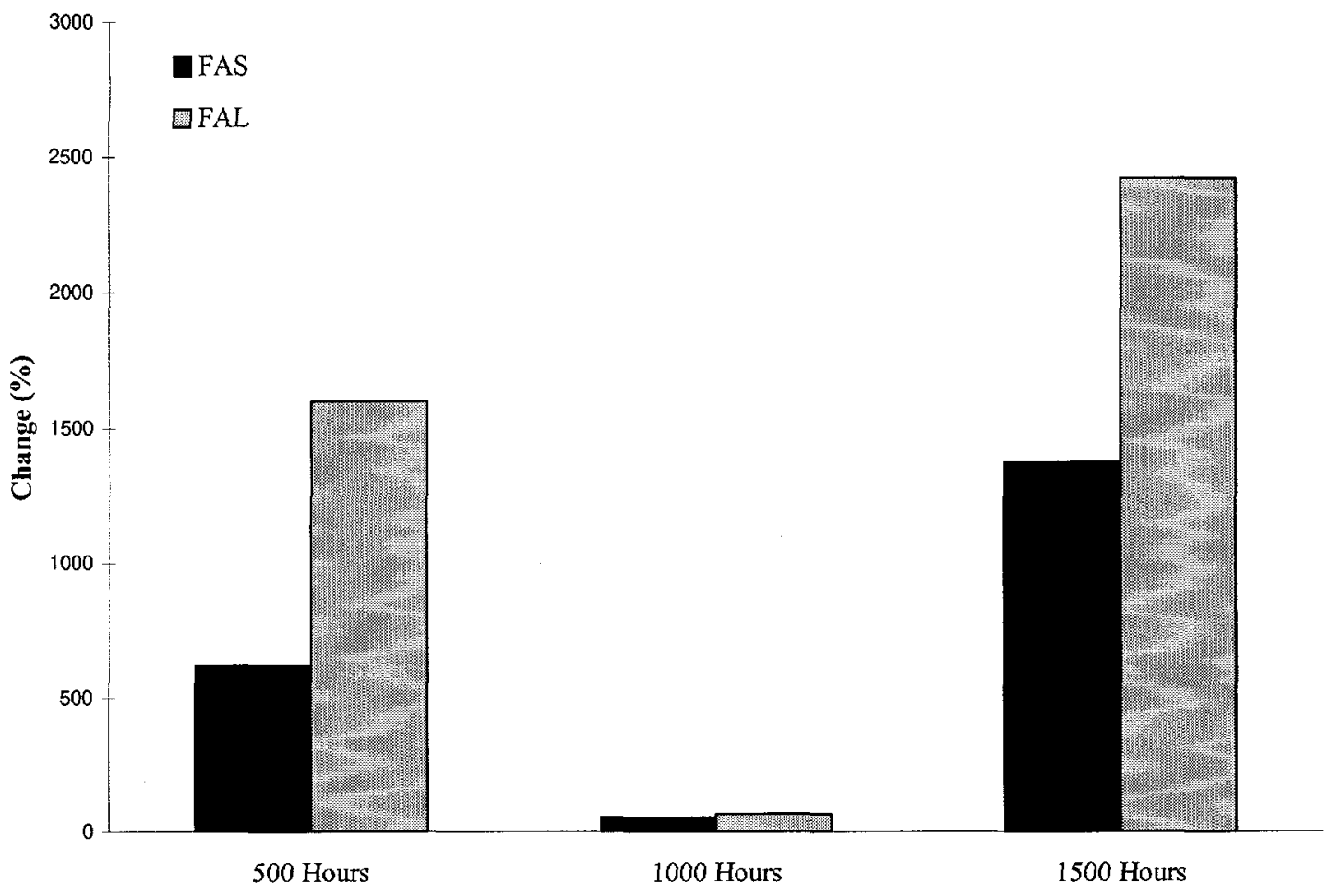

Figure 11: Change in the sulfur content of the iron aluminide alloys. There is a marked increase in the sulfur content of both the alloys.

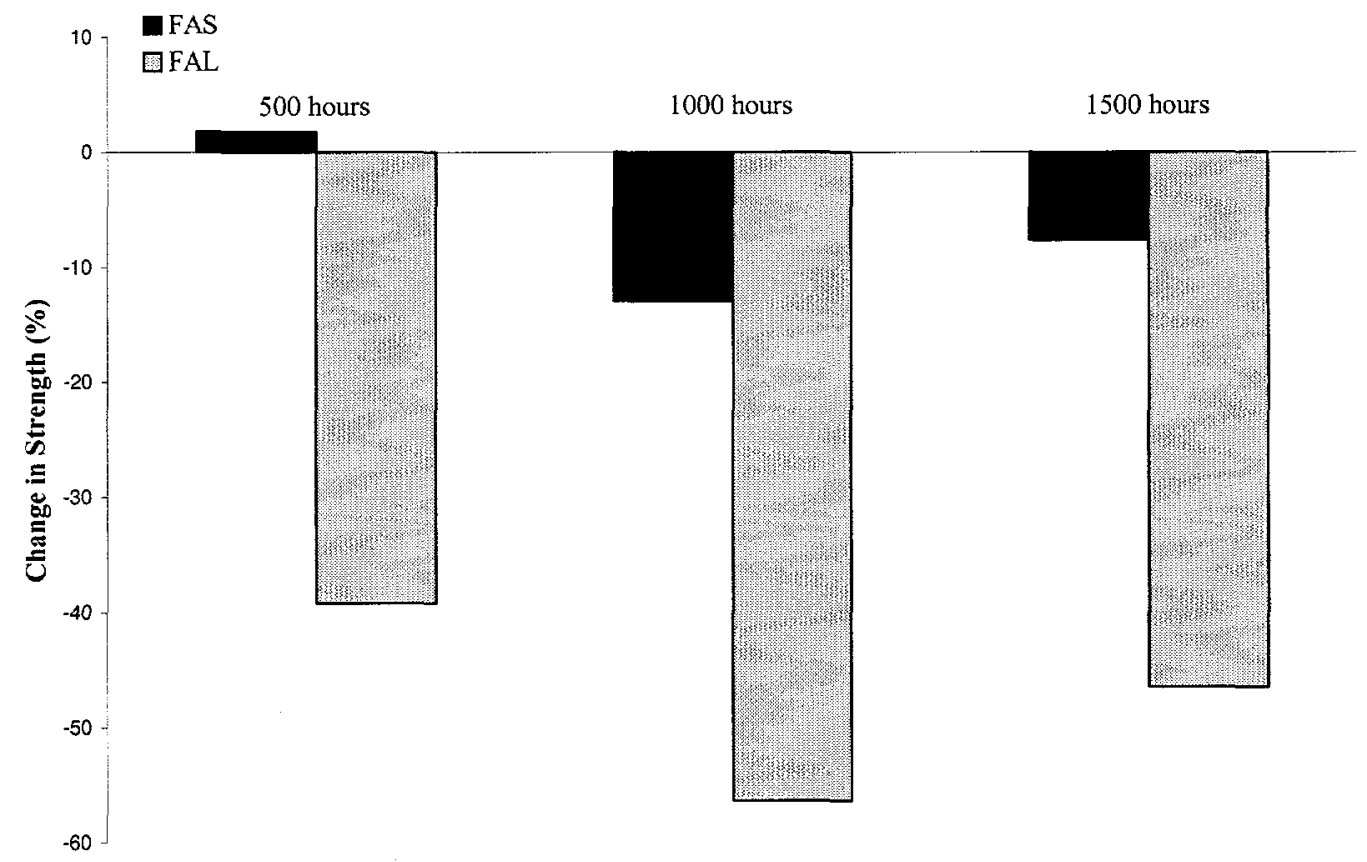

Figure 12: Change in strength of the iron aluminide samples after exposure. The FAS media's strength is unaffected by the exposure to simulated IGCC conditions. The FAL media has a marked decrease in strength, reason currently unknown. 


\section{APPENDIX III}

MERCURY POROSIMETRY 


\section{Mercury Porosimetry FAS Samples}




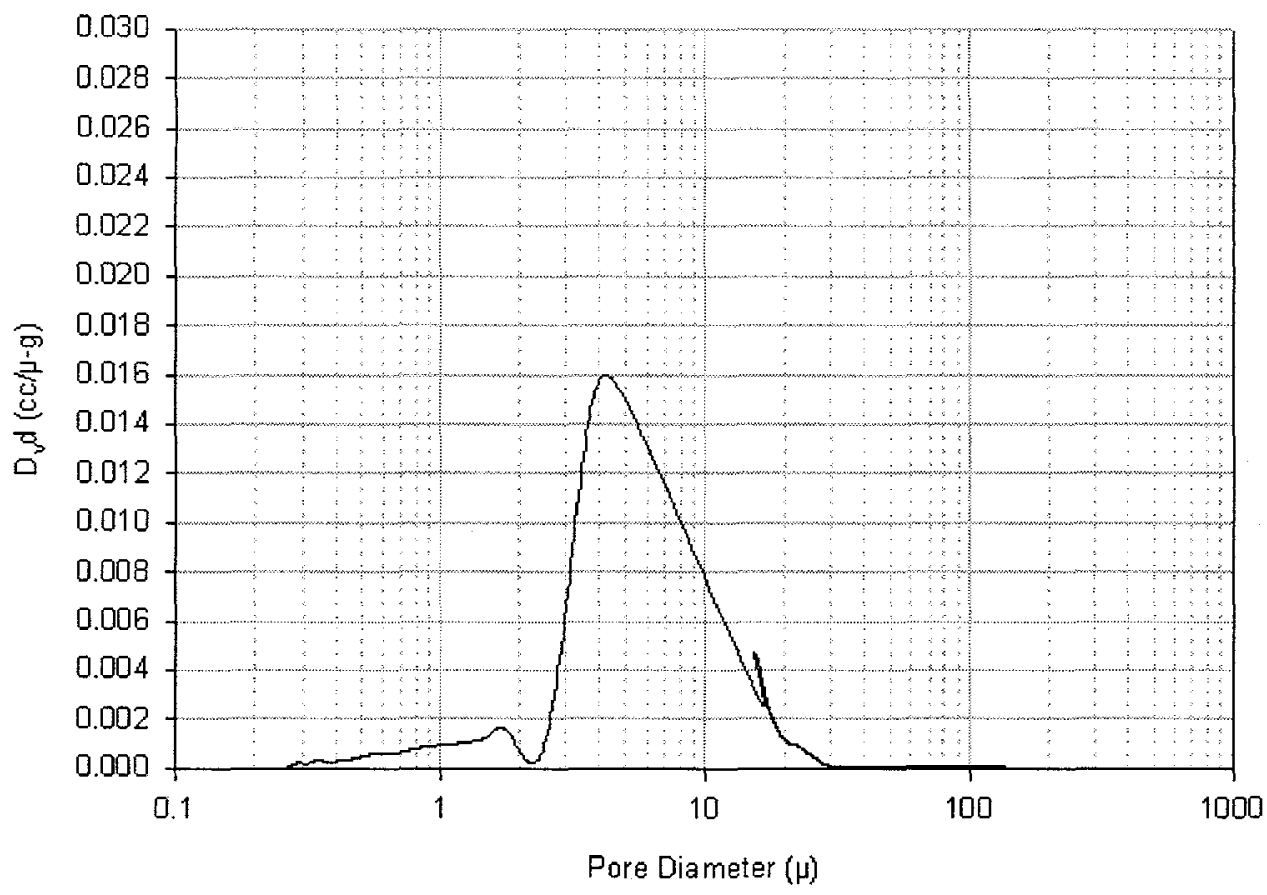

Figure 13: Porosimetry of as-sintered FAS media. Pore distribution centered at approximately 4.5 micron.

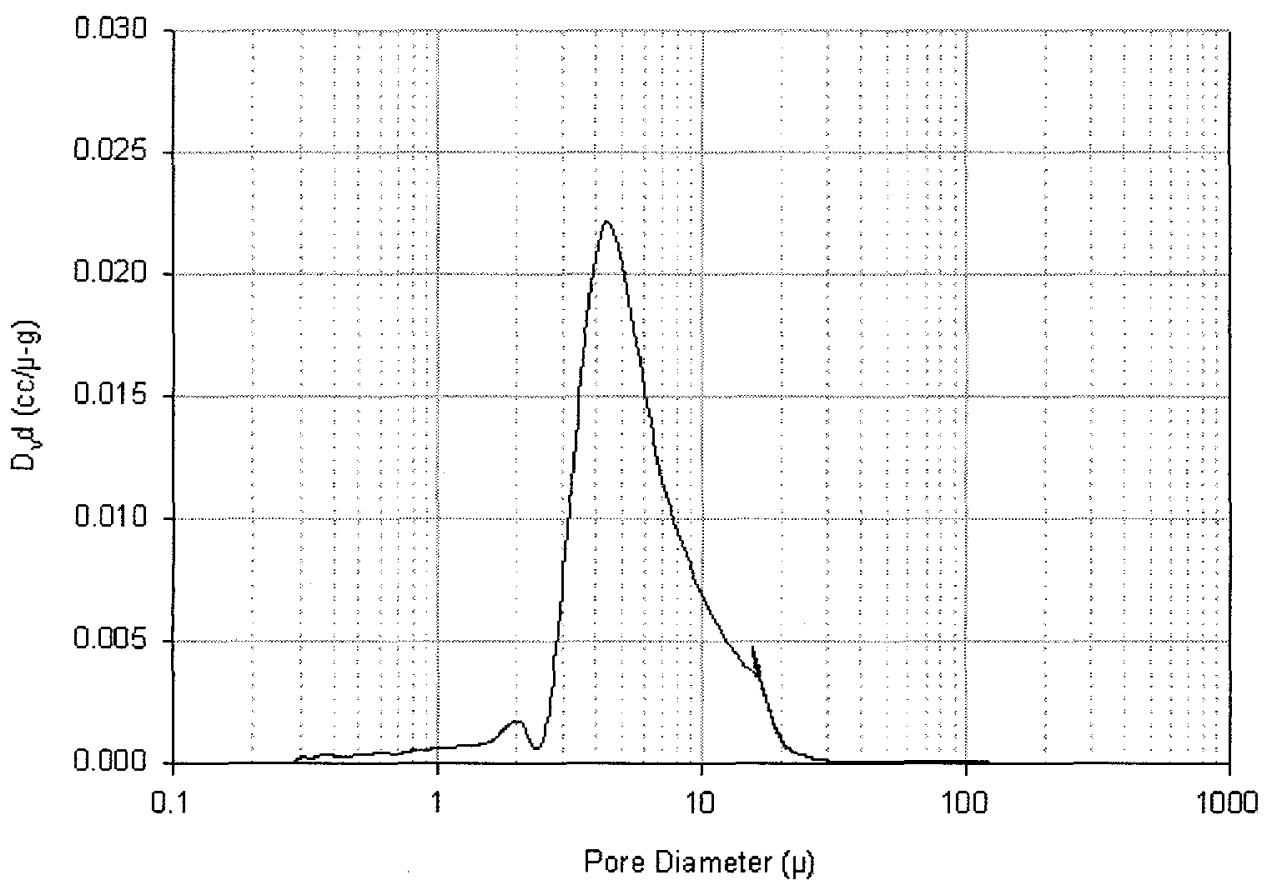

Figure 14: Porosimetry of preoxidized FAS media. Pore distribution centered at approximately 3.5 micron. 


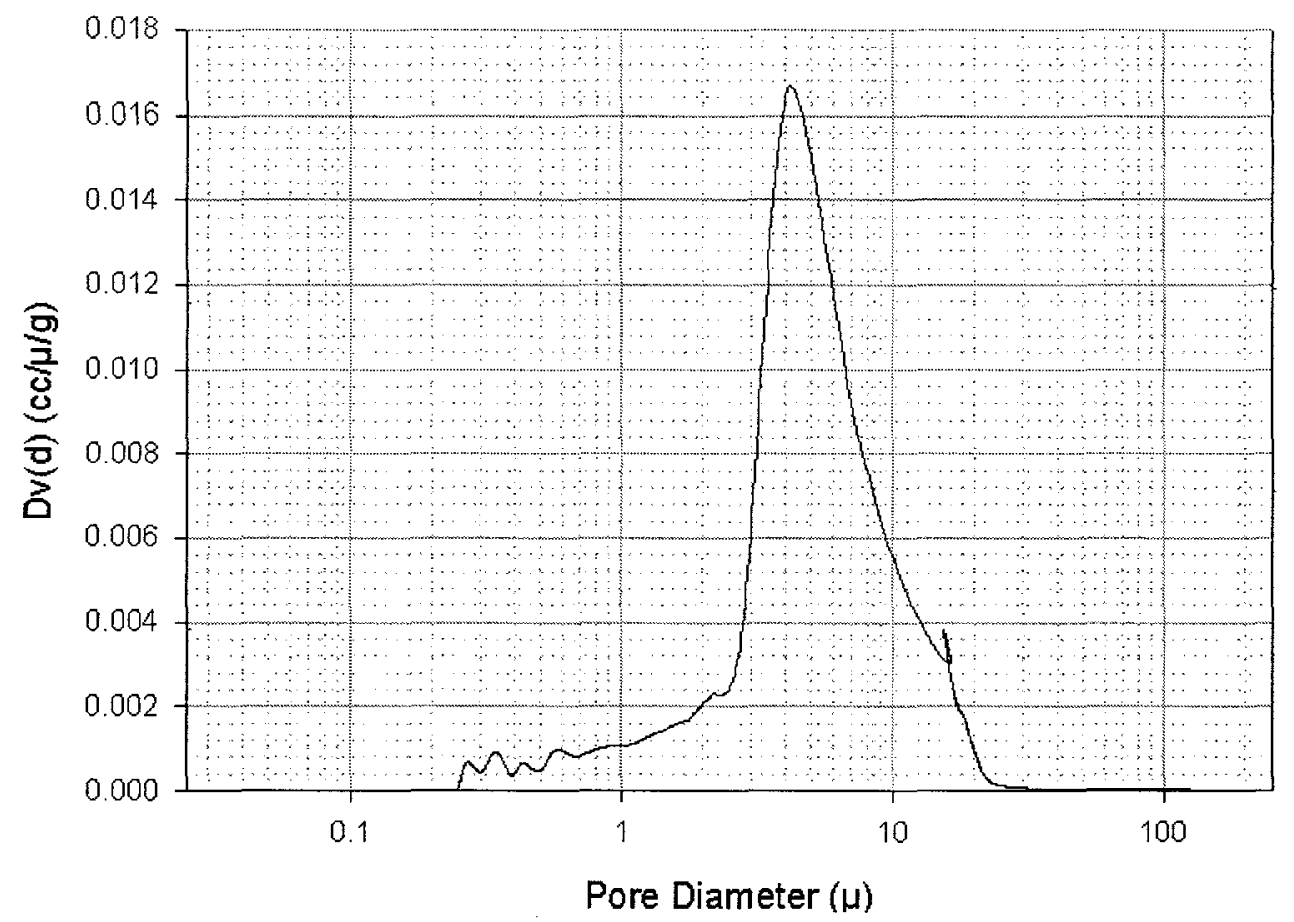

Figure 15: Porosimetry of FAS media exposed for 500 hours. Pore distribution center at approximately 4.0 micron.

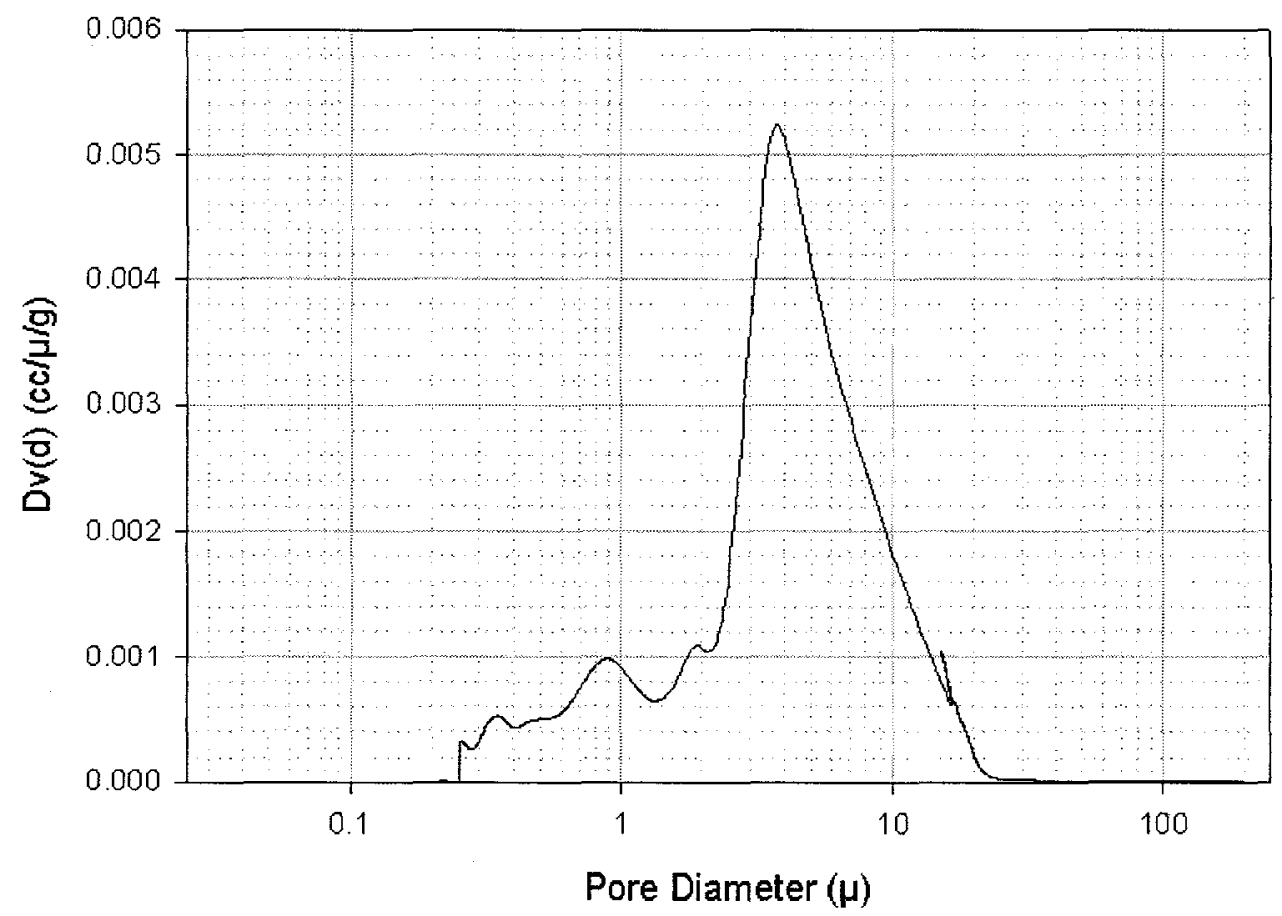

Figure 16: Porosimetry of FAS media exposed for 1000 hours. Pore distribution center at approximately 3.5 micron. 


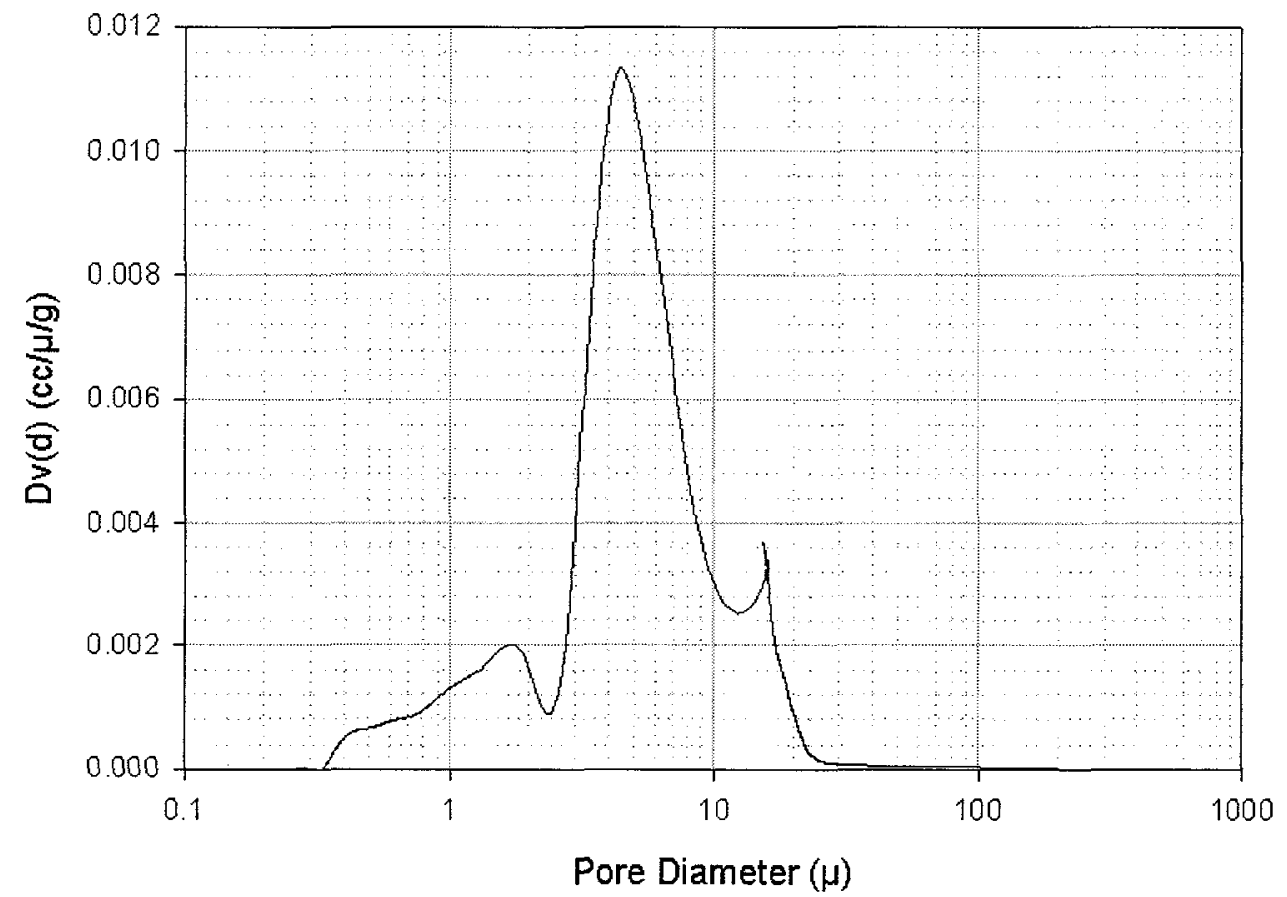

Figure 17: Porosimetry of FAS media exposed for 1500 hours. Pore distribution center at approximately 3.5 micron. 


\section{Mercury Porosimetry \\ FAL Samples}




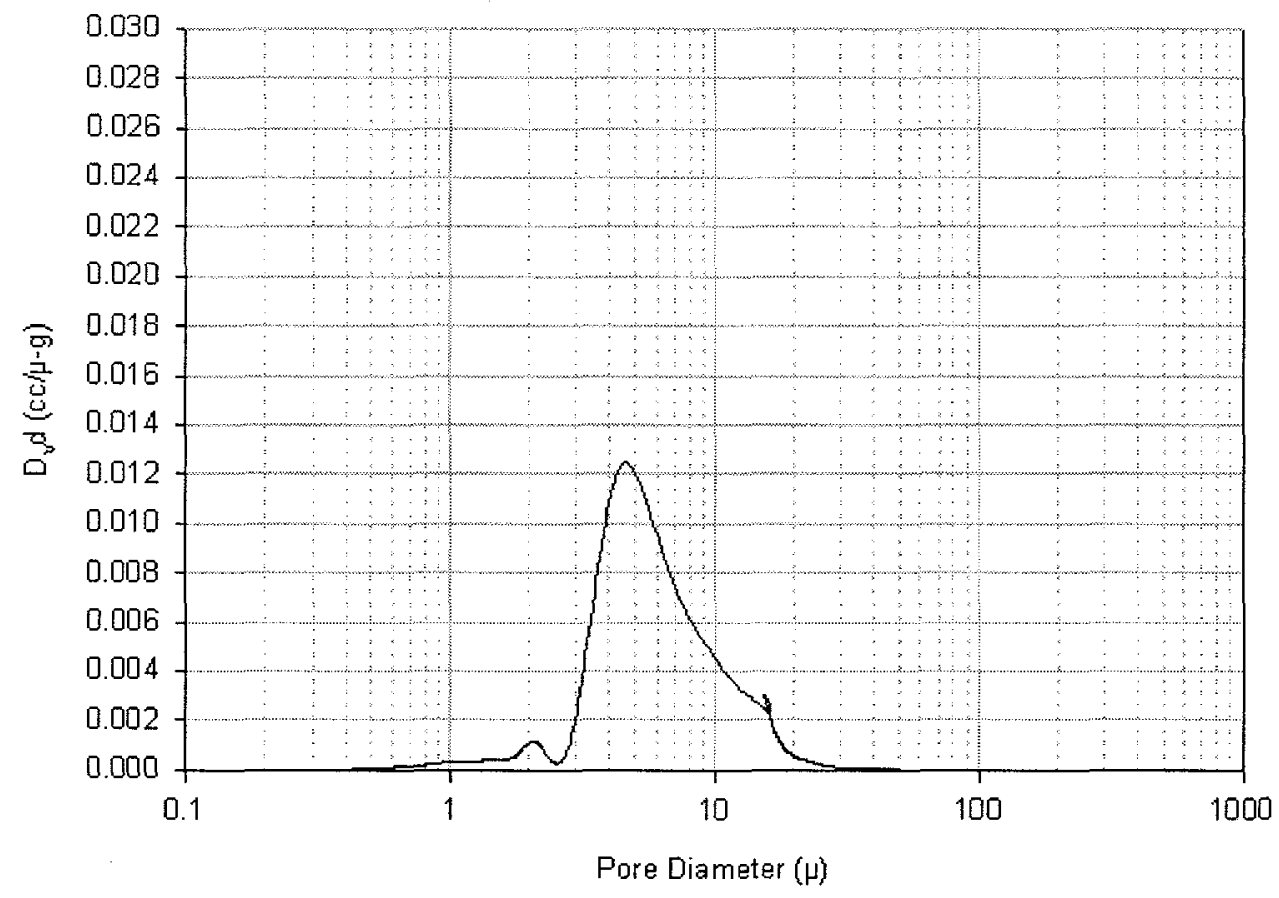

Figure 18: Porosimetry of as-sintered FAL media. Pore distribution centered at approximately 4.5 micron.

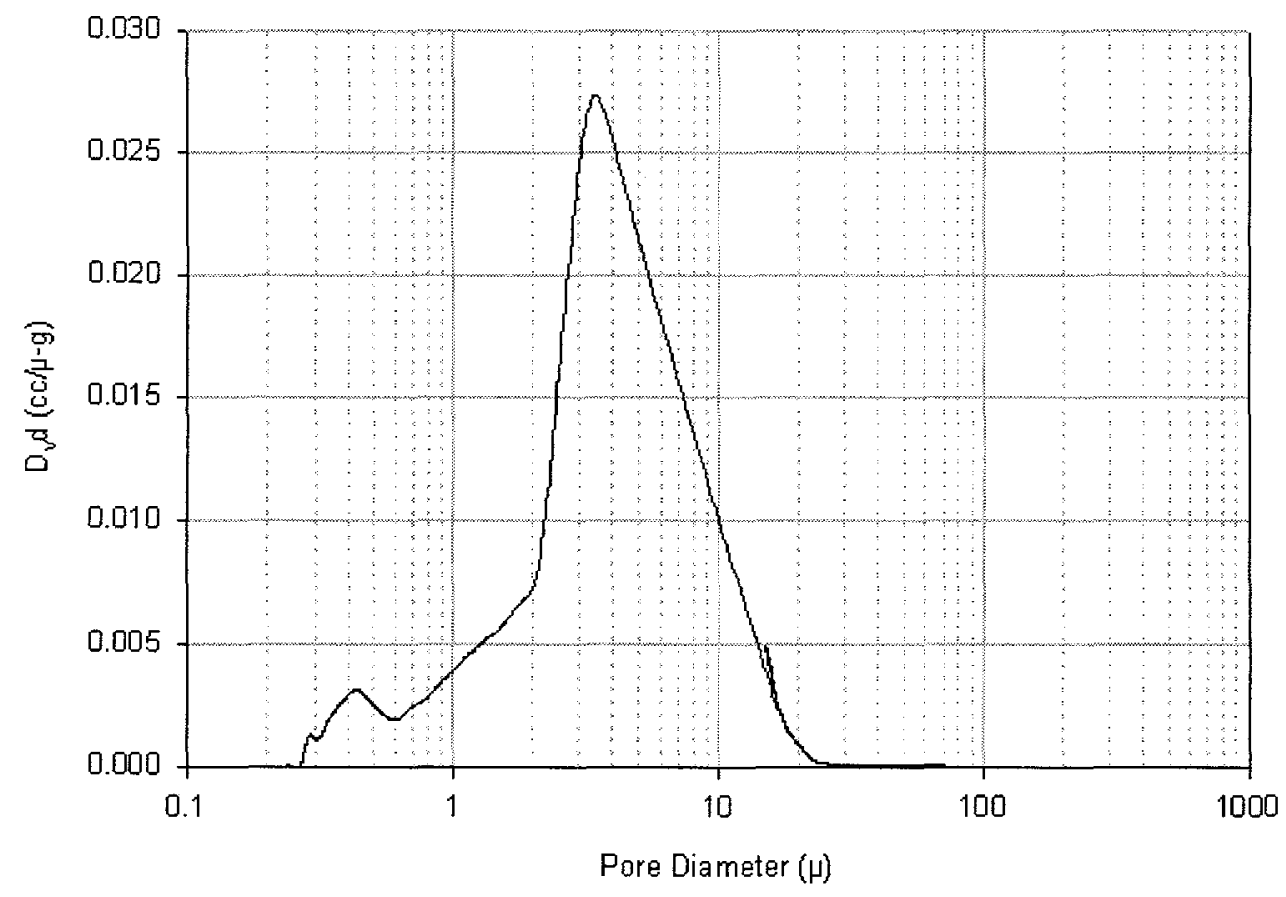

Figure 19: Porosimetry of preoxidized FAL media. Pore distribution centered at approximately 3.5 micron. 


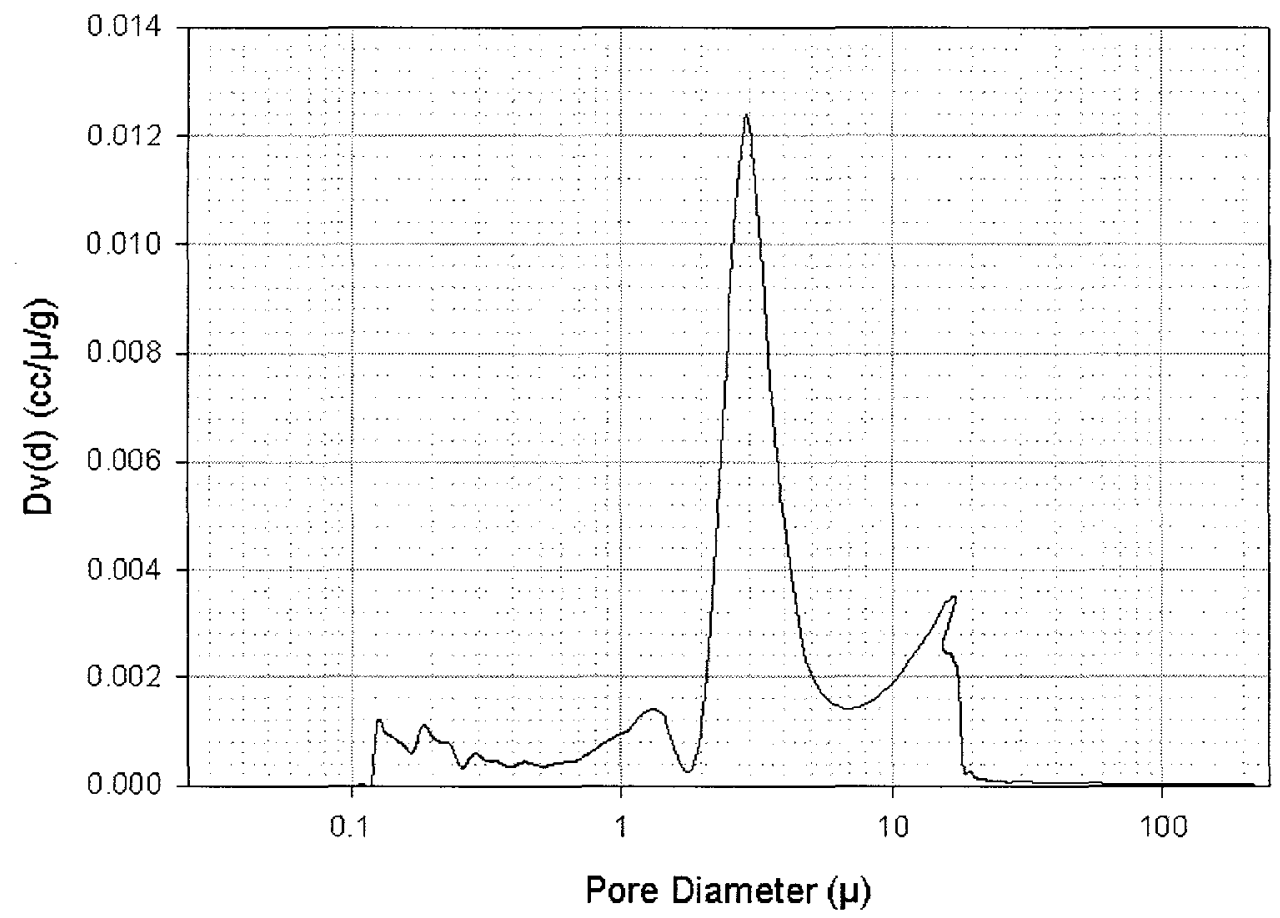

Figure 20: Porosimetry of FAL media exposed for $\mathbf{5 0 0}$ hours. Pore distribution center at approximately 3.0 micron.

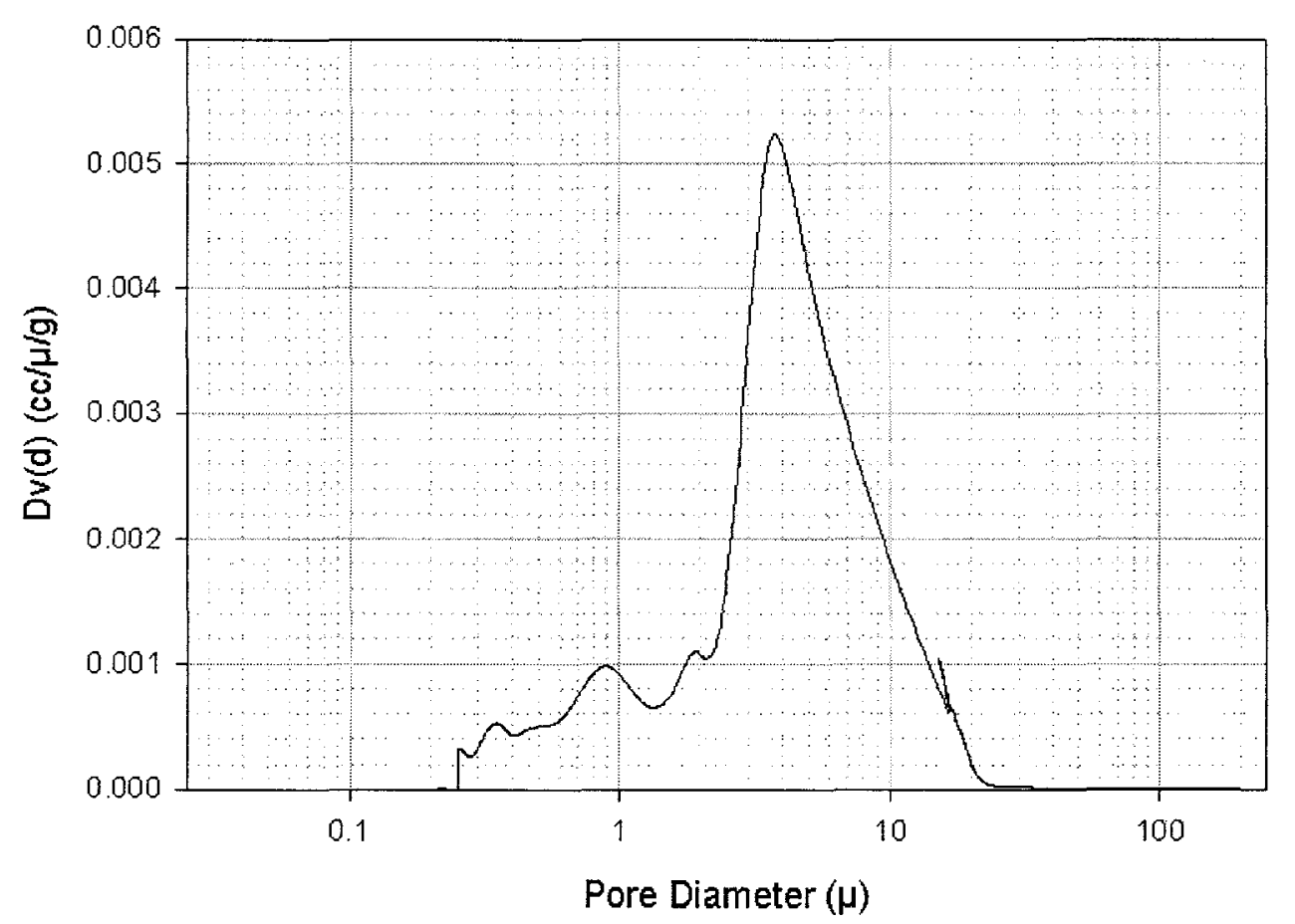

Figure 21: Porosimetry of FAL media exposed for 1000 hours. Pore distribution center at approximately 3.5 micron. 


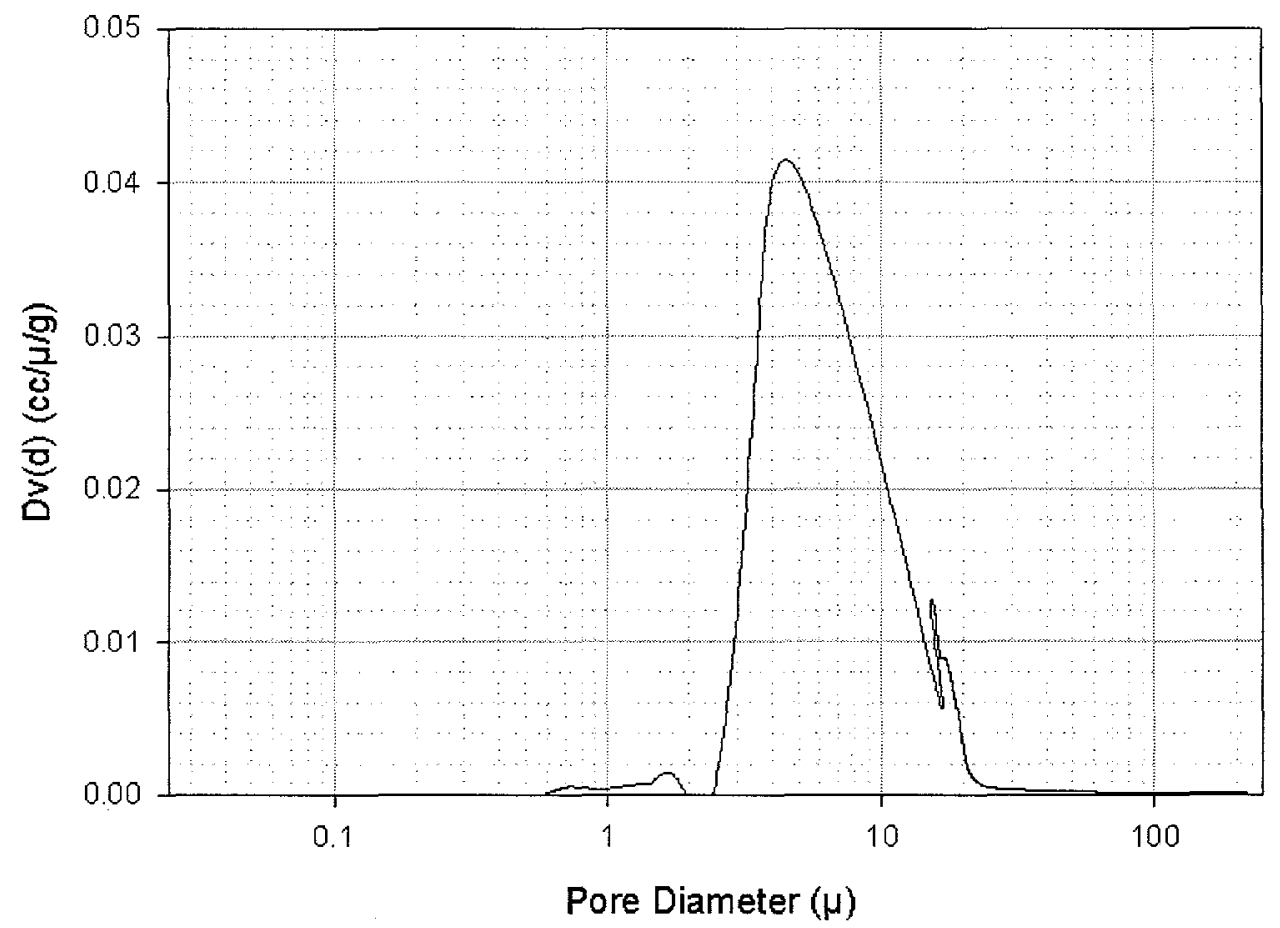

Figure 22: Porosimetry of FAL media exposed for 1500 hours. Pore distribution center at approximately 4.5 micron. 
APPENDIX IV

SEM IMAGES 


\section{SEM Images \\ FAS Control Sample}




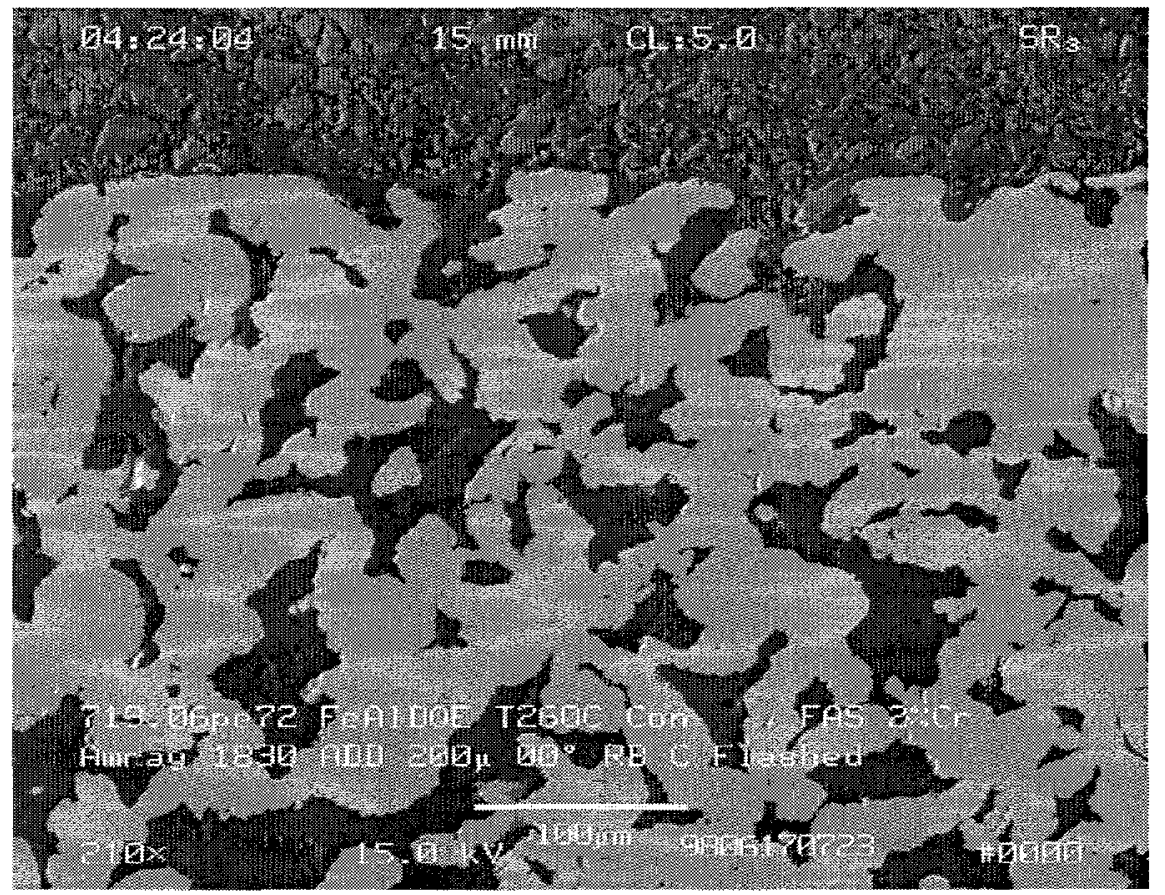

Figure 23: Cross-section of FAS control sample. Preoxidized for seven hours at $800^{\circ} \mathrm{C}$. Top edge of sample is upstream surface.

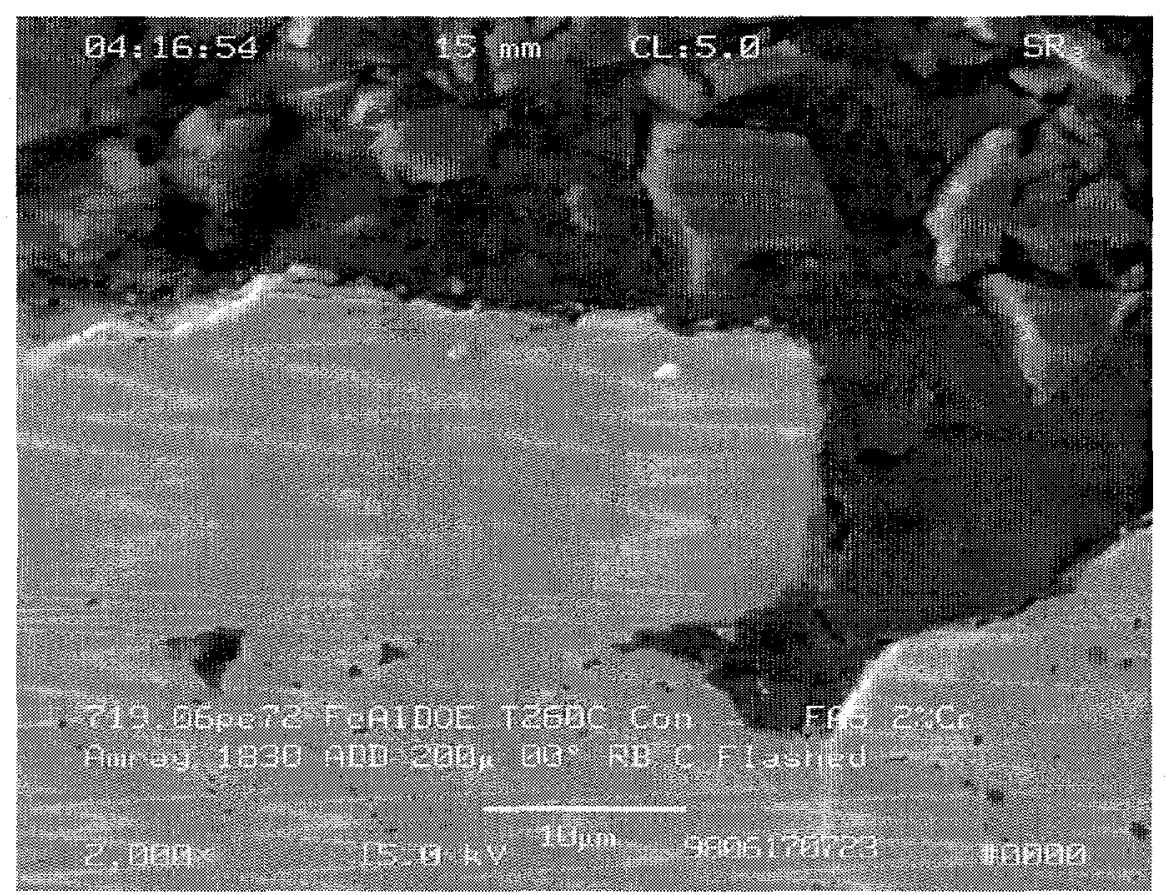

Figure 24: Cross-section of FAS control sample. Preoxidized for seven hours at $800^{\circ} \mathrm{C}$. Alumina oxide layer can not be seen. 


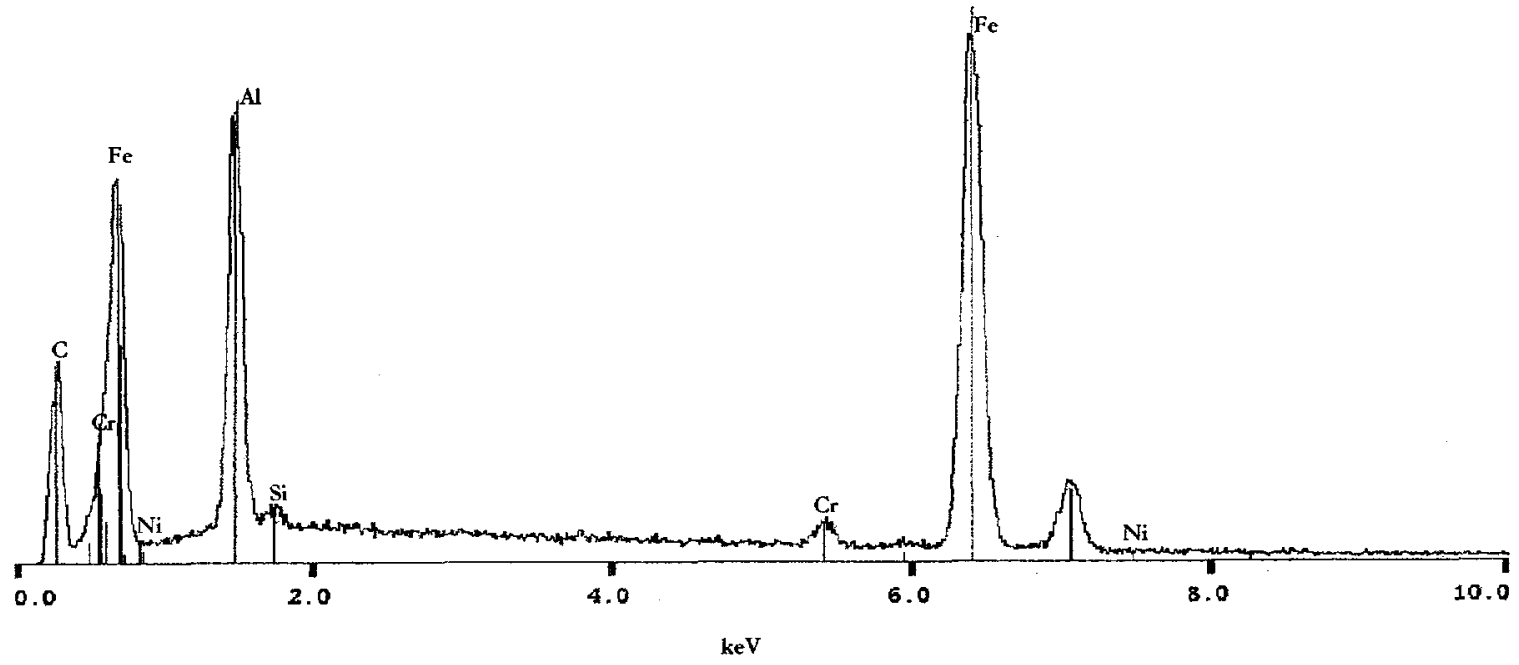

Figure 25: Partial field spectrum of base metal in Figure 24. Typical iron aluminide signature.

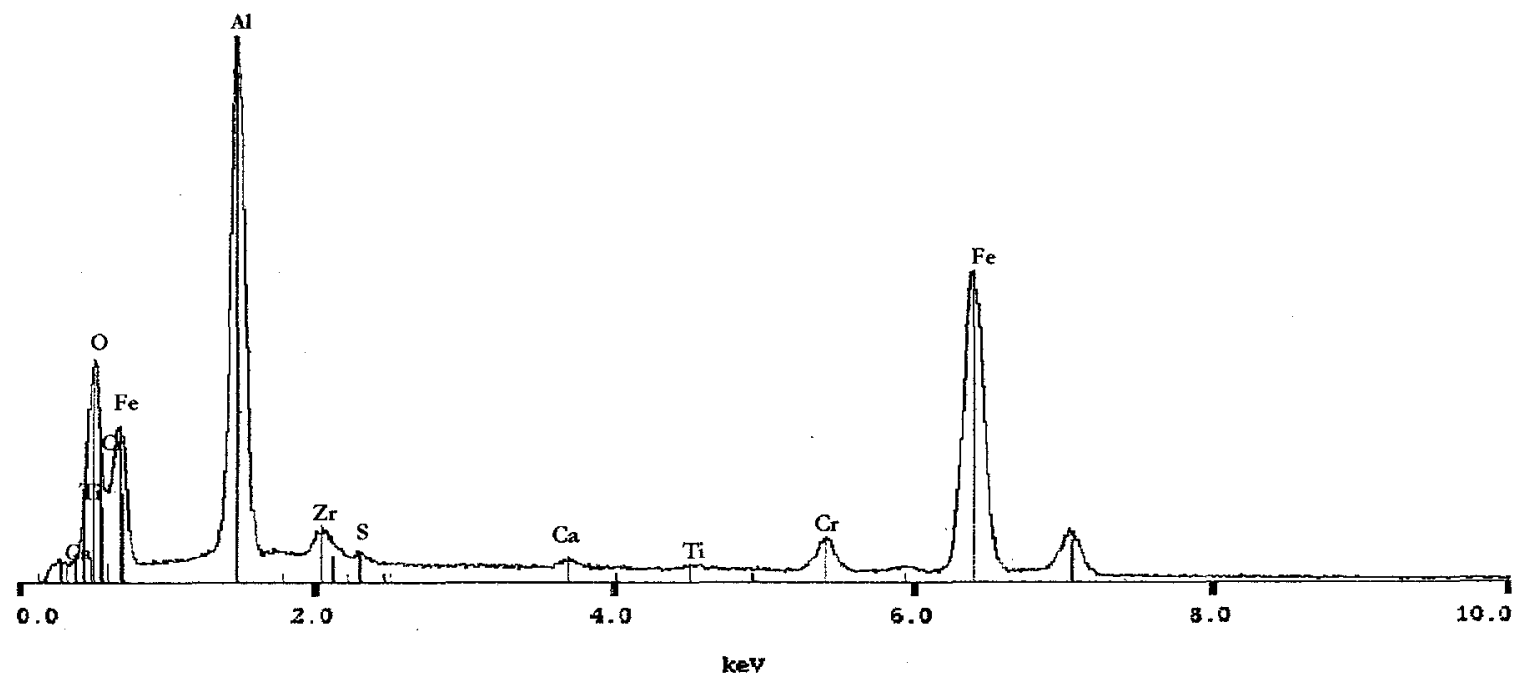

Figure 26: Partial field of upstream surface of Figure 24. Presence of oxygen indicates a thin alumina layer. 


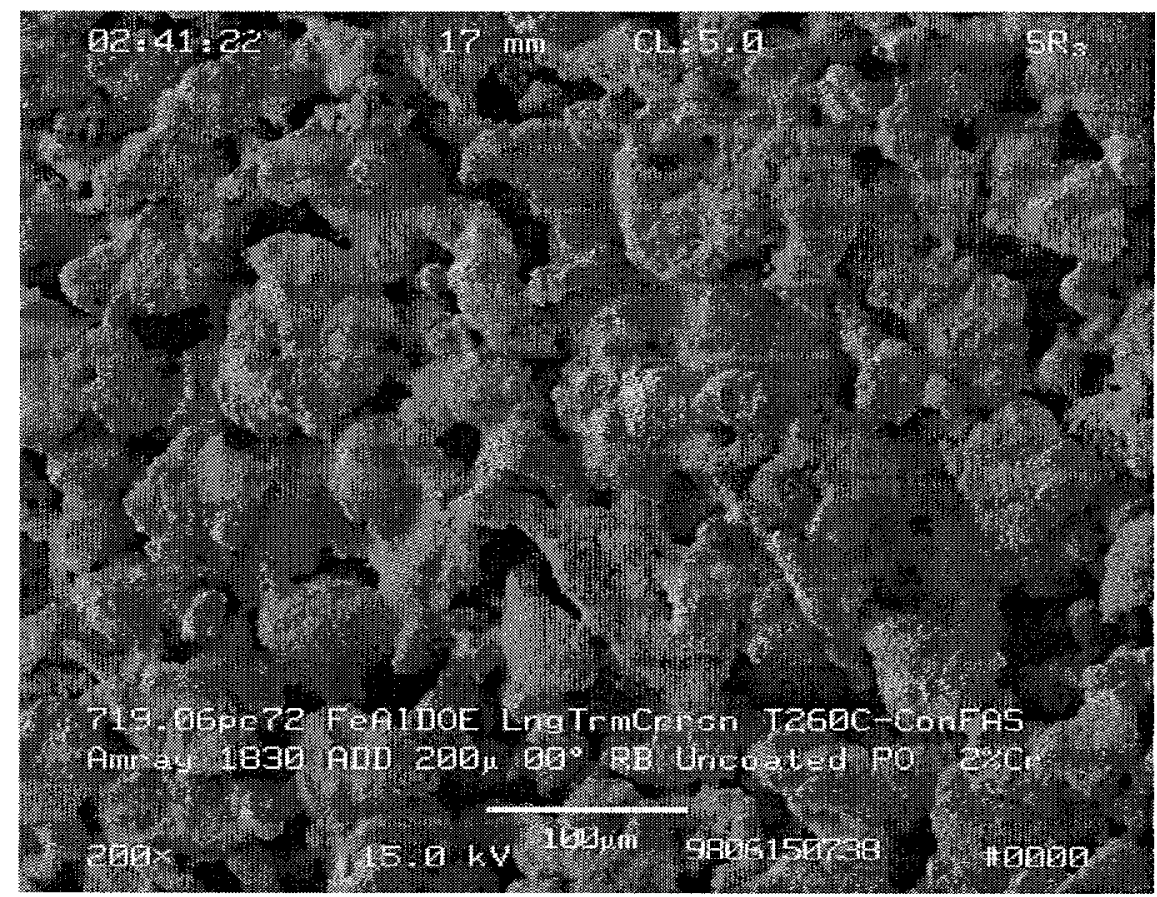

Figure 27: Upstream surface of FAS control sample. Preoxidized for seven hours at $800^{\circ} \mathrm{C}$. Sinter bonds between individual powder particles can be seen.

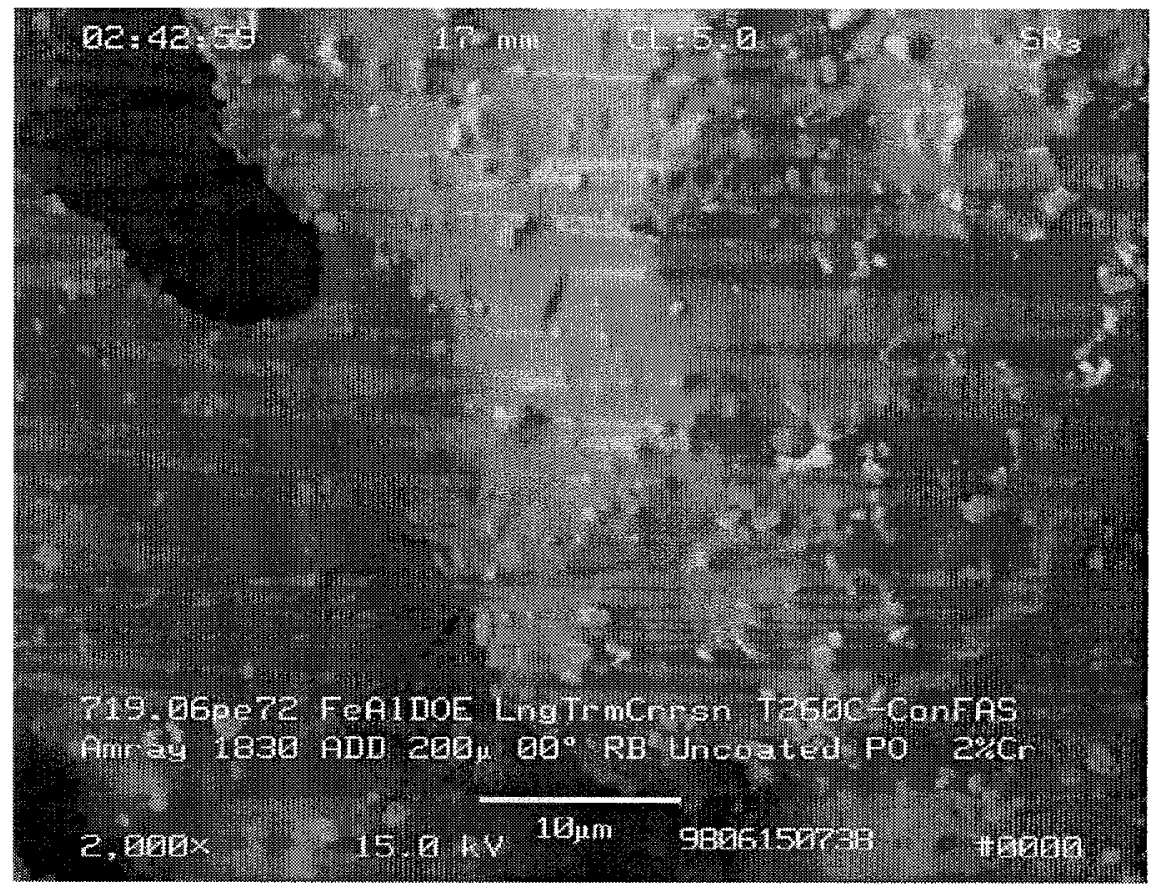

Figure 28: Upstream surface of FAS control sample. Preoxidized for seven hours at $800^{\circ} \mathrm{C}$. Light nodules are zirconia. Typical porous iron aluminide surface. 


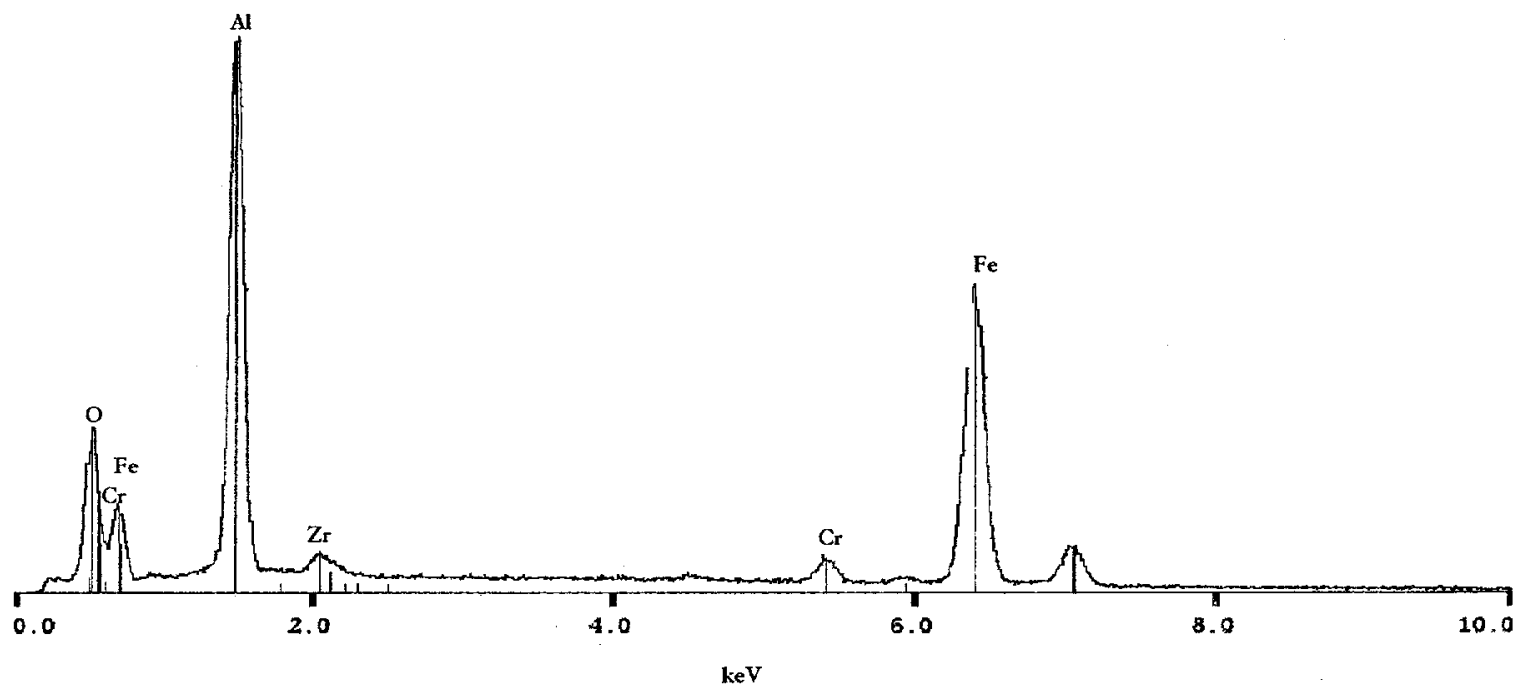

Figure 29: Full screen spectrum of Figure 28. Oxygen peak is from the formation of a continuous aluminum oxide layer.

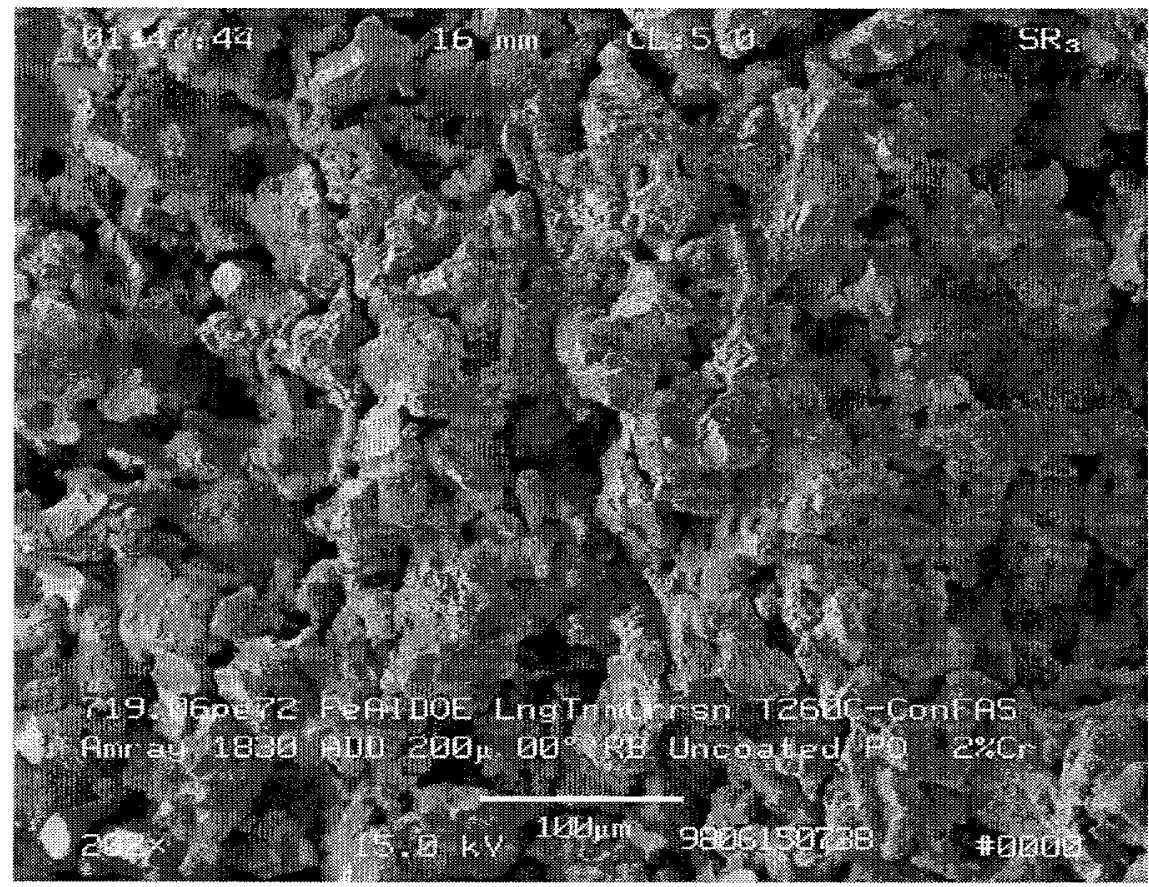

Figure 30: Fracture surface of FAS control sample. Preoxidized for seven hours at $800^{\circ} \mathrm{C}$. Many fractured sinter bonds can be seen. 


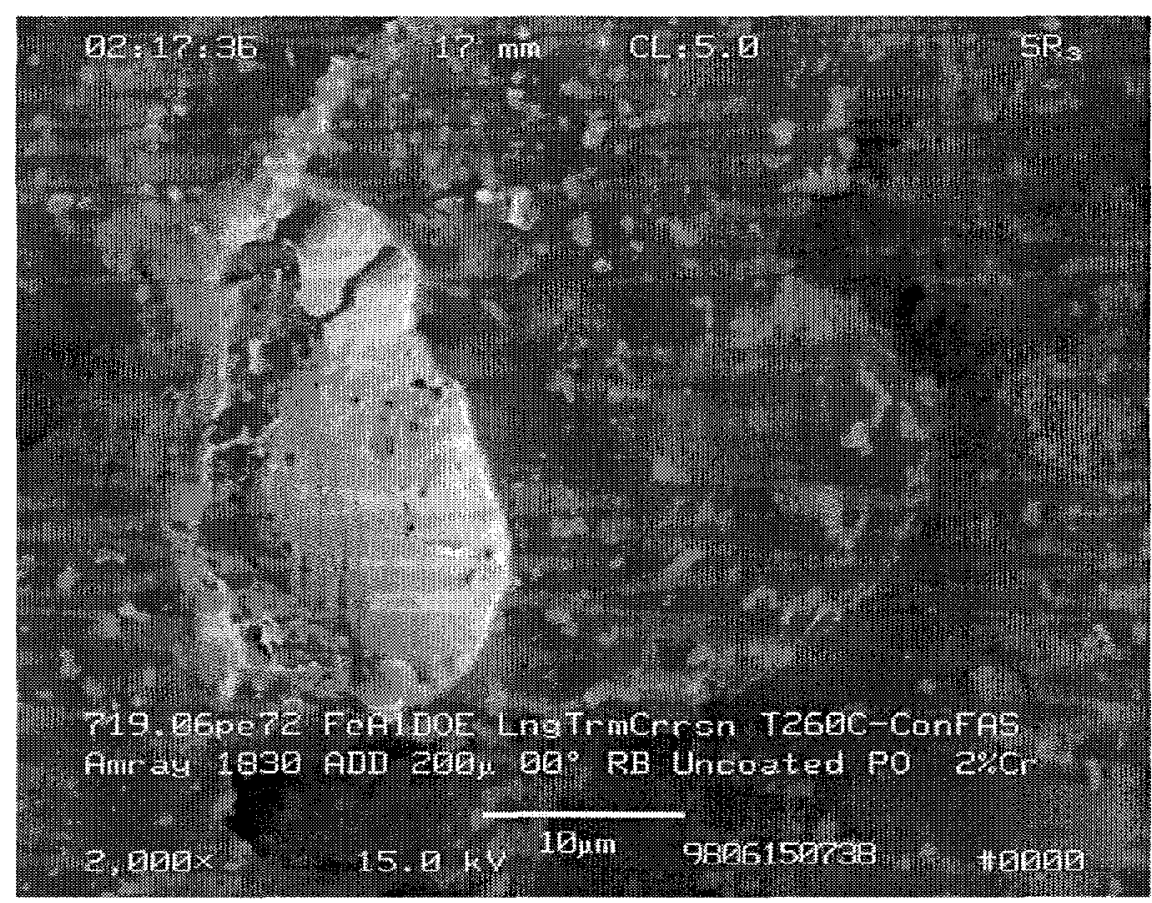

Figure 31: Fracture surface of FAS control sample. Preoxidized for seven hours at $800^{\circ} \mathrm{C}$. Brittle fracture of an iron aluminide sinter bond is shown. Sinter bond contains a small amount of porosity.

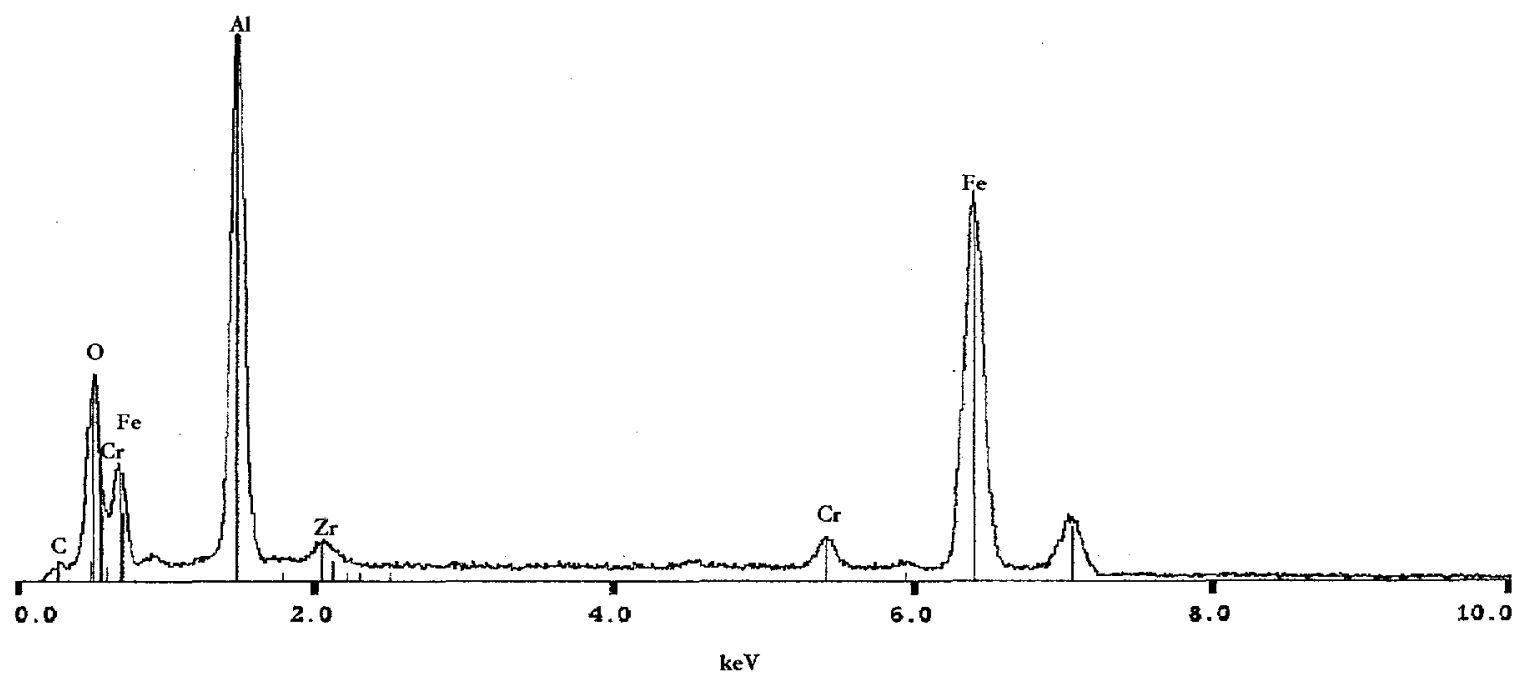

Figure 32: Full screen spectrum of Figure 31. Oxygen peak is from the formation of a continuous aluminum oxide layer. 


\section{SEM Images \\ FAS Sample Exposed for 500 Hours \\ (FAS Sample \#1)}




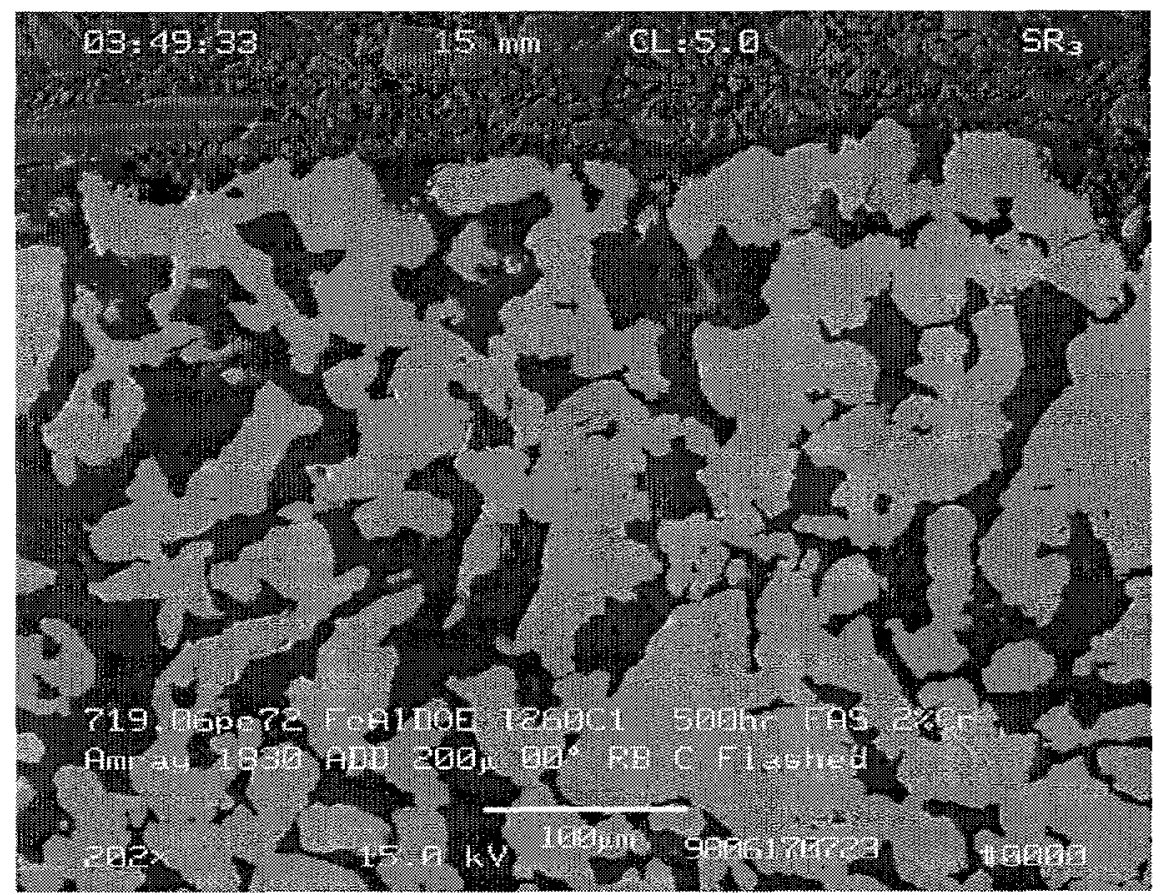

Figure 33: FAS cross-section. Top edge of the sample is the upstream surface. Exposed for 500 hours.

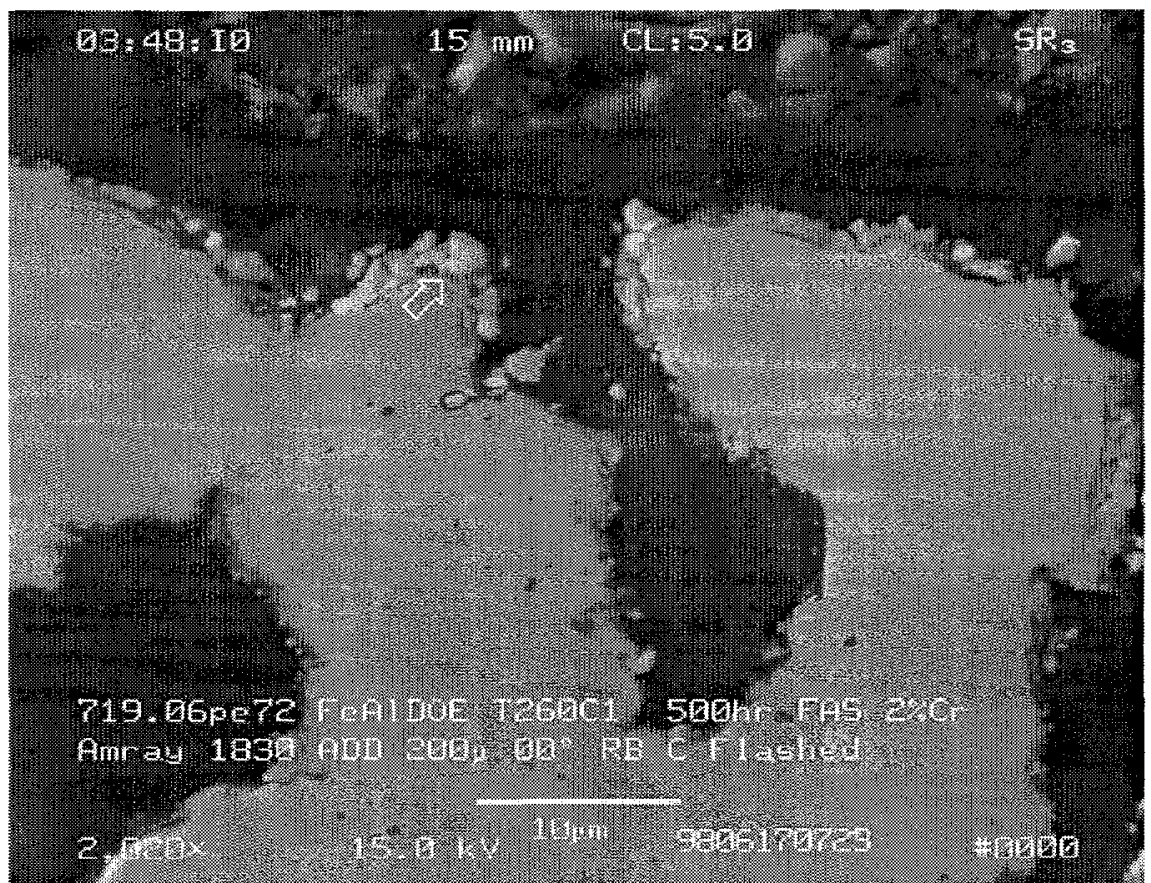

Figure 34: FAS cross-section. Top edge of the sample is the upstream surface. Iron sulfide crystals on surface (arrow). Exposed for $\mathbf{5 0 0}$ hours. 


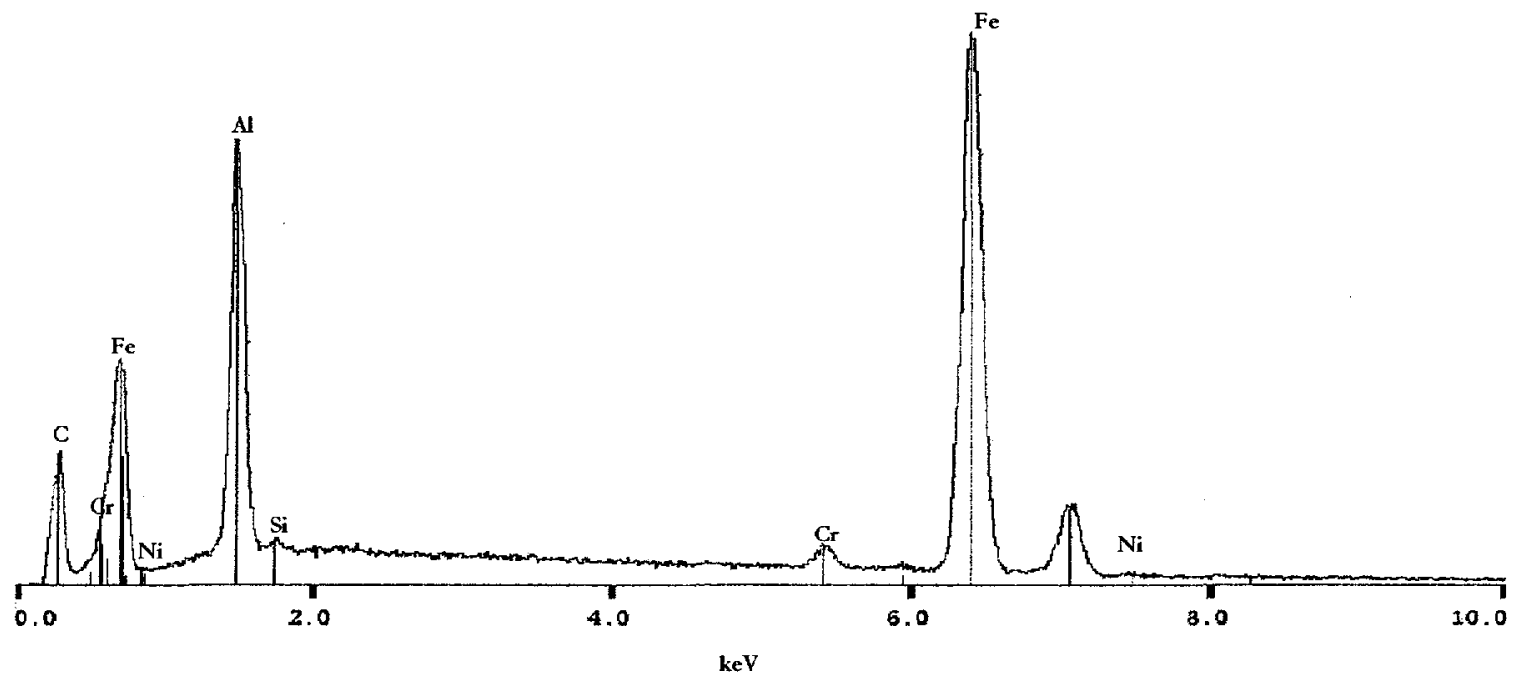

Figure 35: Spectrum of base metal of Figure 34. Typical iron aluminide signature.

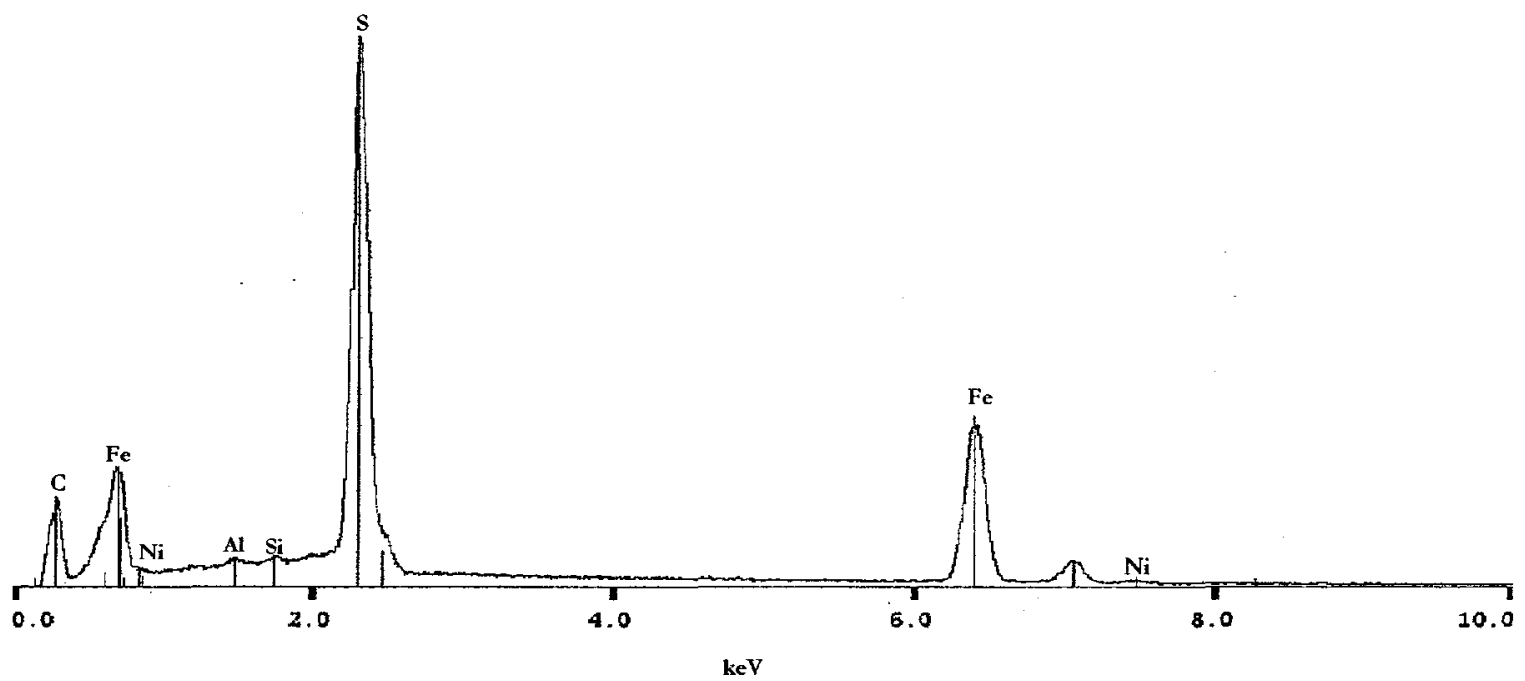

Figure 36: Spectrum of upstream edge of Figure 34. High sulfur peak with iron. A strong indication of iron sulfides. 


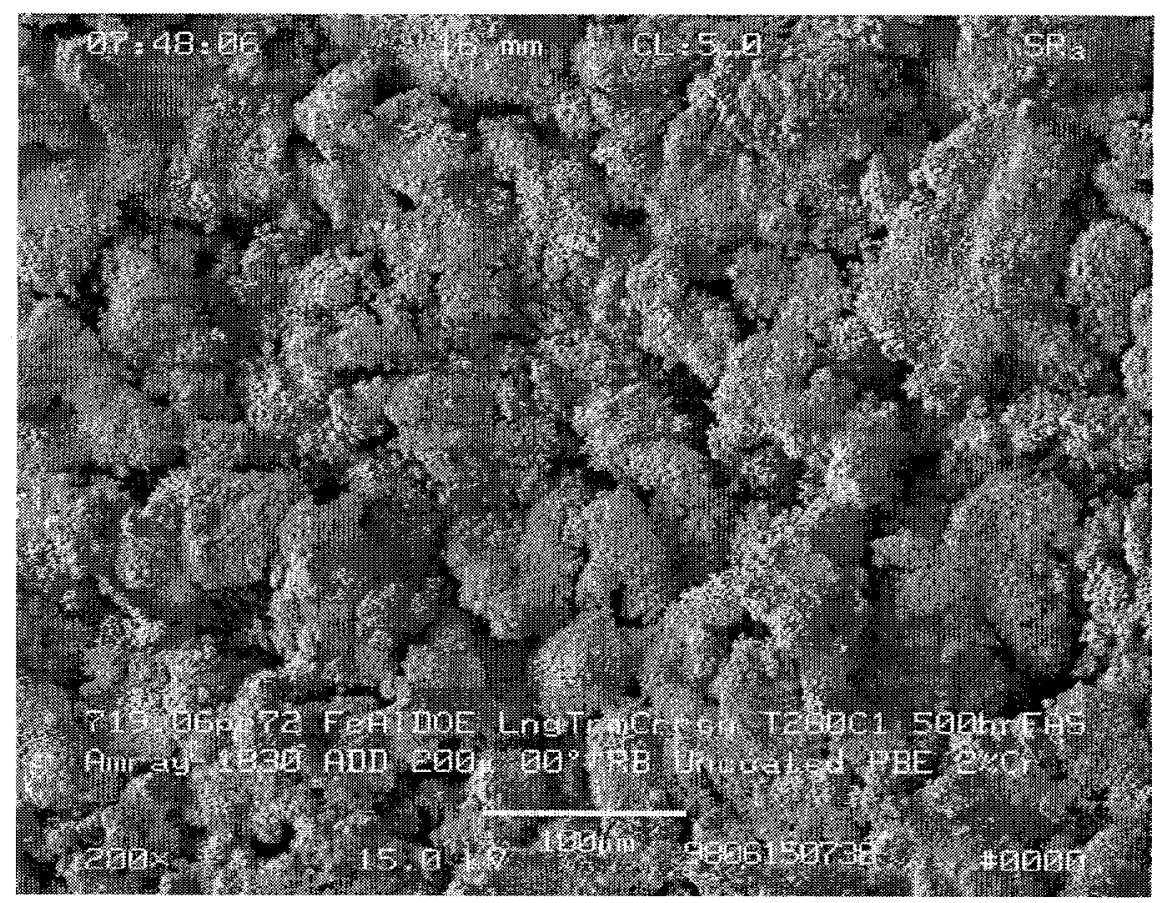

Figure 37: FAS upstream surface. Exposed for 500 hours.

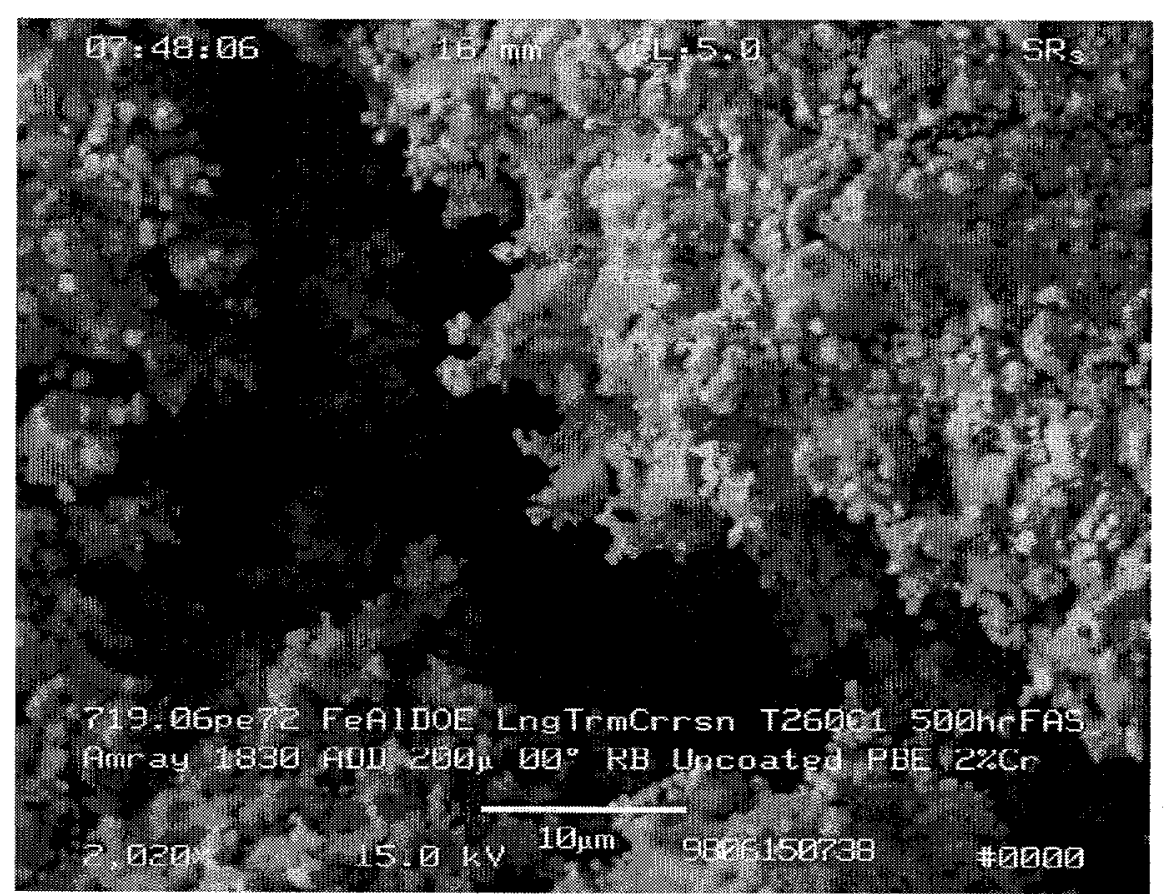

Figure 38: FAS upstream surface. Exposed for 500 hours. Iron sulfide crystals shown. 


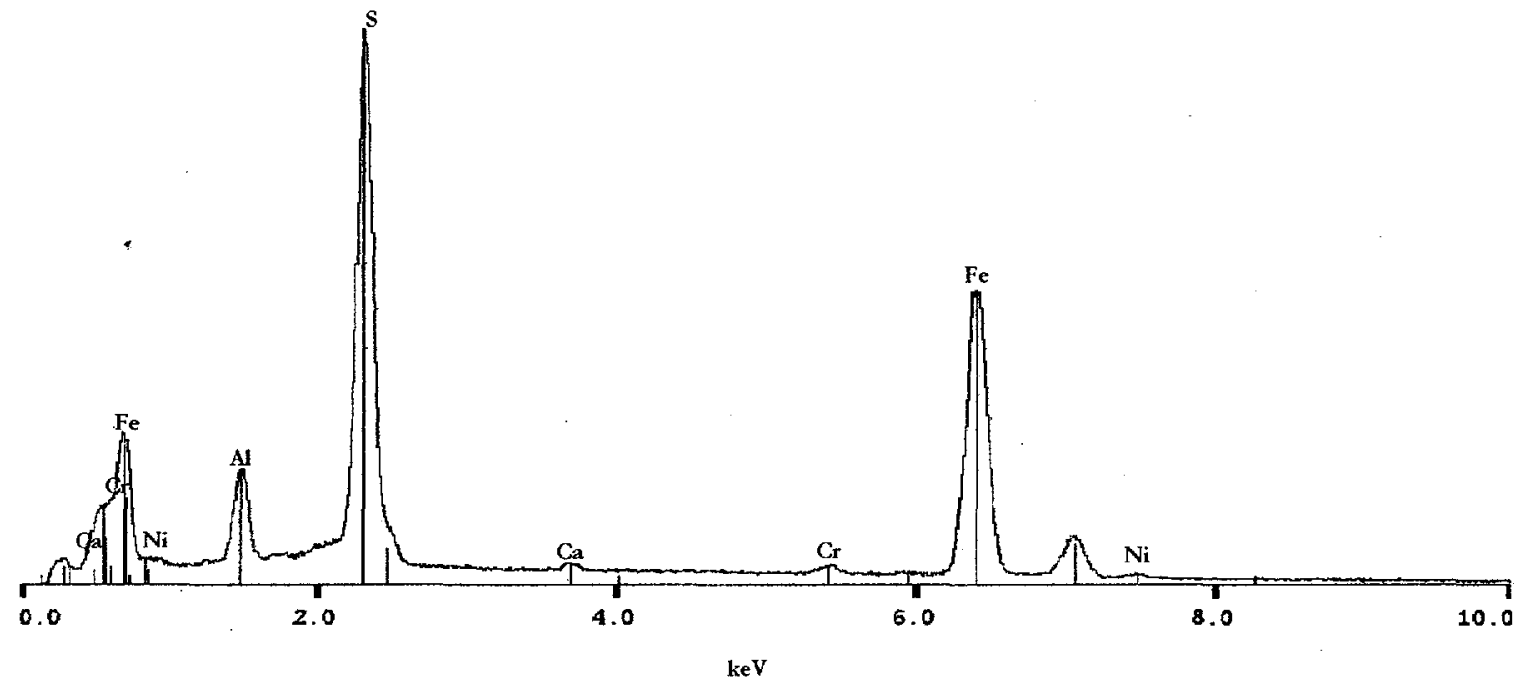

Figure 39: Full screen spectrum of Figure 38. Upstream surface of FAS sample exposed for $\mathbf{5 0 0}$ hours.

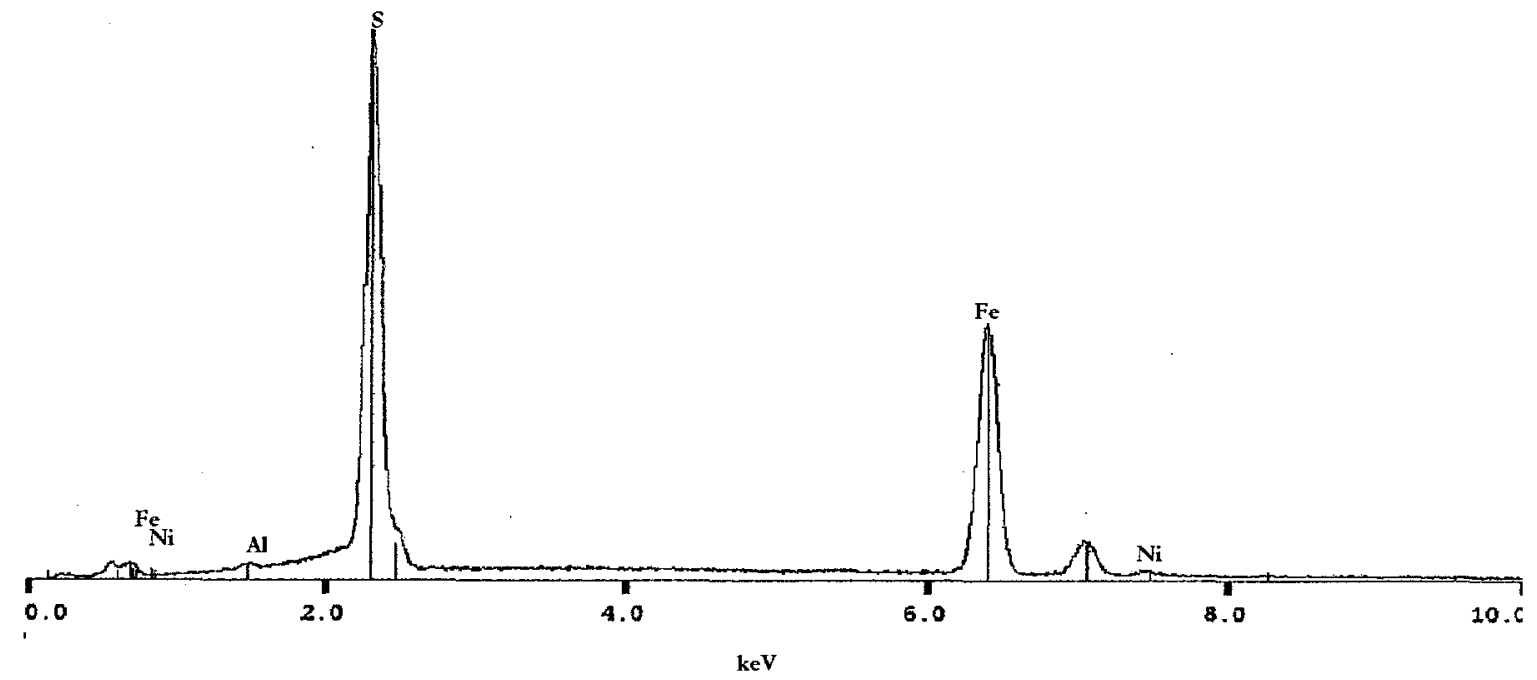

Figure 40: Spot spectrum of crystal structure on surface of Figure 38. 


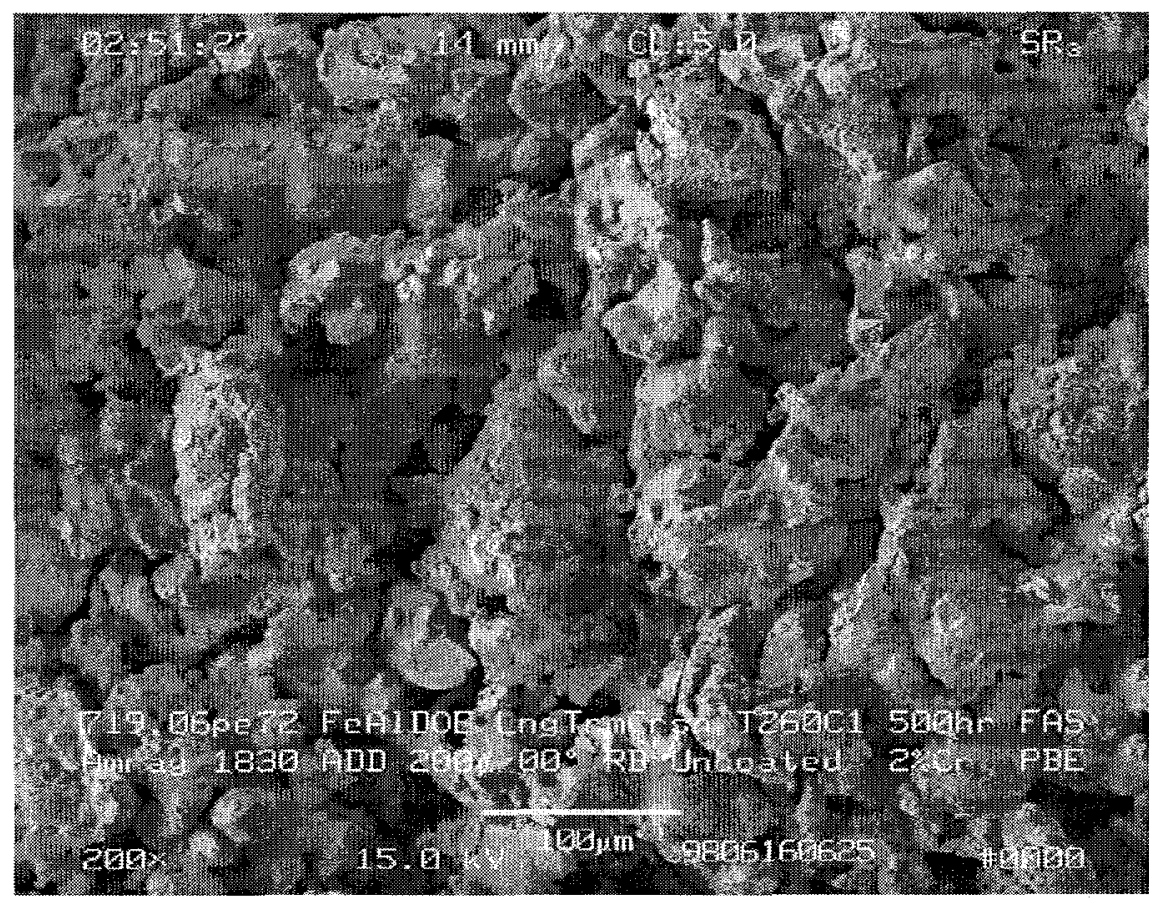

Figure 41: FAS fracture surface. Clean, minimal reaction. Exposed for 500 hours.

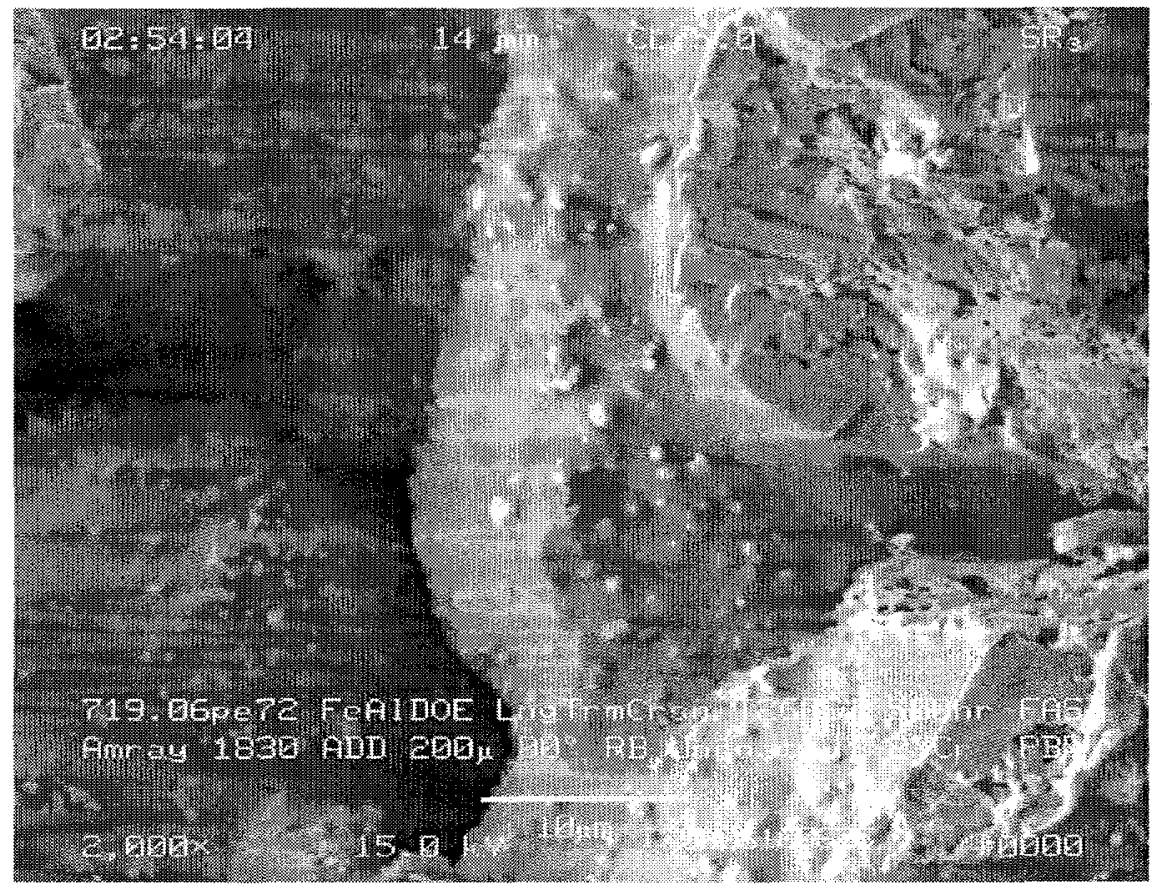

Figure 42: FAS fracture surface. Appears to be a typical iron aluminide surface. Exposed for $\mathbf{5 0 0}$ hours. Bright zirconium/zirconia nodules on surface. 


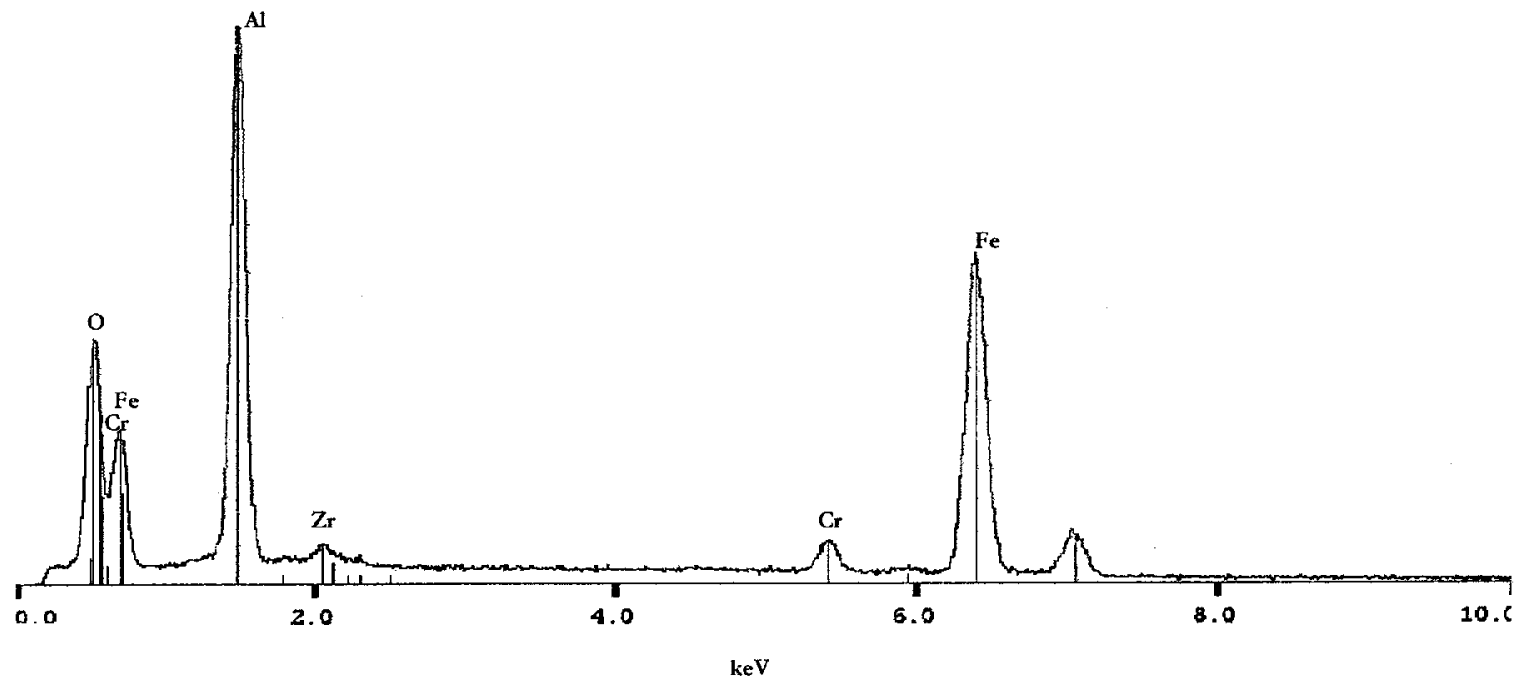

Figure 43: Full screen spectrum of Figure 42. No sulfur present. 


\section{SEM Images \\ FAS Sample Exposed for 1000 Hours}

(FAS Sample \#2) 


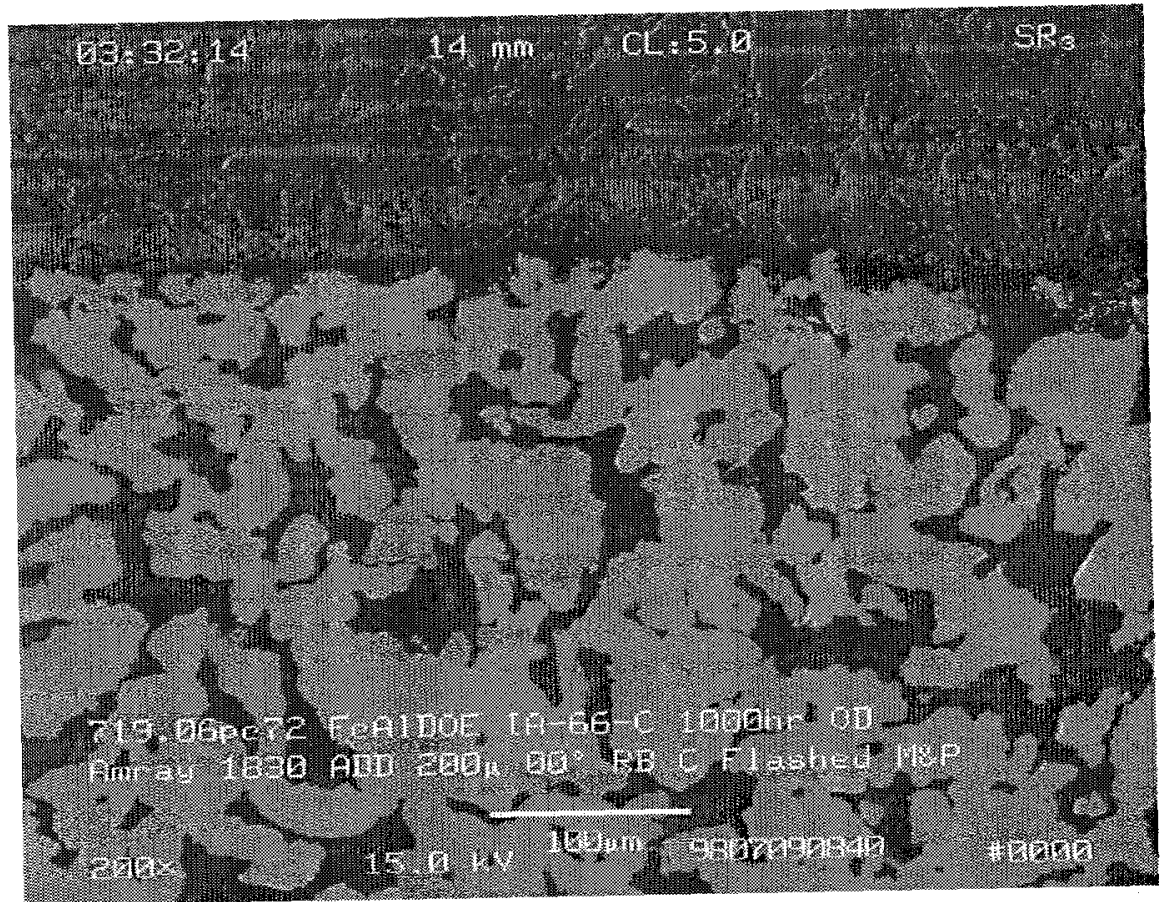

Figure 44: FAS cross-section. Upstream edge shown. Exposed for 1000 hours.

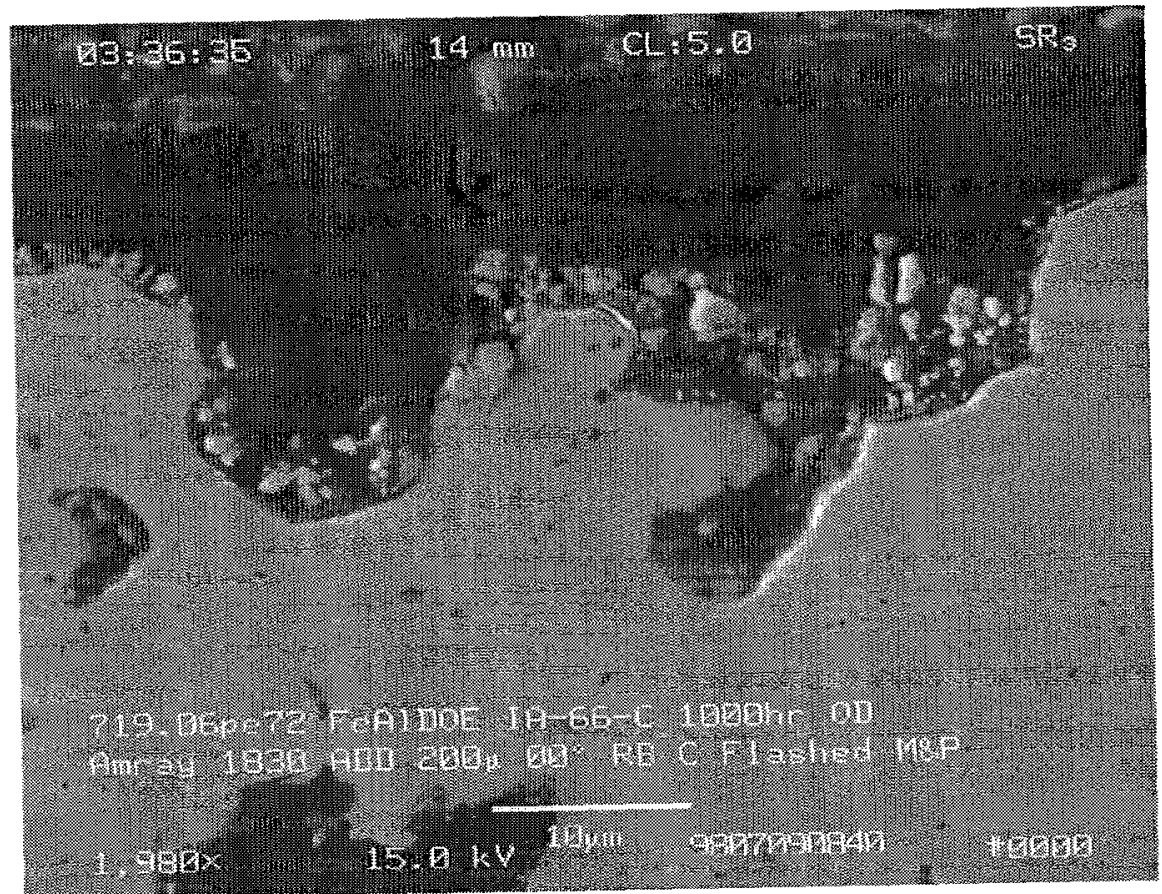

Figure 45: FAS cross-section. Upstream edge shown. Exposed for 1000 hours. Similar iron sulfide crystal formation as seen in Figure 34. 


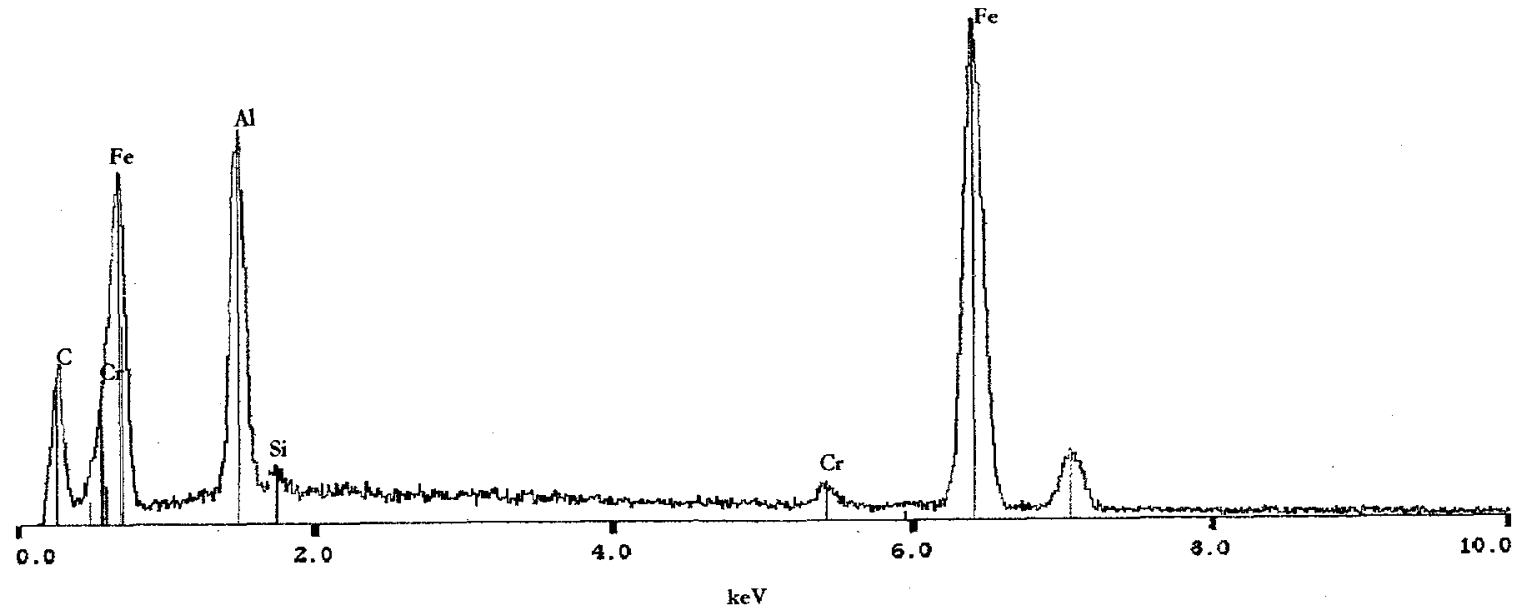

Figure 46: Partial field of base metal in Figure 45. Typical iron aluminide signature. No sulfur penetration.

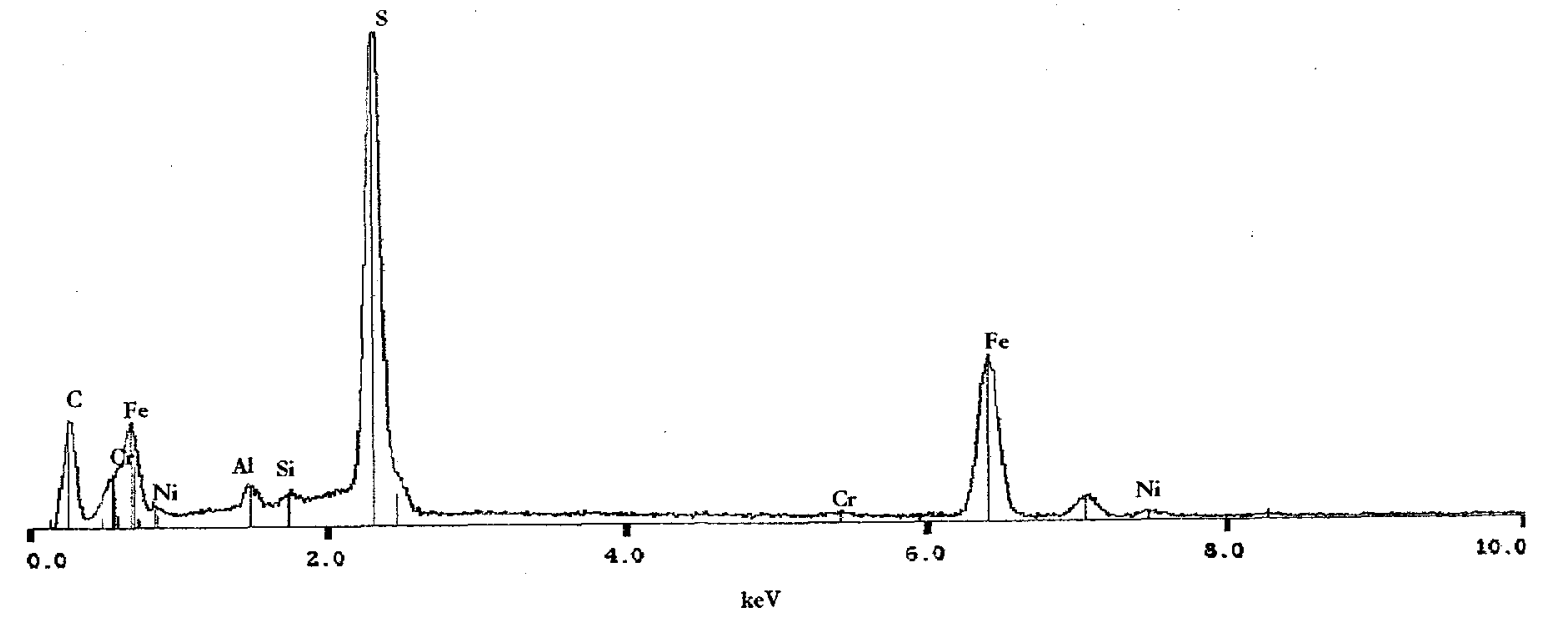

Figure 47: Partial field of upstream edge of Figure 45. High sulfur and iron. A strong indication of iron sulfides. 


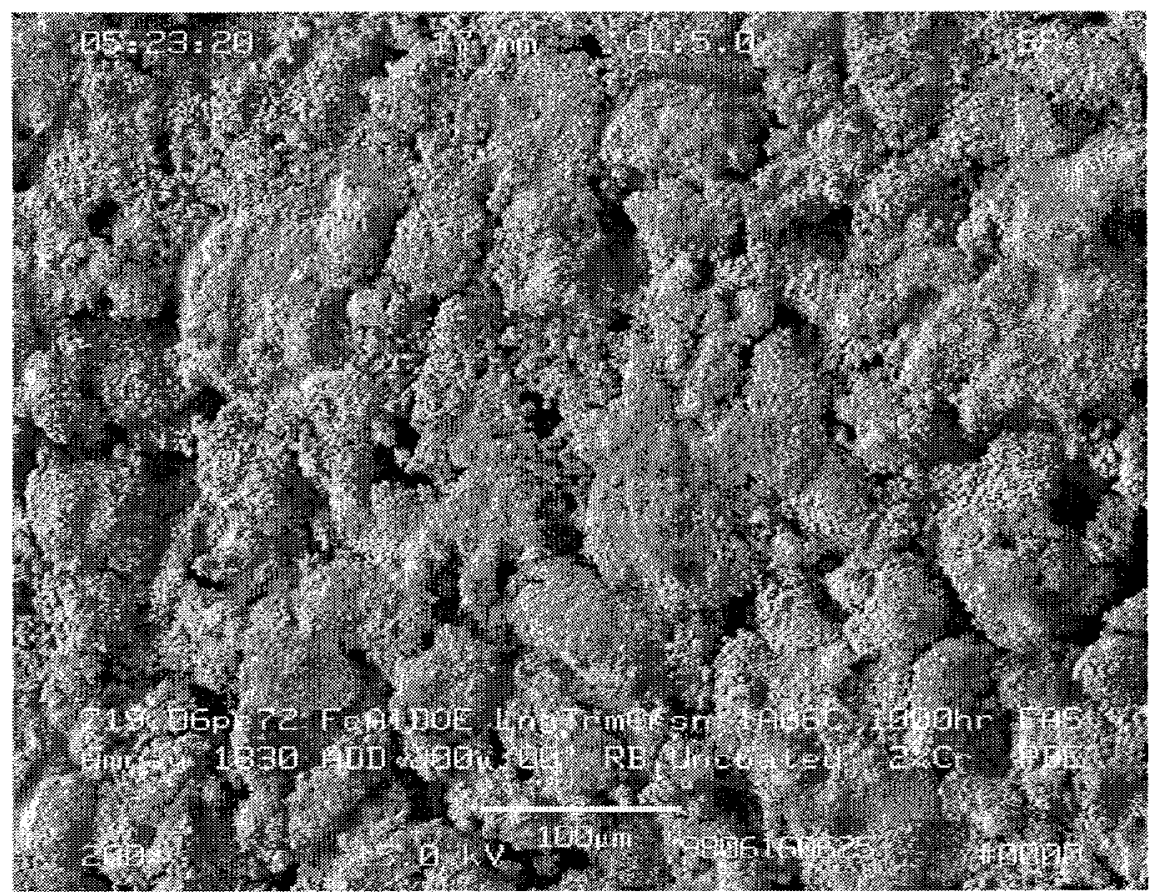

Figure 48: FAS upstream surface. Exposed for 1000 hours. Covered in iron sulfide crystals.

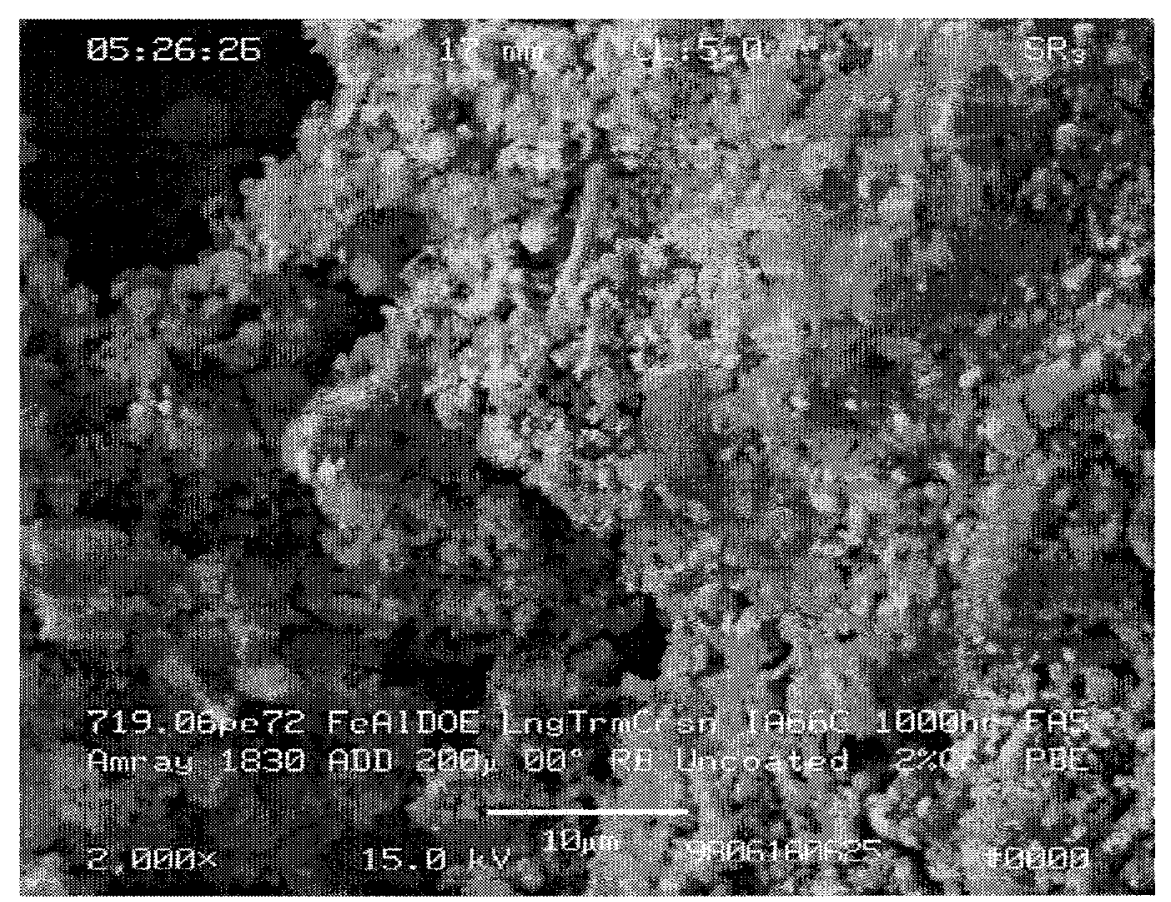

Figure 49: FAS upstream surface. Exposed for 1000 hours. 


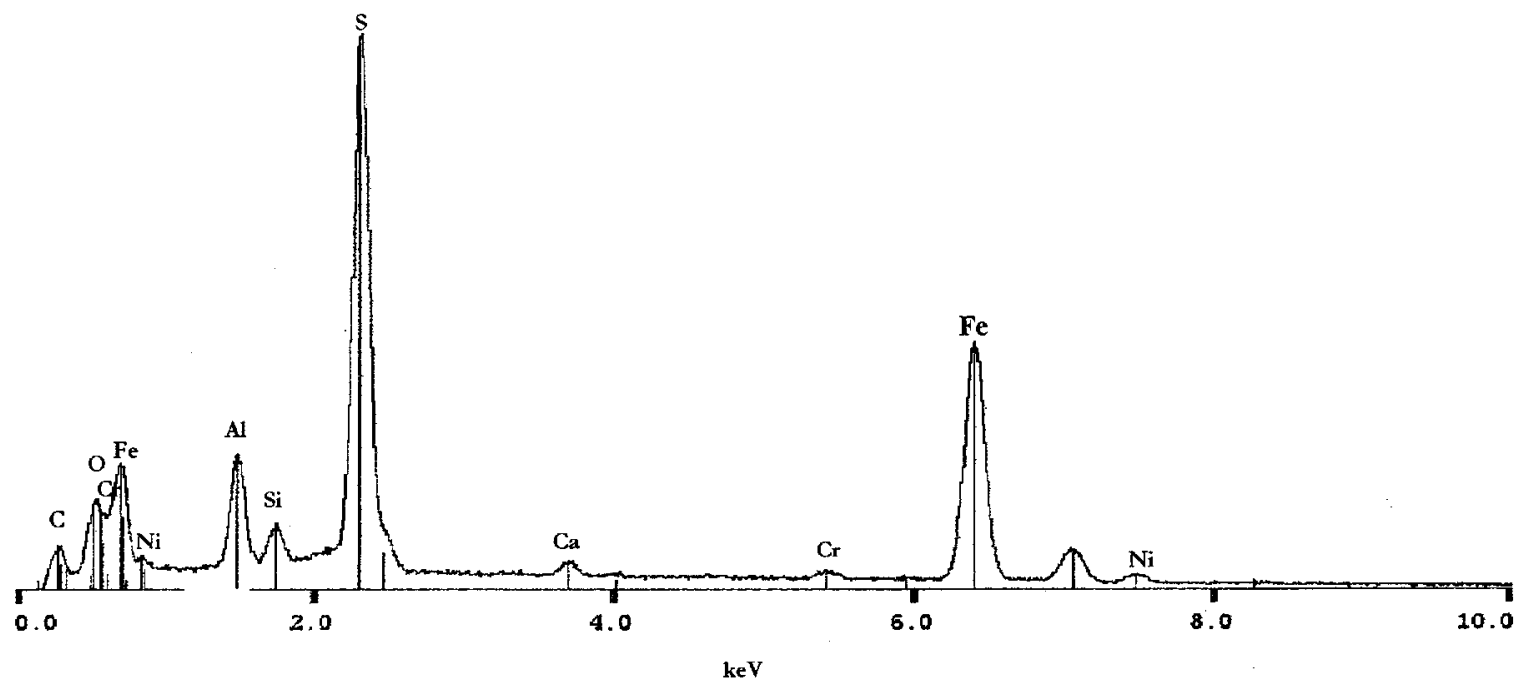

Figure 50: Full screen spectrum of Figure 49. High sulfur and iron. Strong indication of iron sulfide.

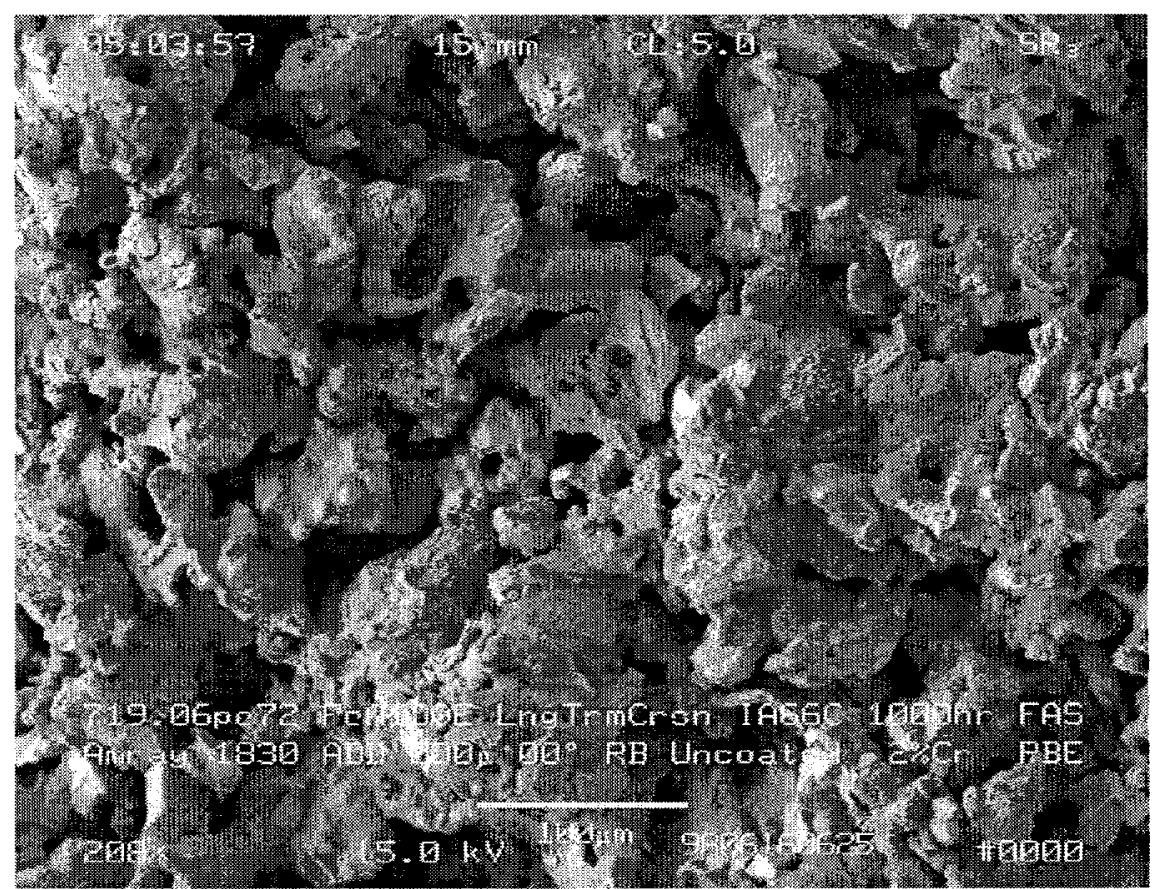

Figure 51: FAS fracture surface. Exposed for 1000 hours. 


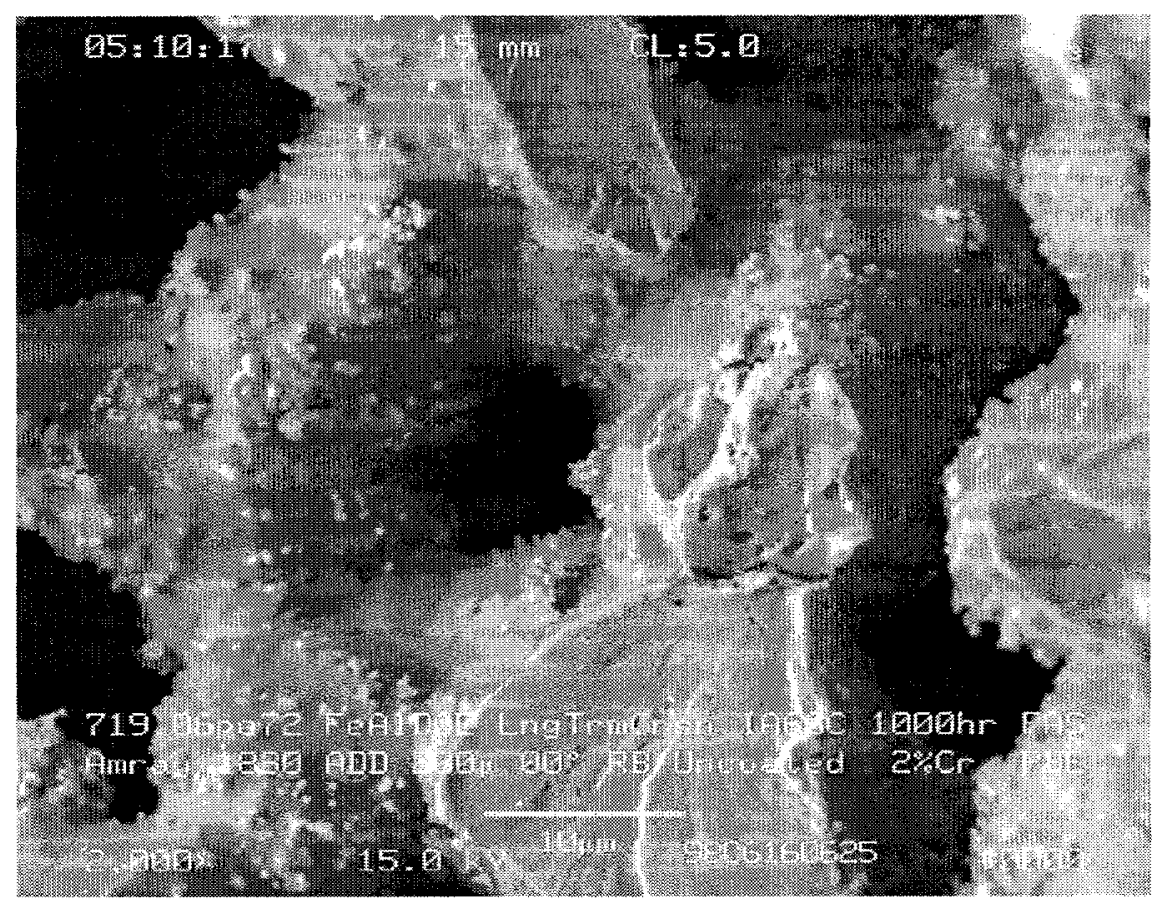

Figure 52: FAS fracture surface. Exposed for 1000 hours. Zirconia nodules, some porosity in the sinter bonds.

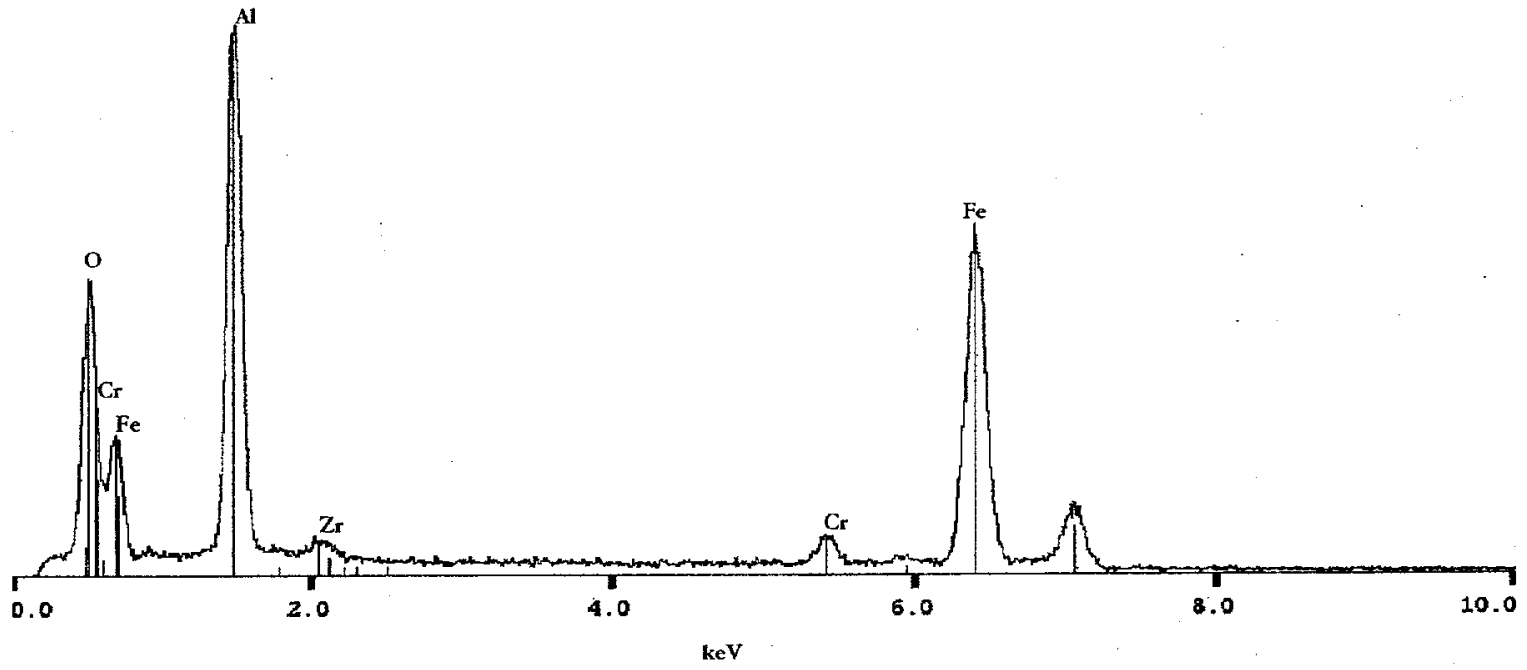

Figure 53: Full screen spectrum of Figure 52. Oxygen peak indicates a thin alumina layer on the surface of the sample. 


\section{SEM Images \\ FAS Sample Exposed for 1500 Hours \\ (FAS Sample \#3)}




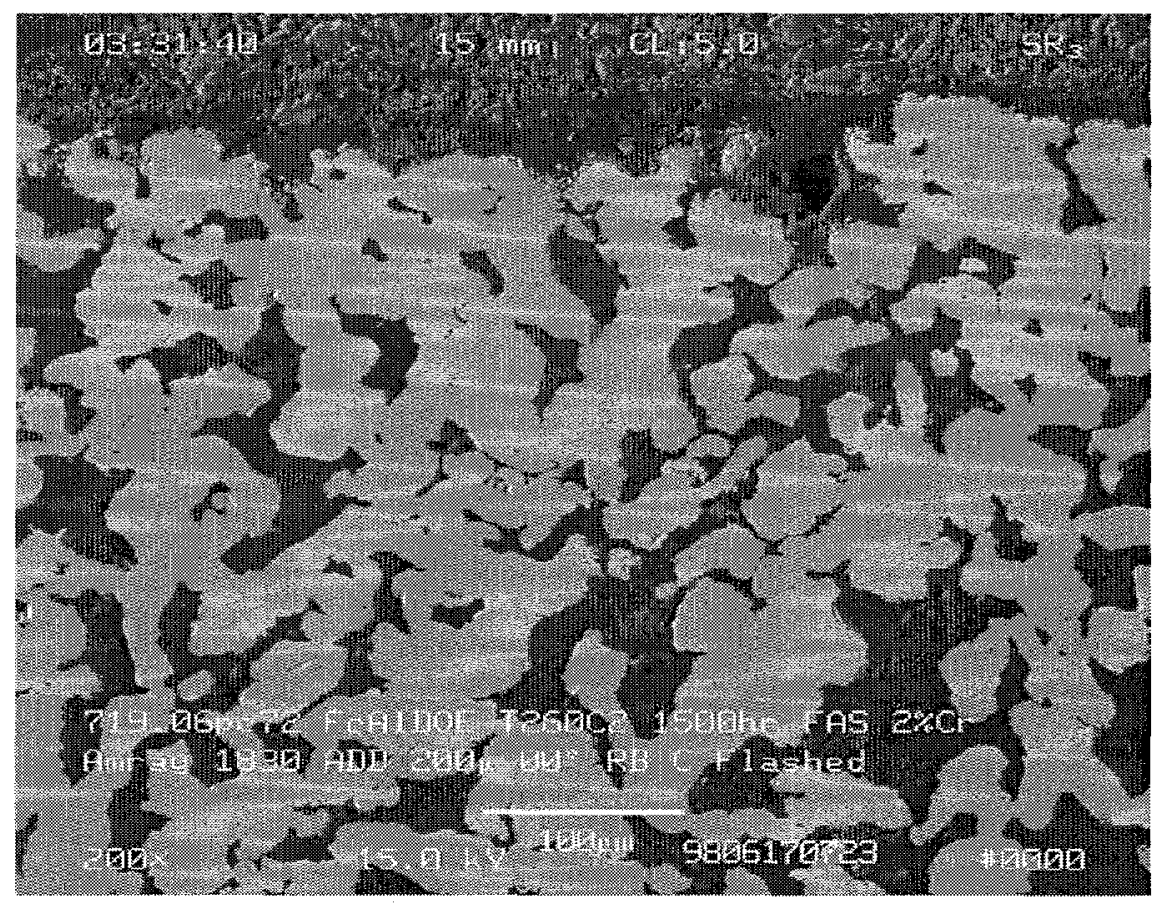

Figure 54: FAS cross-section. Upstream edge shown. Exposed for 1500 hours. Iron sulfide crystals on upstream edge are barely visible at this magnification.

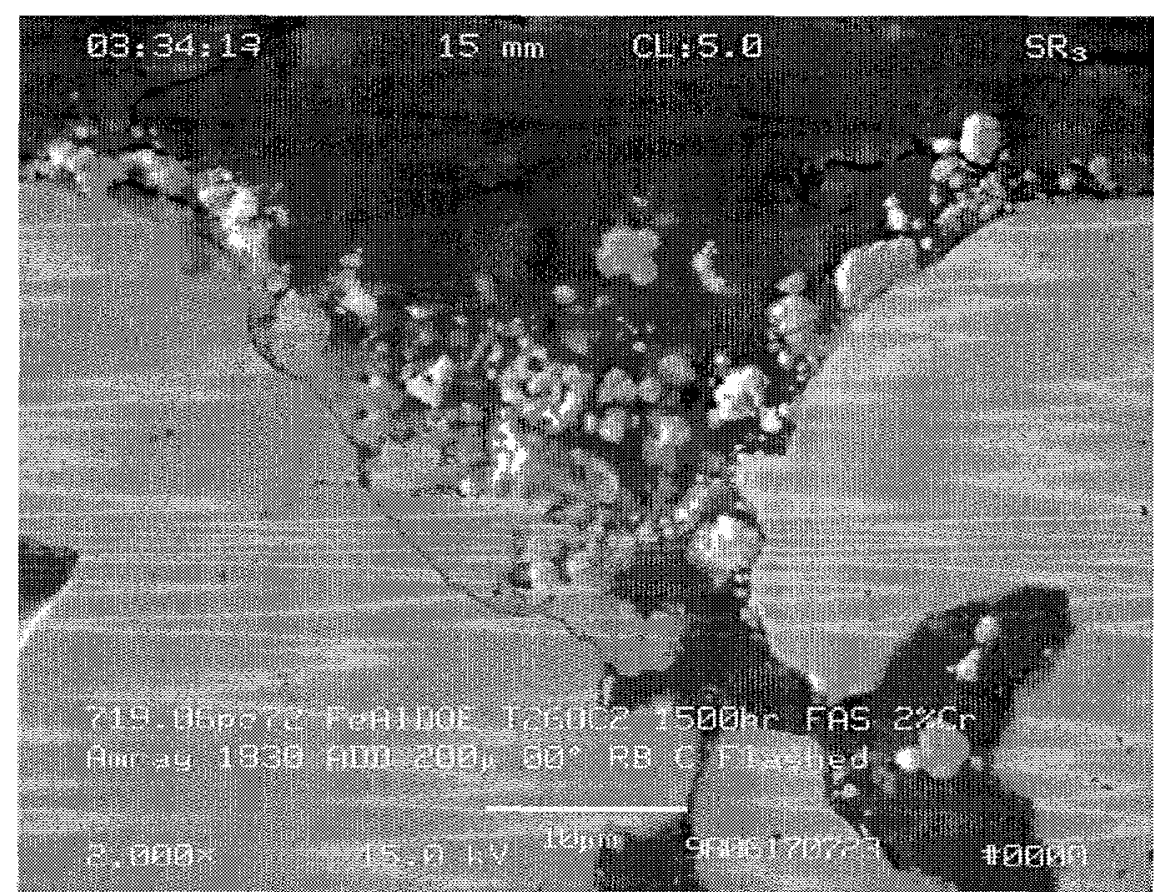

Figure 55: FAS cross-section. Upstream edge shown. Exposed for 1500 hours. Amount of crystals are similar to Figure 34. No increase in sulfide formation over time, after $\mathbf{5 0 0}$ hours of exposure. 


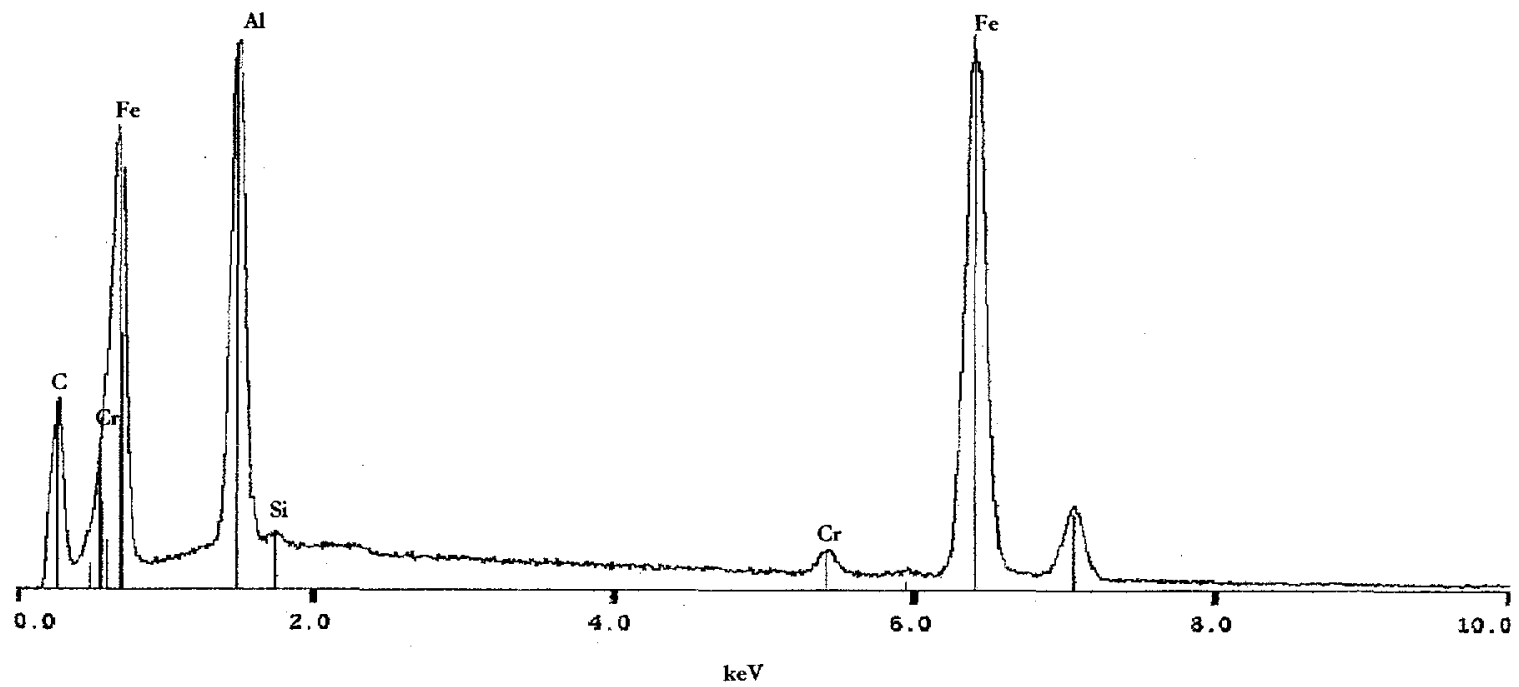

Figure 56: Spectrum of base metal on Figure 55. Typical iron aluminide signature.

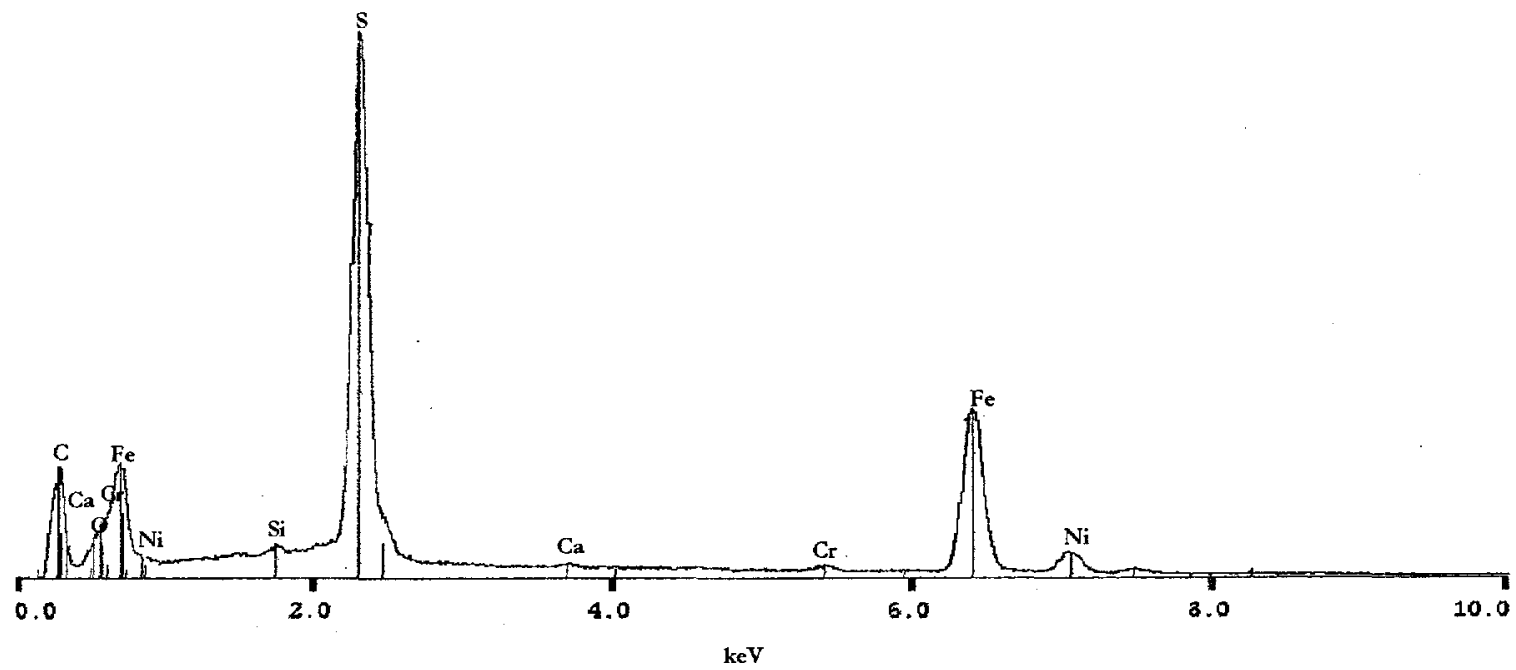

Figure 57: Spectrum of upstream edge of Figure 55. High sulfur and iron. Strong indication of iron sulfides. 

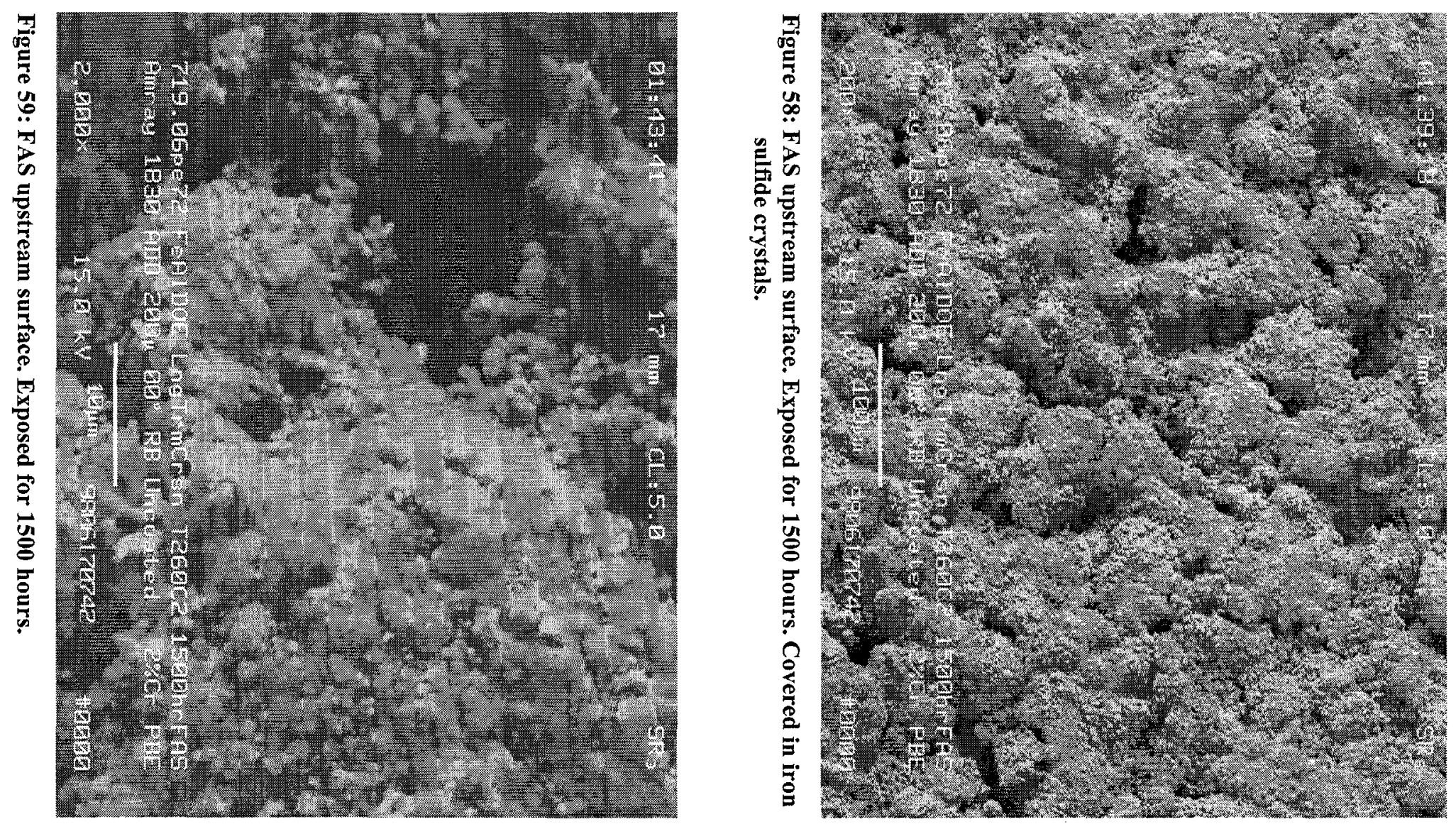


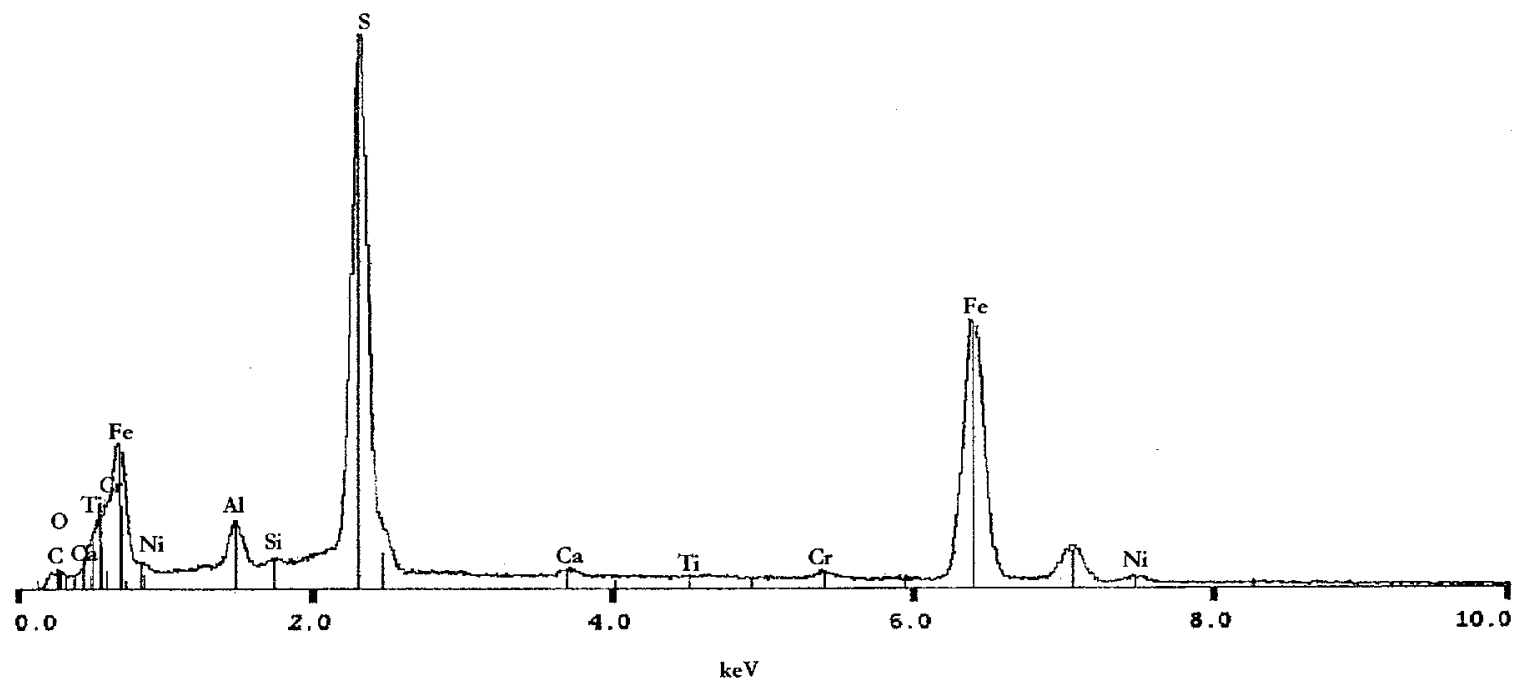

Figure 60: Full screen spectrum of Figure 59. High sulfur and iron. Strong indication of iron sulfides.

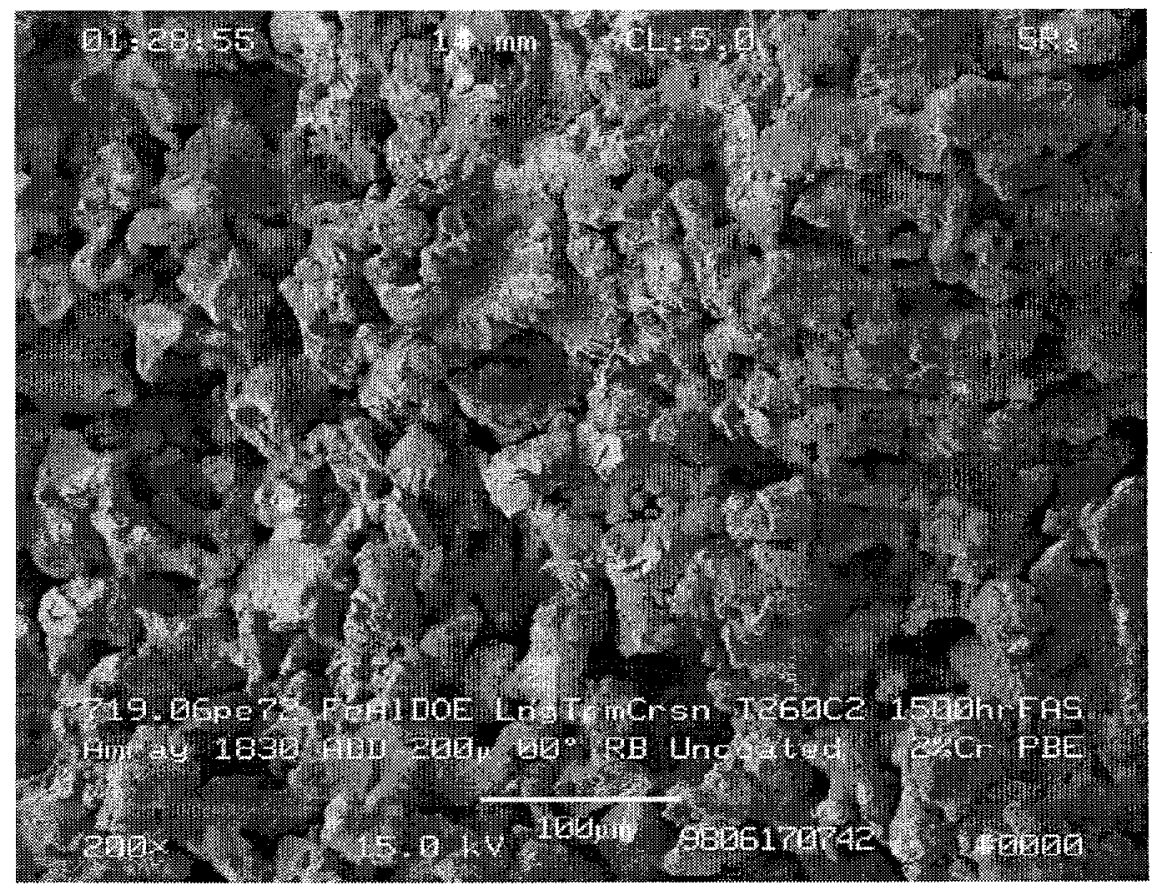

Figure 61: FAS fracture surface. Exposed for 1500 hours. 


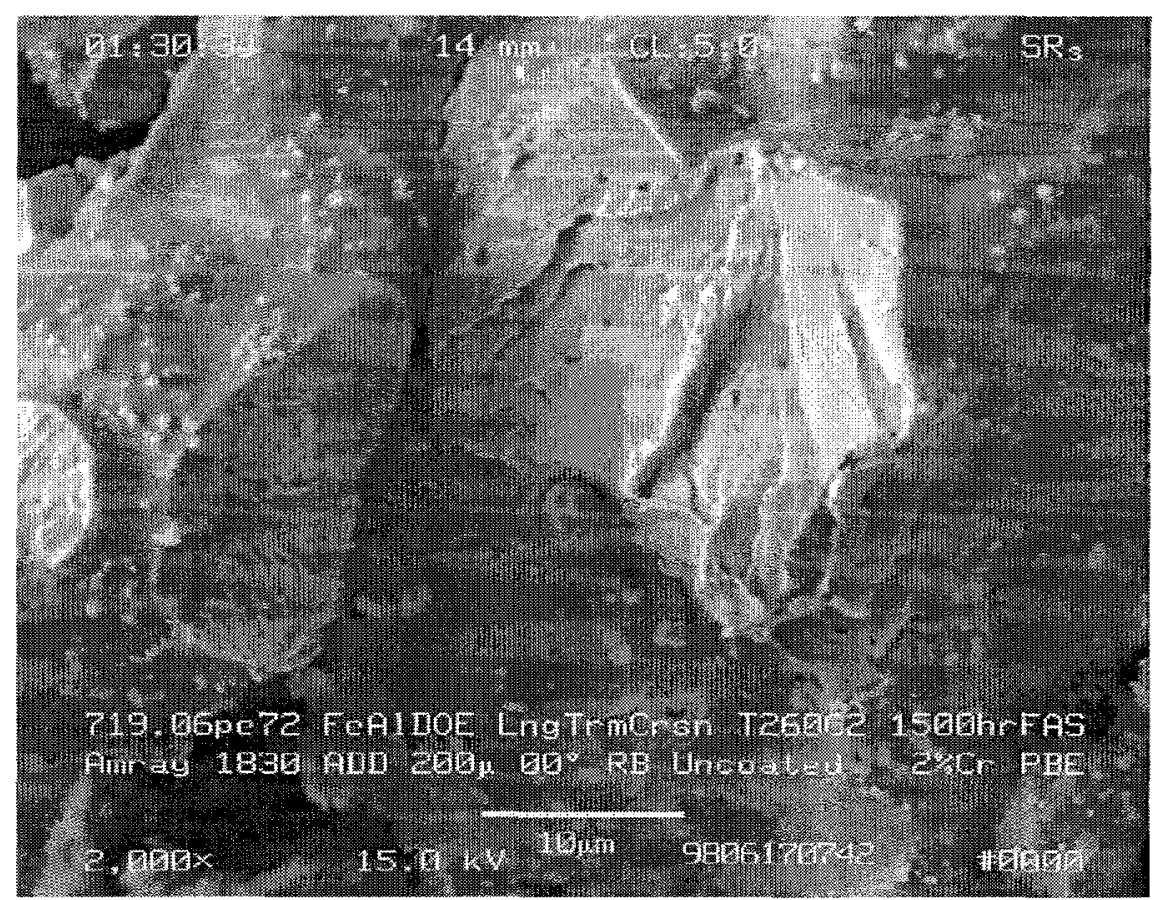

Figure 62: FAS fracture surface. Exposed for 1500 hours. Typical unexposed iron aluminide fracture surface with some porosity at sinter bond, zirconium/zirconia nodules on surface. Brittle transgranular fracture.

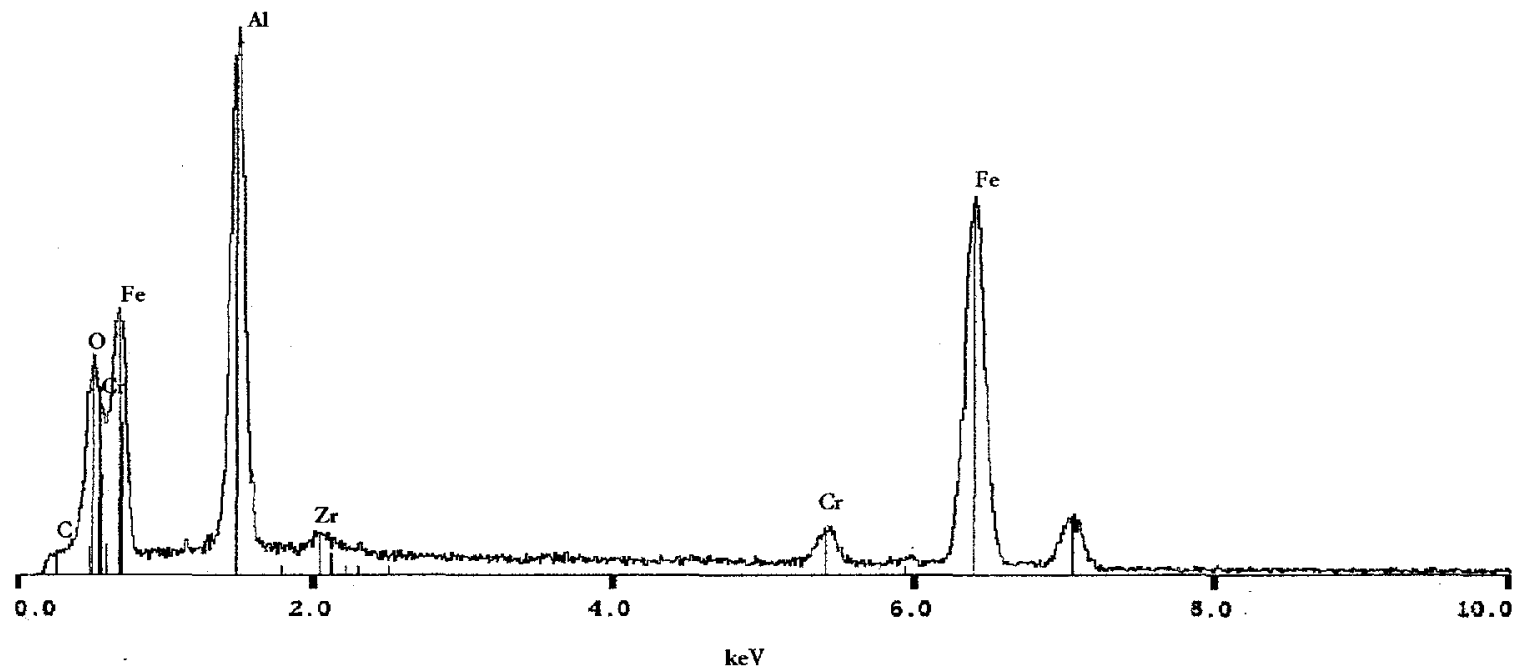

Figure 63: Full screen spectrum of Figure 62. Typical iron aluminide signature. 


\section{SEM Images \\ FAL Control Sample}




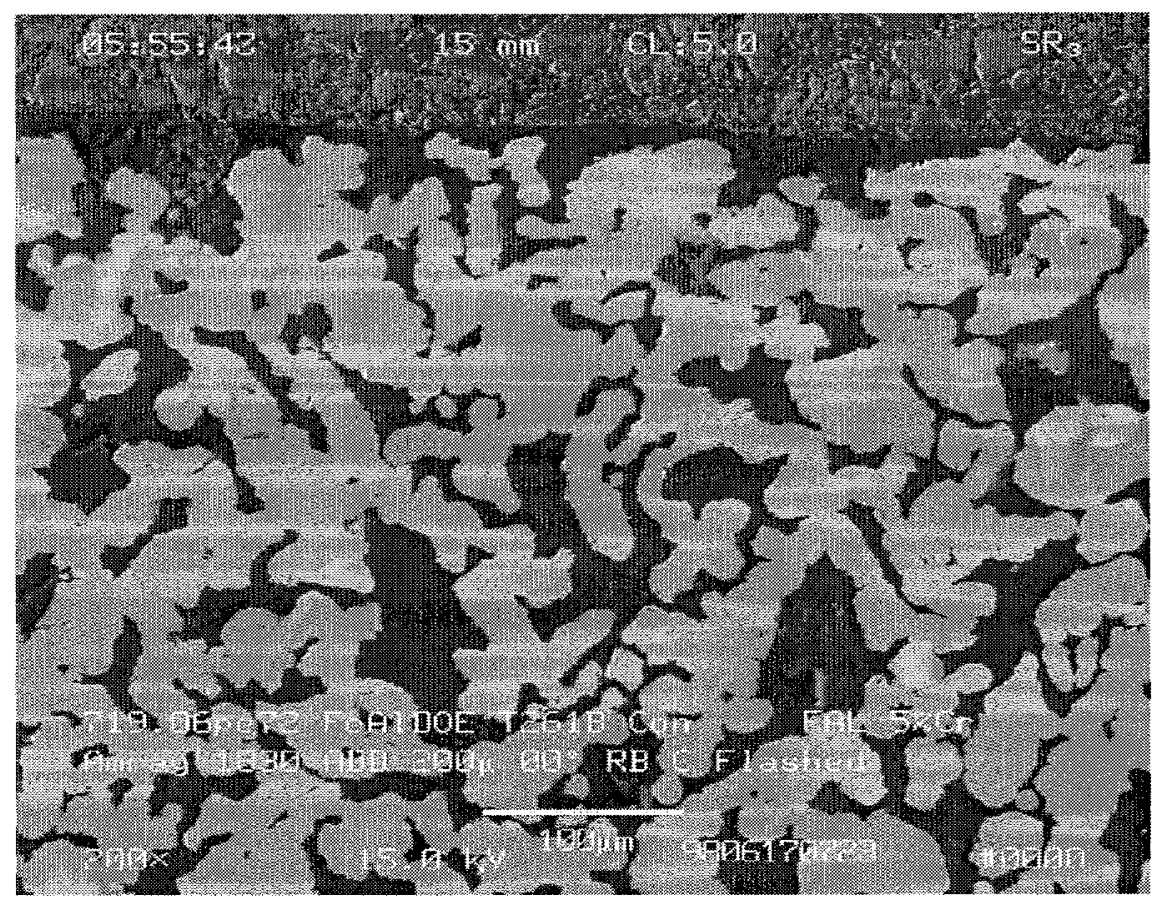

Figure 64: Cross-section of FAL control sample. Preoxidized for seven hours at $800^{\circ} \mathrm{C}$.

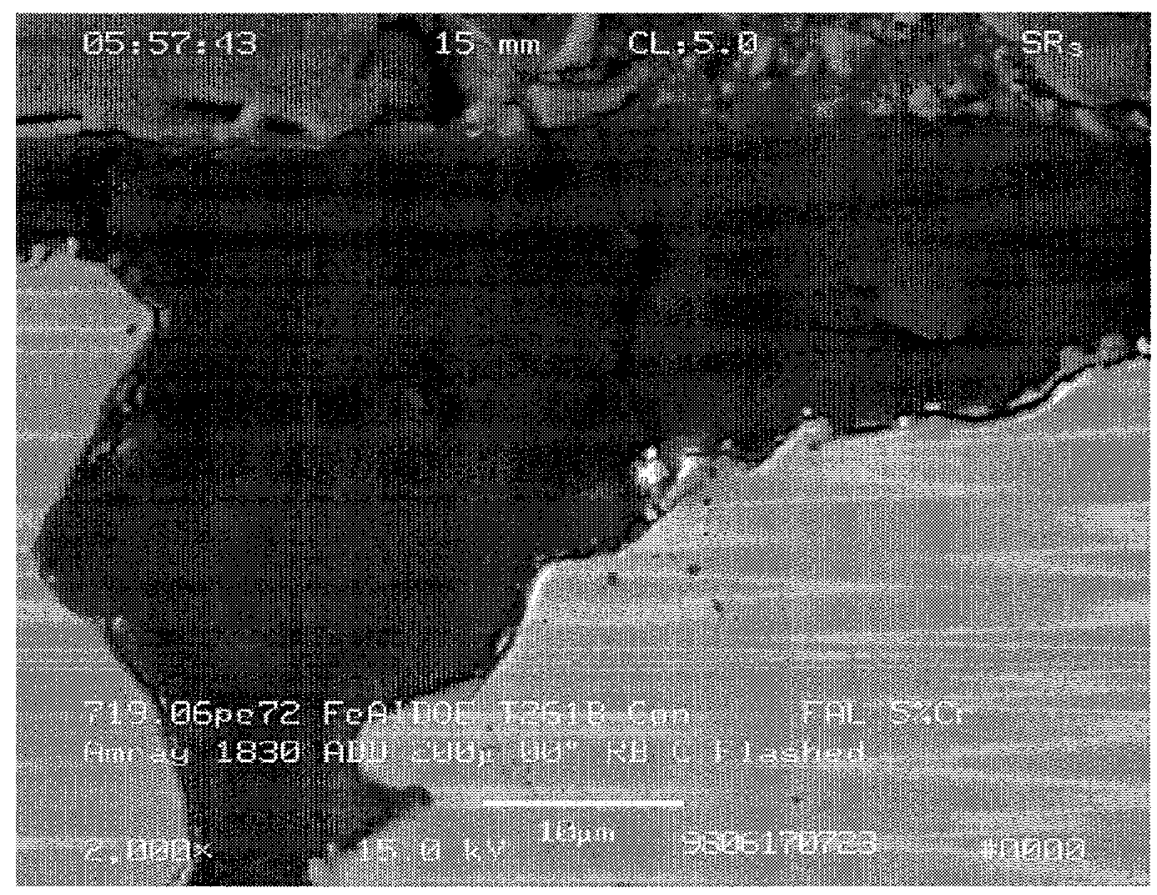

Figure 65: Cross-section of FAL control sample. Preoxidized for seven hours at $800^{\circ} \mathrm{C}$. 


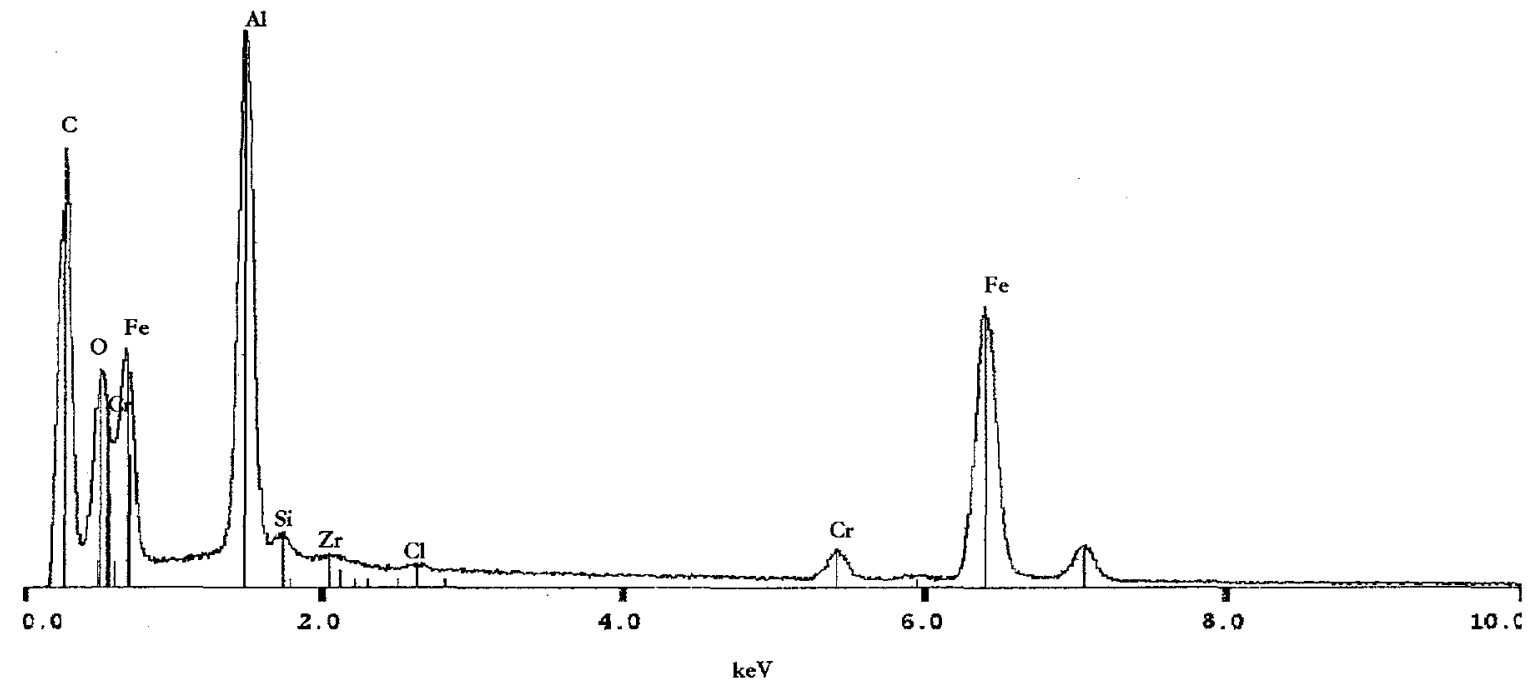

Figure 66: Partial field spectrum of base metal of Figure 65. High carbon is from carbon flashing.

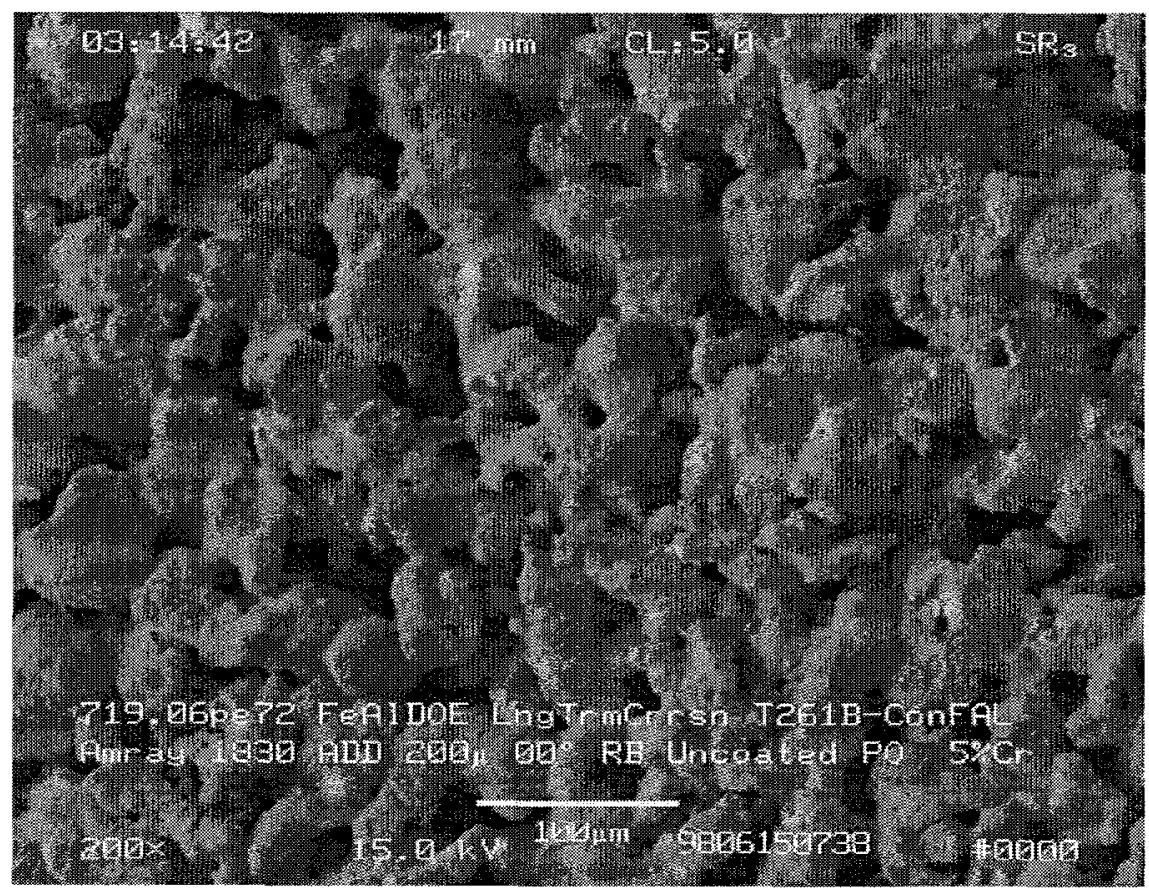

Figure 67: Upstream surface of FAL control sample. Preoxidized for seven hours at $800^{\circ} \mathrm{C}$. 


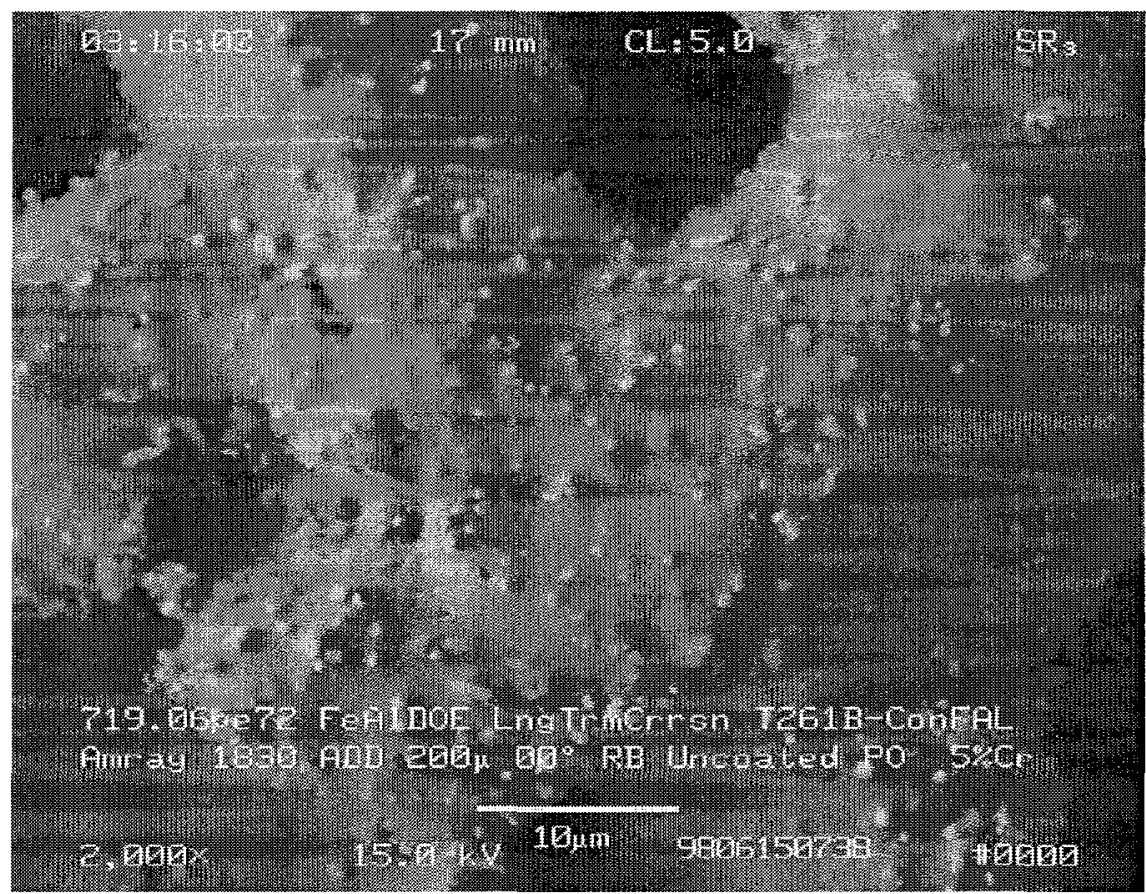

Figure 68: Upstream surface of FAL control sample. Preoxidized for seven hours at $800^{\circ} \mathrm{C}$.

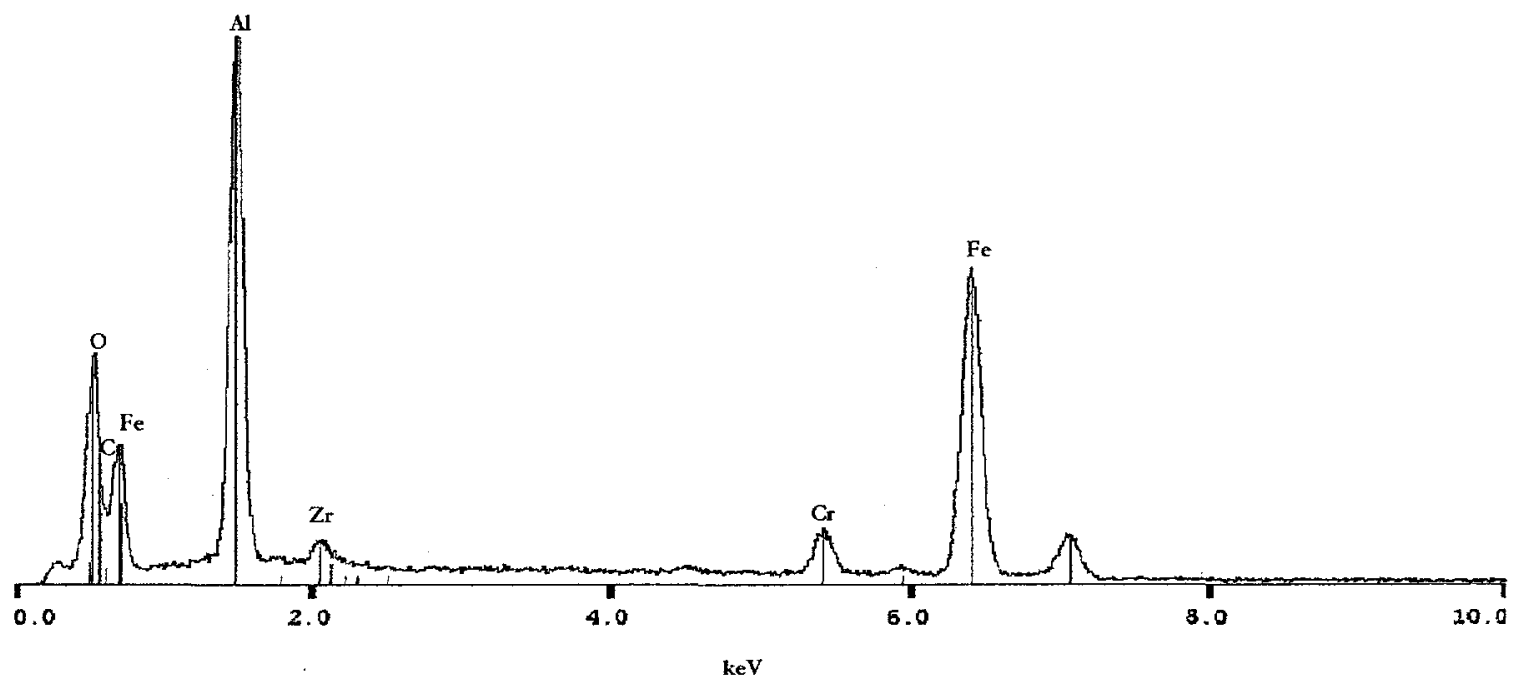

Figure 69: Full screen spectrum of Figure 68. Typical iron aluminide signature. 


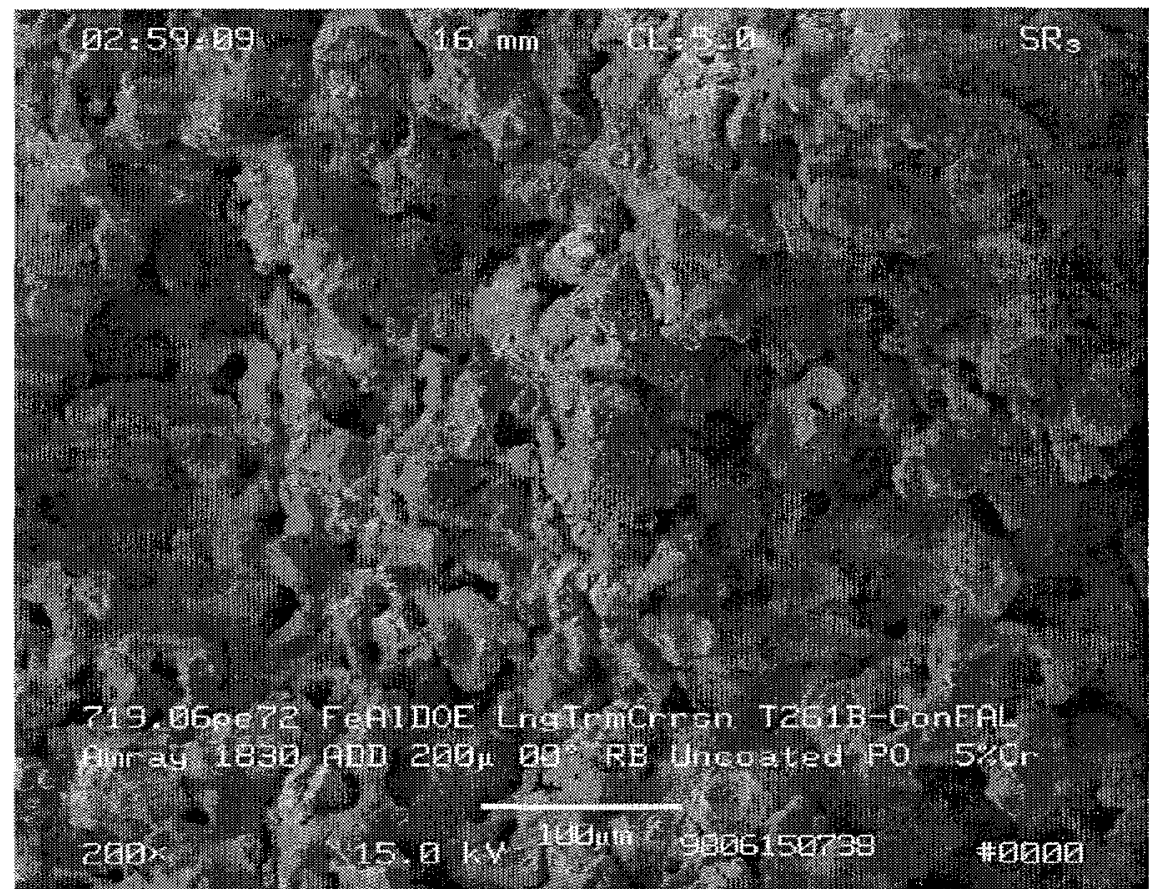

Figure 70: Fracture surface of FAL control sample. Preoxidized for seven hours at $800^{\circ} \mathrm{C}$.

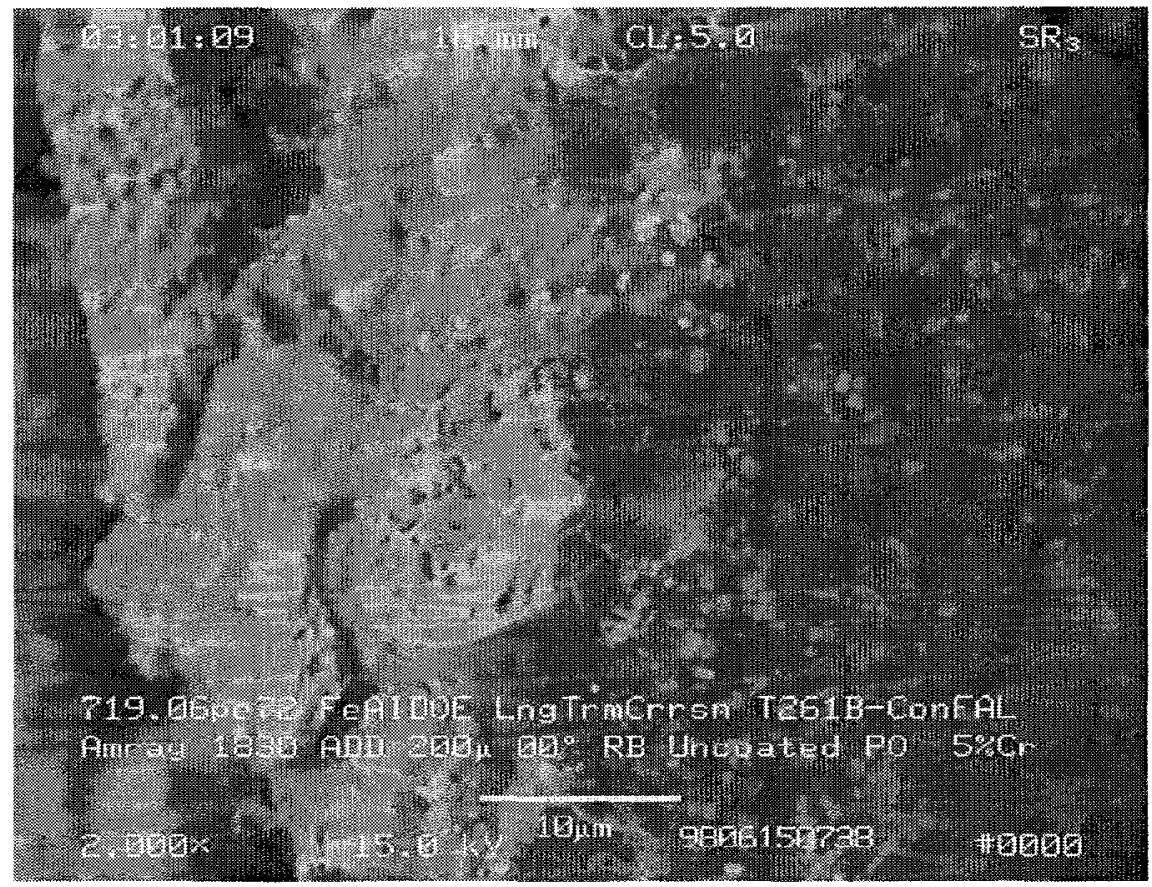

Figure 71: Fracture surface of FAL control sample. Preoxidized for seven hours at $800^{\circ} \mathrm{C}$. 


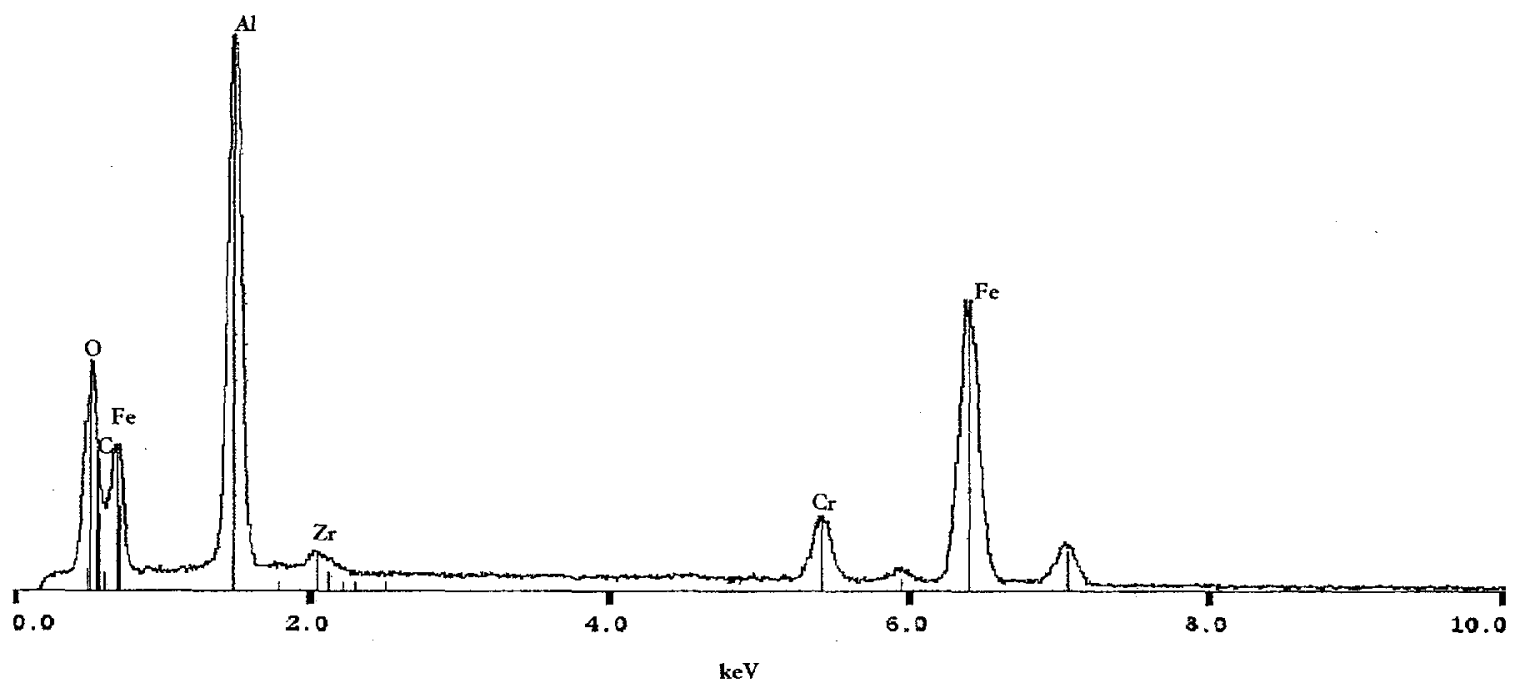

Figure 72: Full screen spectrum of Figure 71. Typical iron aluminide signature. Alumina layer is detected by the presence of oxygen. 


\section{SEM Images \\ FAL Sample Exposed for 500 Hours \\ (FAL Sample \#1)}




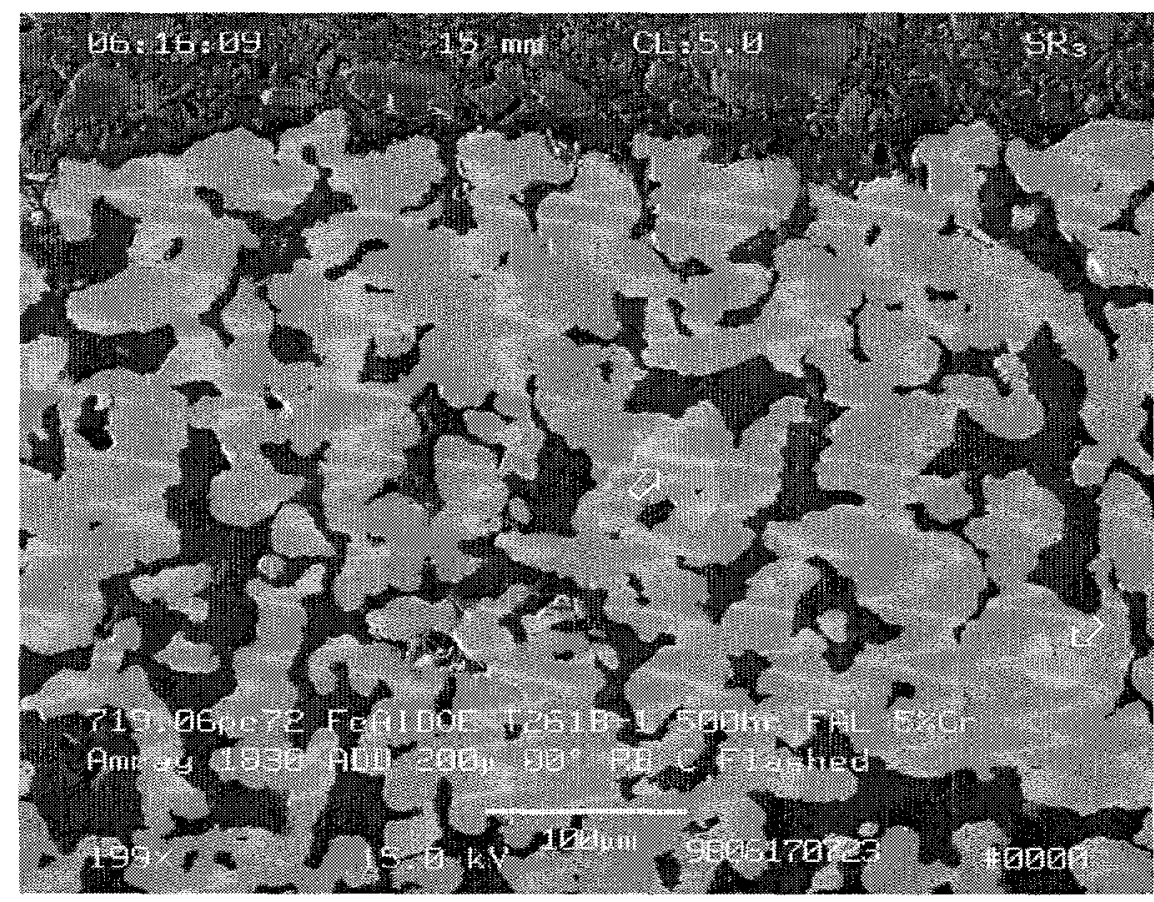

Figure 73: FAL cross-section. Upstream edge shown. Exposed for $\mathbf{5 0 0}$ hours. Lighter areas are from the carbon flashing peeling off (arrows).

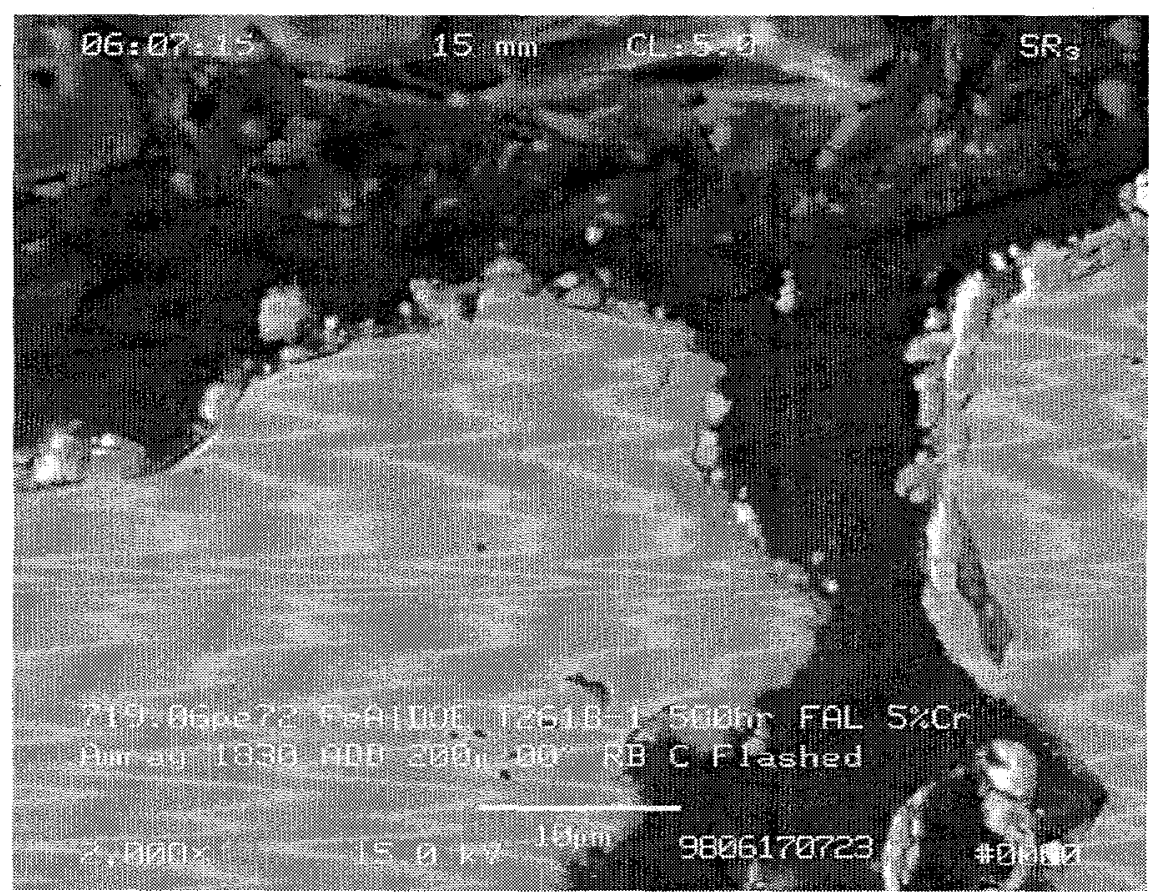

Figure 74: FAL cross-section. Upstream edge shown. Exposed for 500 hours. Some iron sulfide crystals on the upstream surface. 


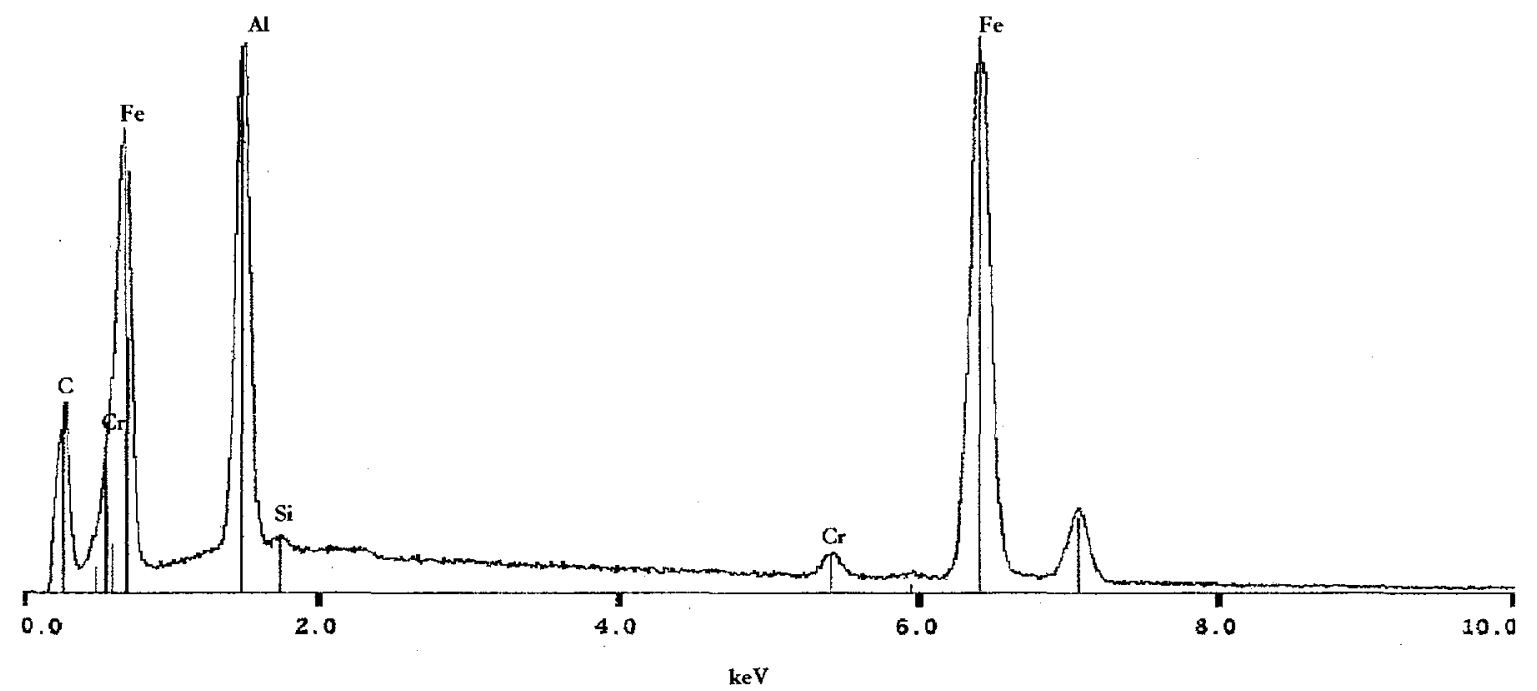

Figure 75: Spectrum of the base metal of Figure 74. Typical iron aluminide signature.

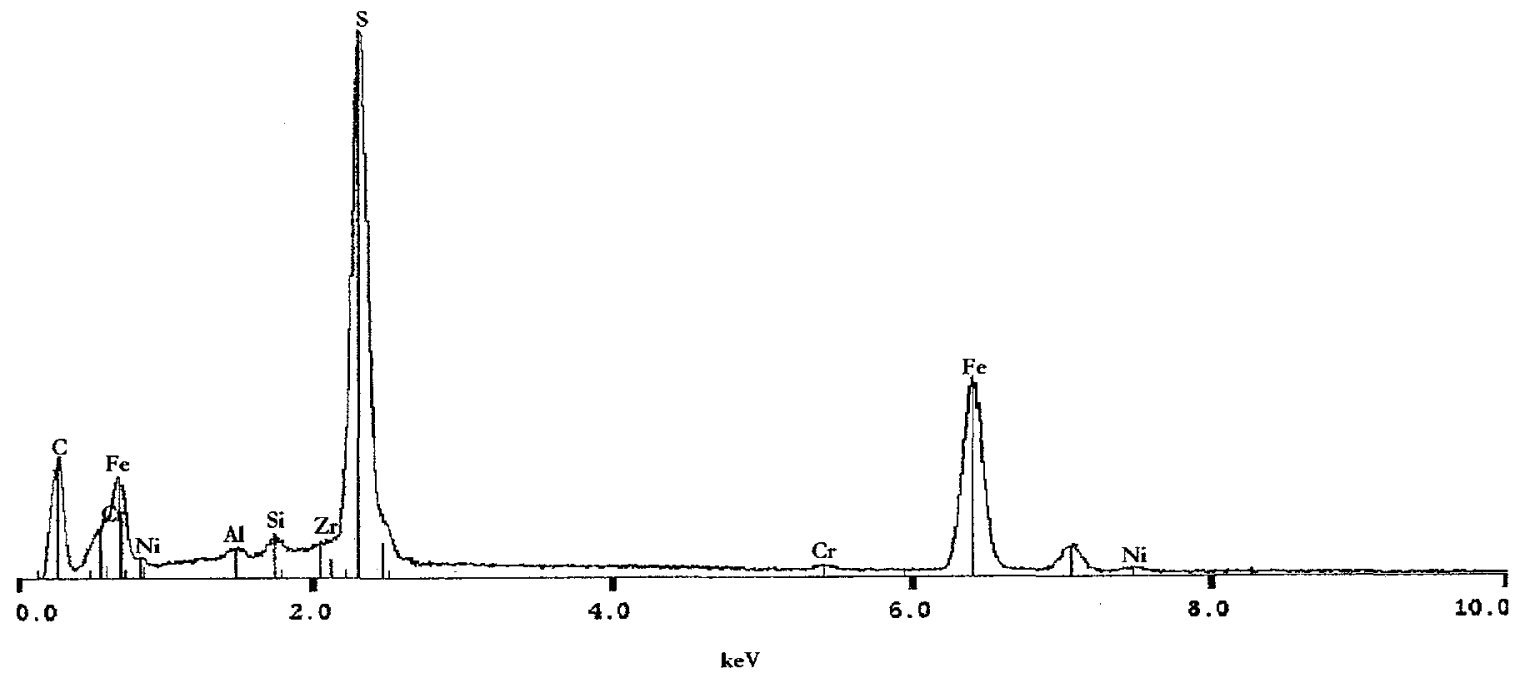

Figure 76: Spectrum of the upstream edge of Figure 74. High sulfur and iron. Strong indication of iron sulfides. 


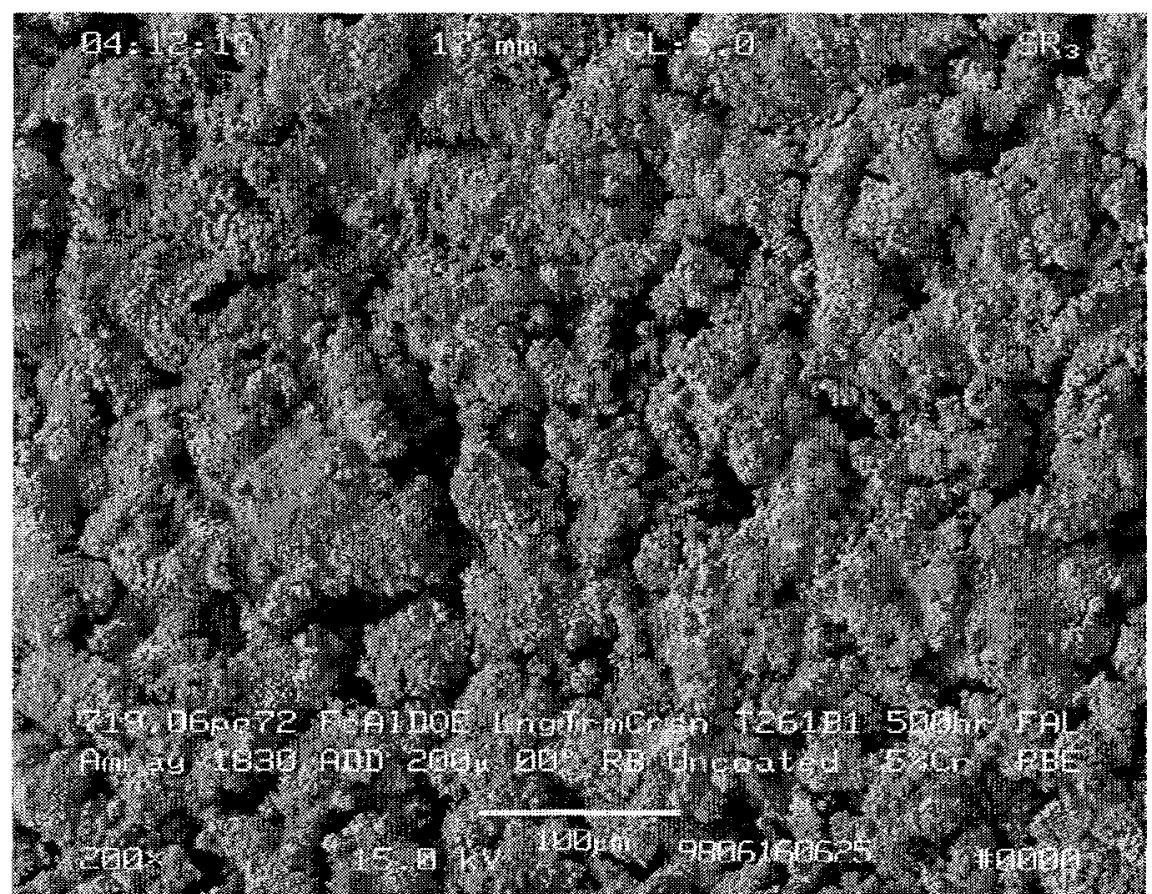

Figure 77: FAL upstream surface. Exposed for 500 hours.

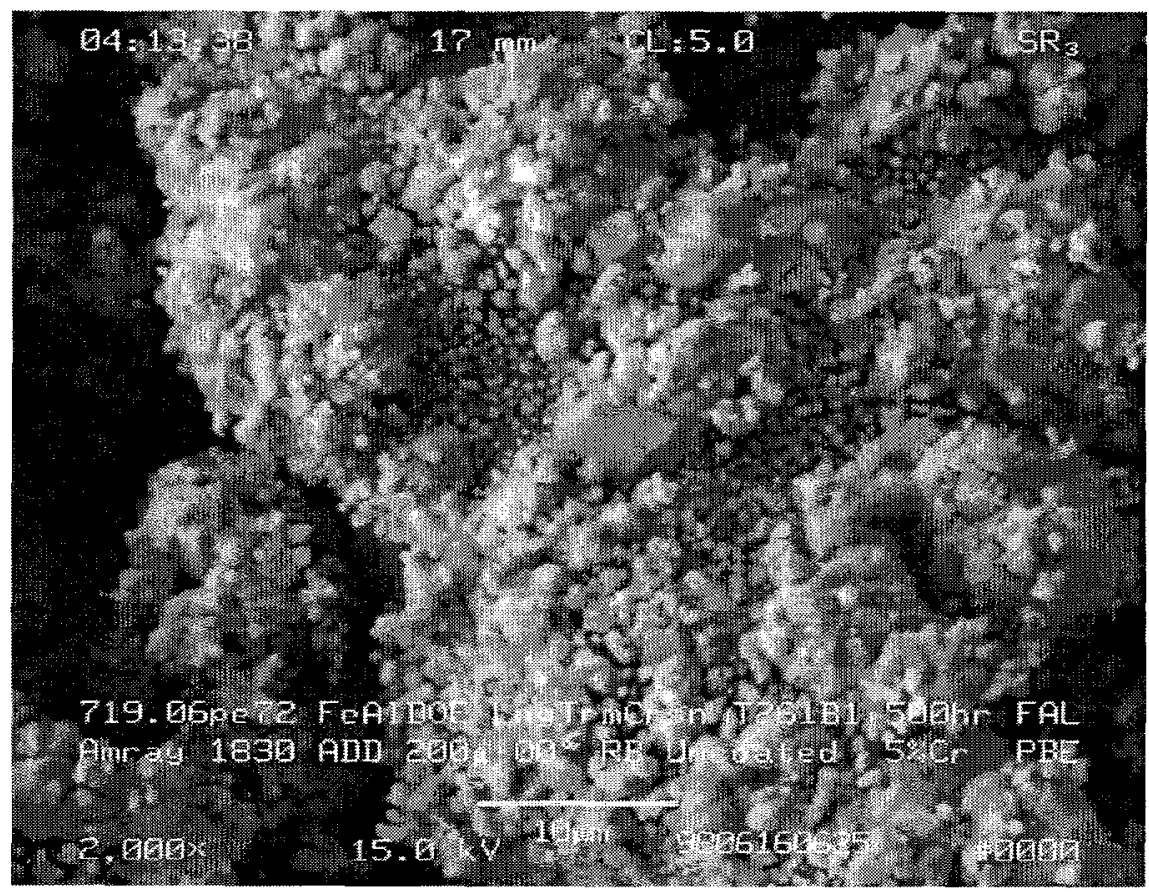

Figure 78: FAL upstream surface. Exposed for 500 hours. 


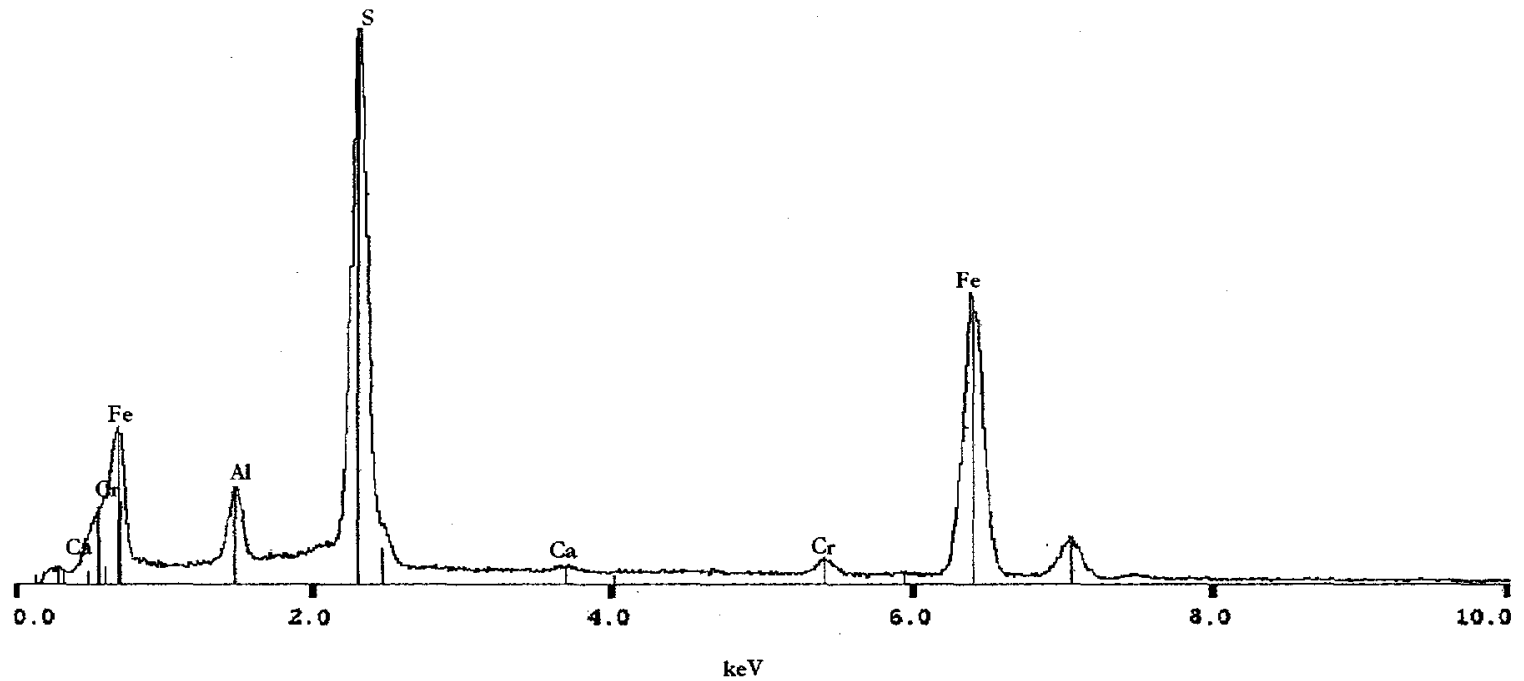

Figure 79: Full screen spectrum of Figure 78. Upstream surface of FAL sample exposed for $\mathbf{5 0 0}$ hours. Sample is probably covered with iron sulfides.

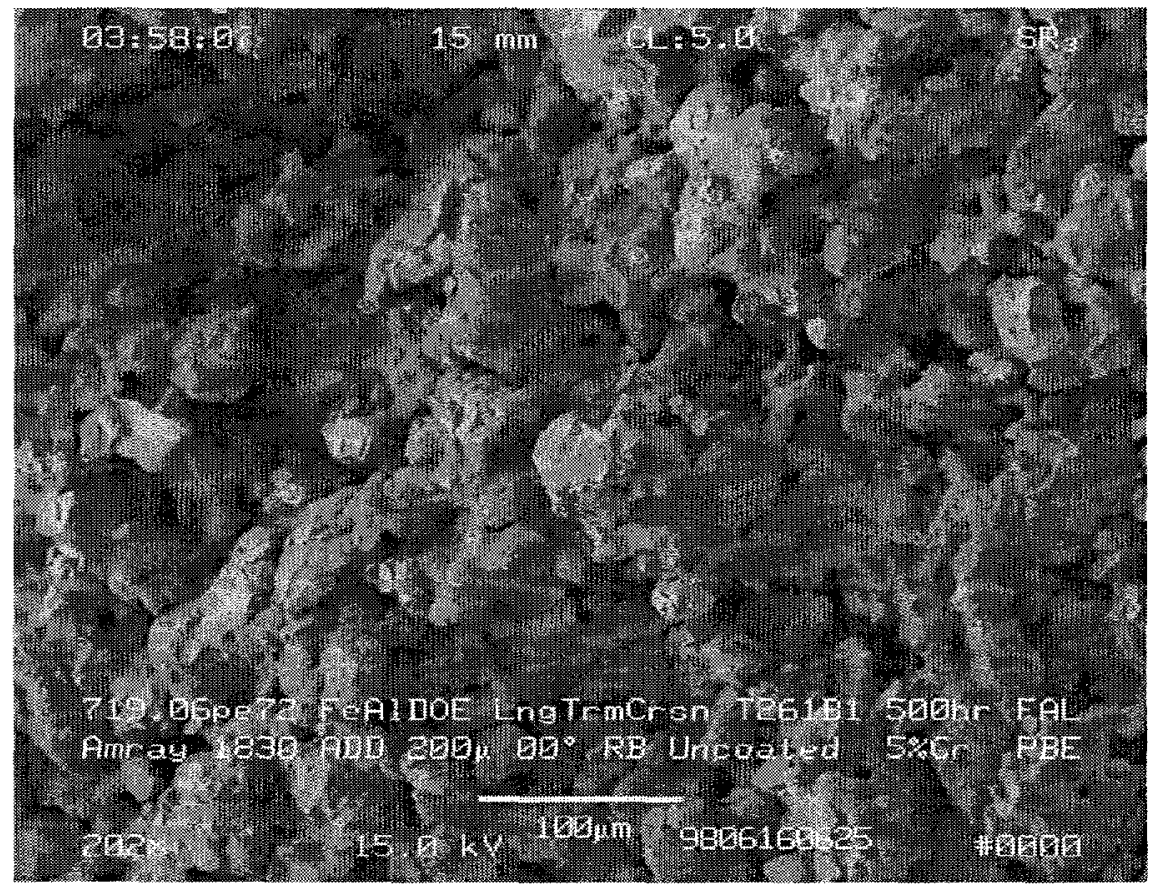

Figure 80: FAL fracture surface. Exposed for $\mathbf{5 0 0}$ hours. 


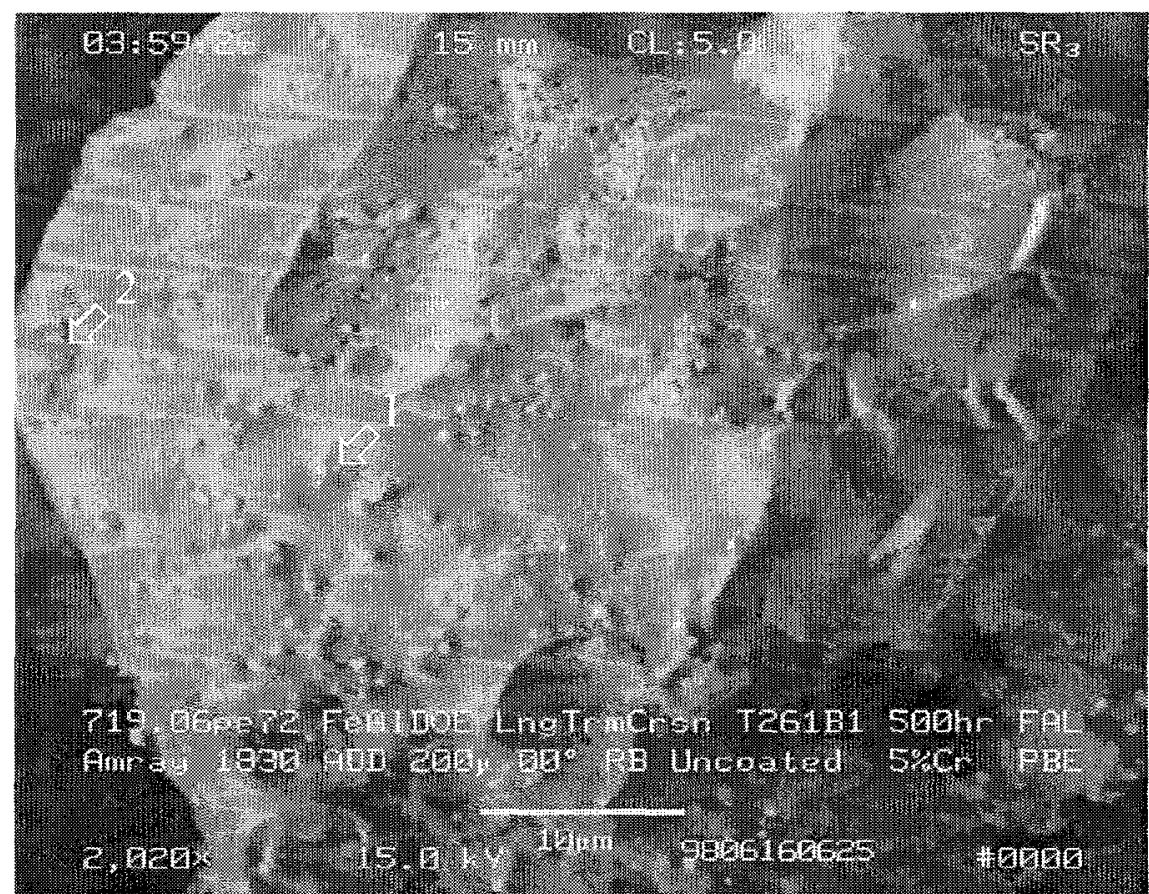

Figure 81: FAL fracture surface. Exposed for 500 hours. Typical unexposed iron aluminide fracture surface with some porosity at sinter bond, zirconium/zirconia nodules on surface. Brittle transgranular fracture. Spectrum of areas (1) and (2) presented in the following figures.

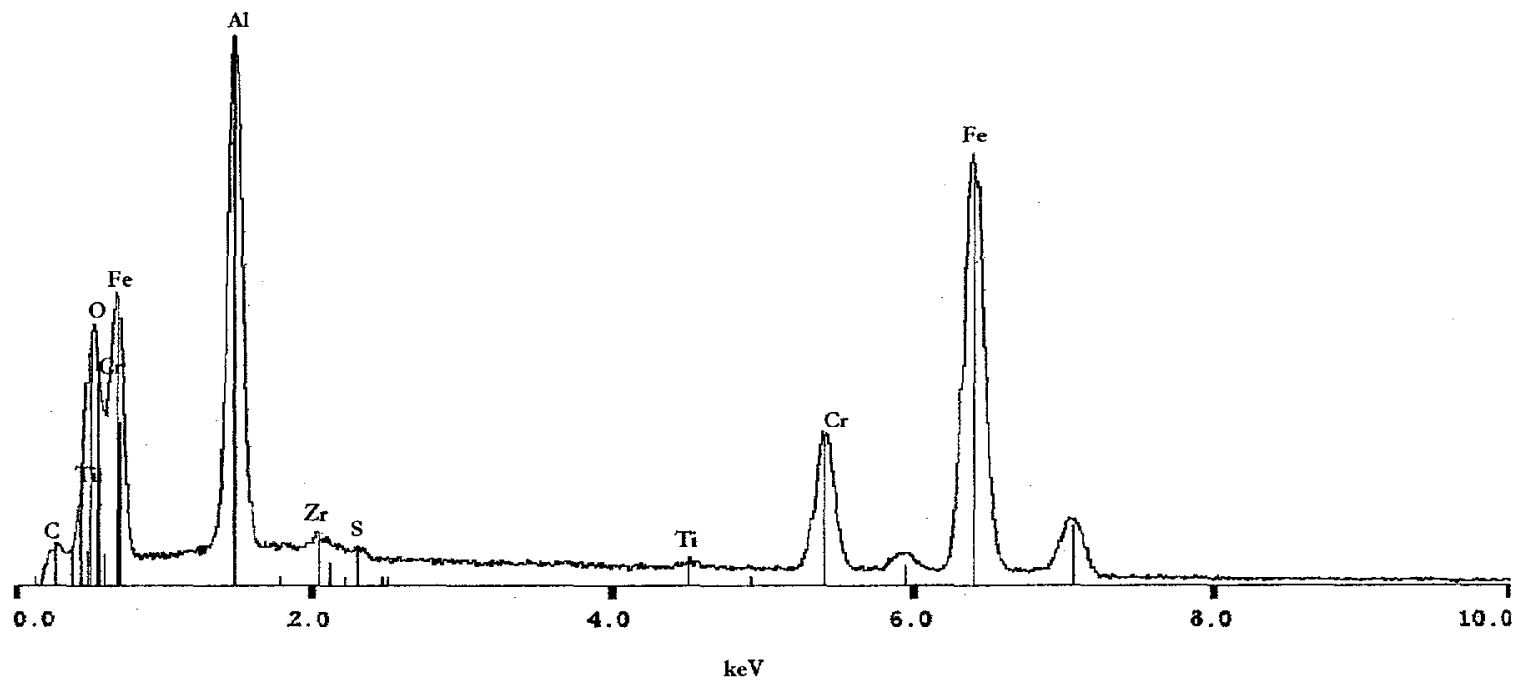

Figure 82: Full screen spectrum of Figure 81. Upstream surface of FAL sample exposed for 500 hours at $2000 \mathrm{X}$. Typical iron aluminide spectrum with a small amount of sulfur. 


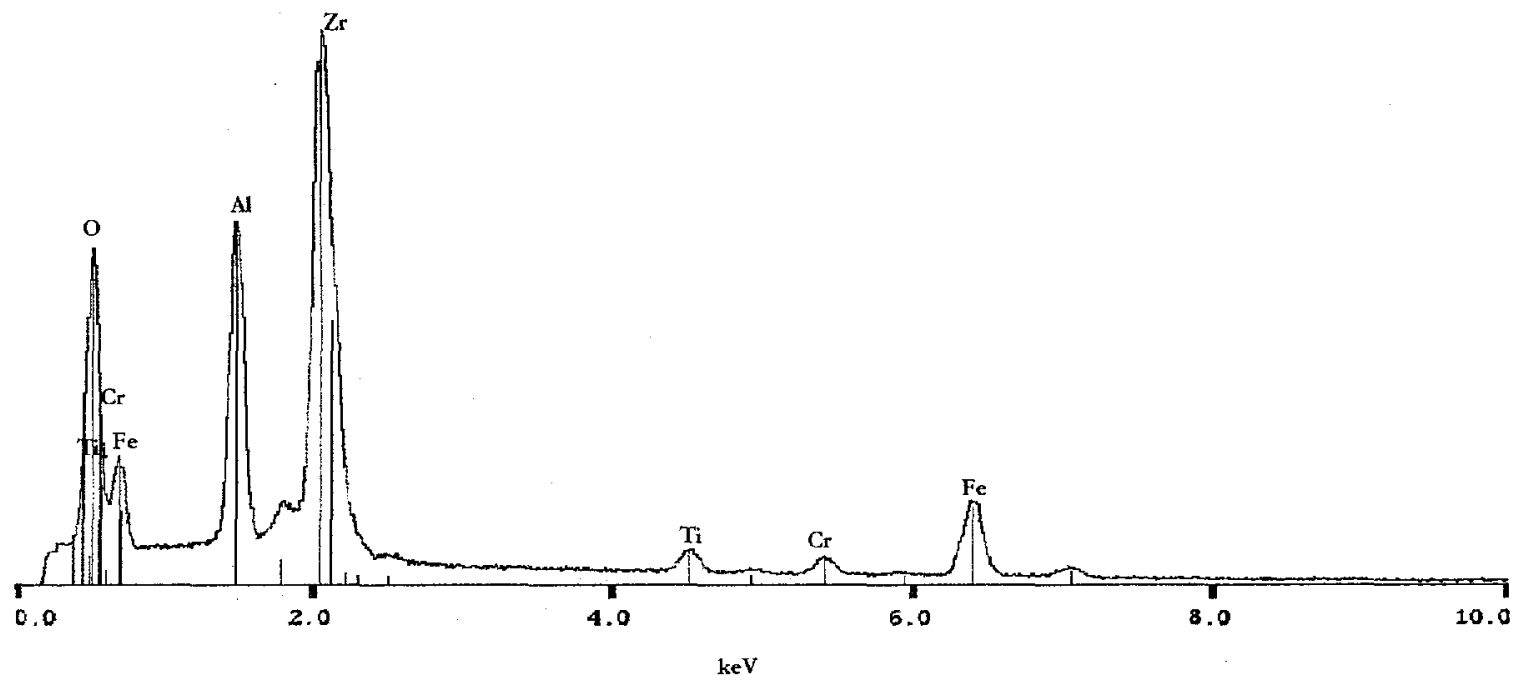

Figure 83: Spot spectrum of bright nodules (1) on Figure 81. Bright nodules are probably zirconium/zirconia.

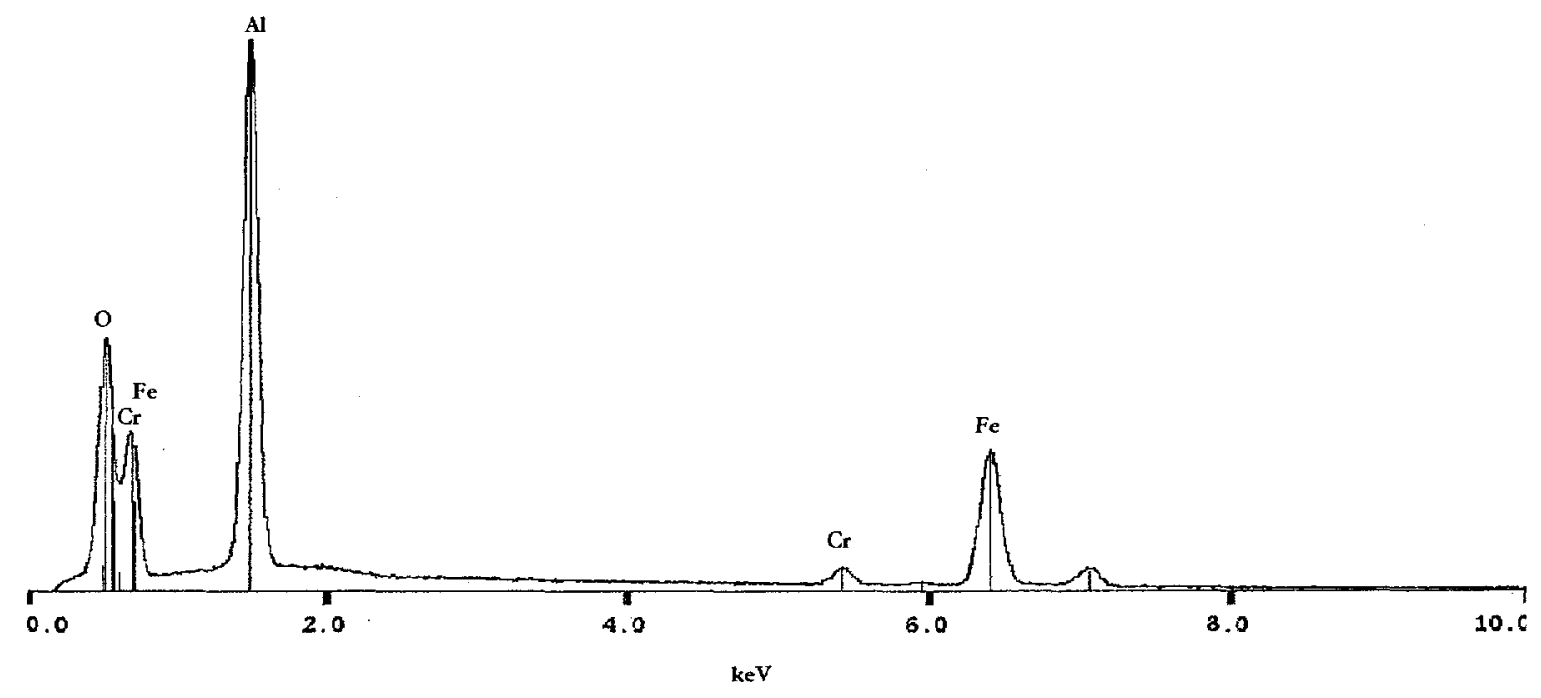

Figure 84: Spot spectrum of dark clusters (2) on Figure 81. The dark clusters are probably alumina crystals. 


\section{SEM Images \\ FAL Sample Exposed for 1000 Hours \\ (FAL Sample \#2)}




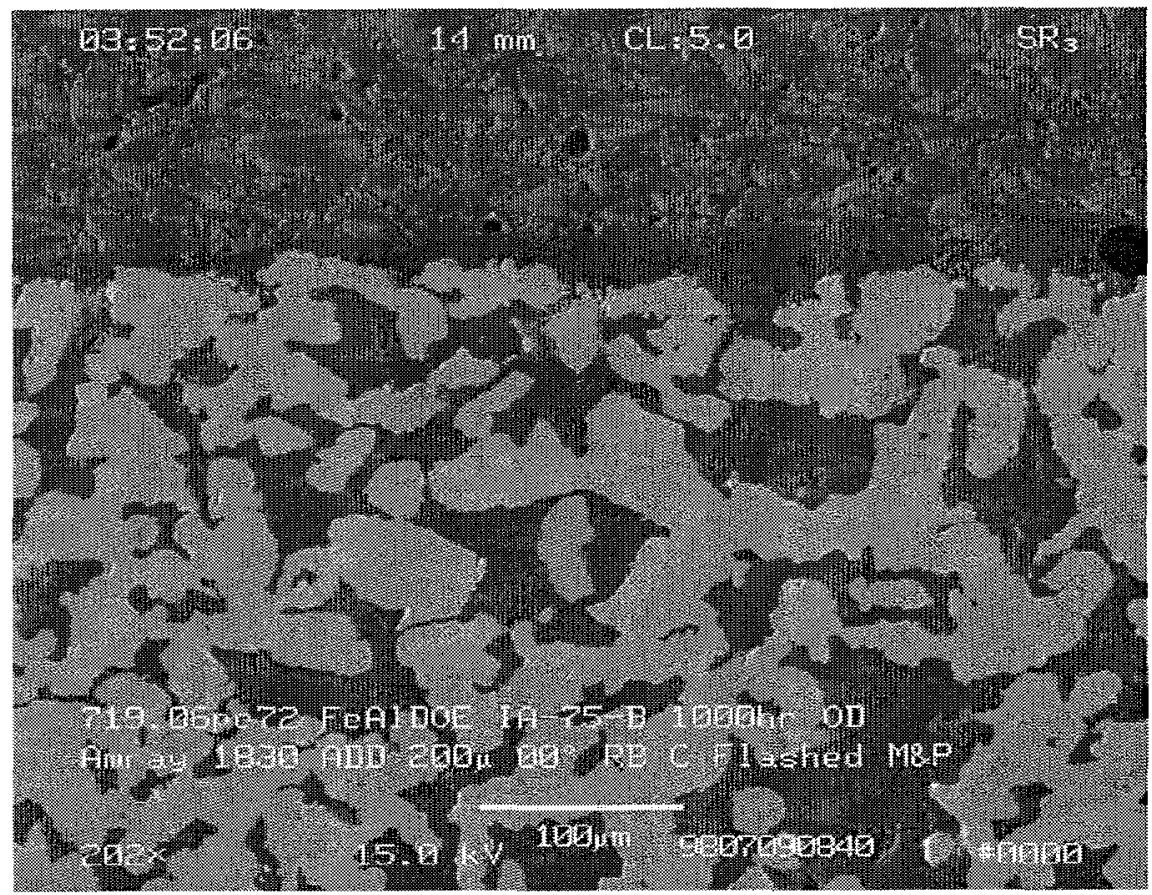

Figure 85: FAL cross-section. Upstream edge shown. Exposed for 1000 hours.

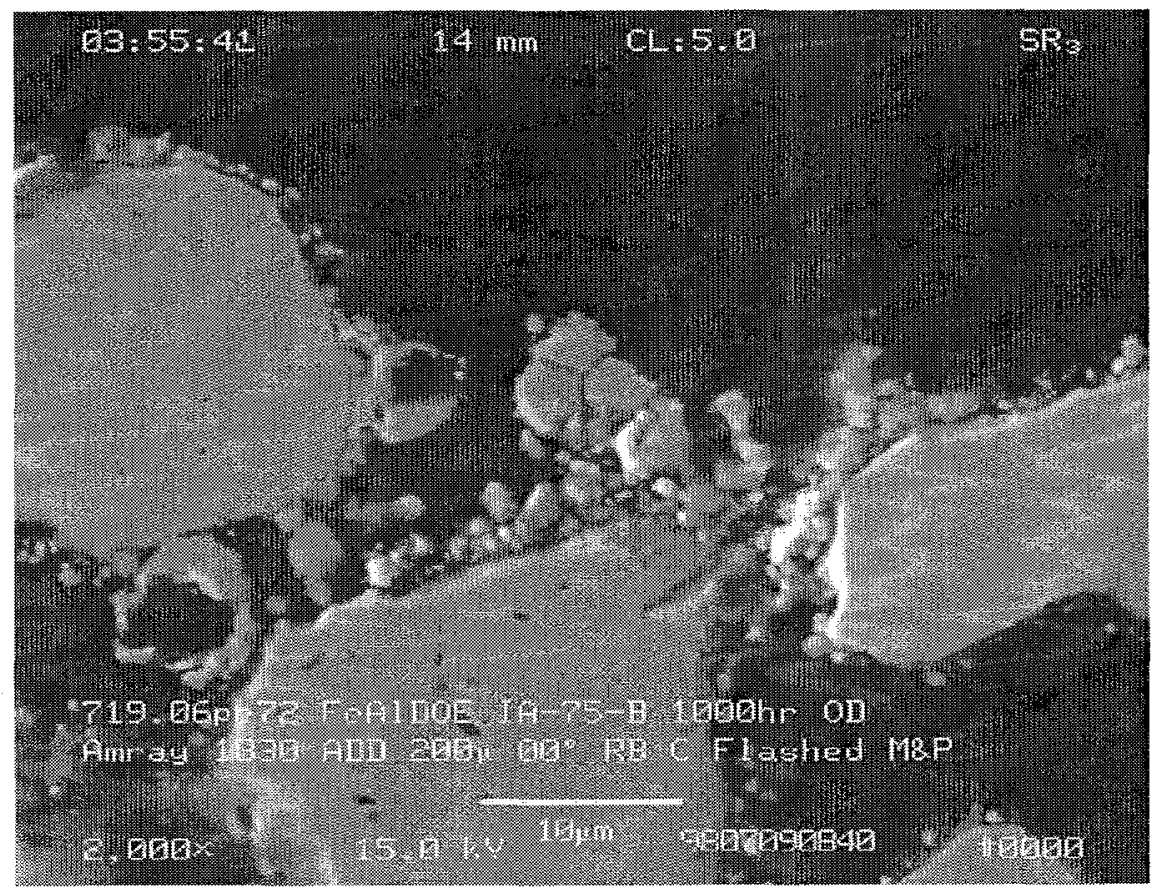

Figure 86: FAL cross-section. Upstream edge shown. Exposed for 1000 hours. Iron sulfide crystals on the upstream surface. 


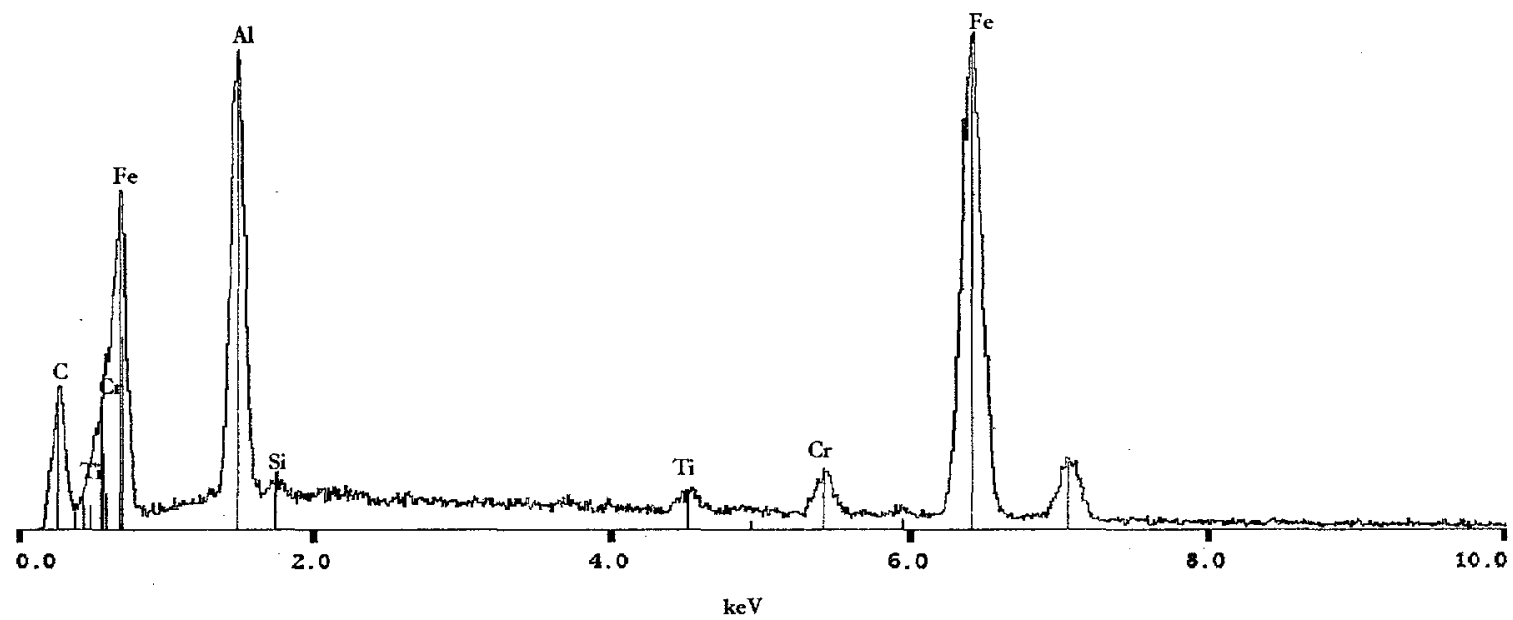

Figure 87: Partial field spectrum of base metal in Figure 86. Typical iron aluminide spectrum.

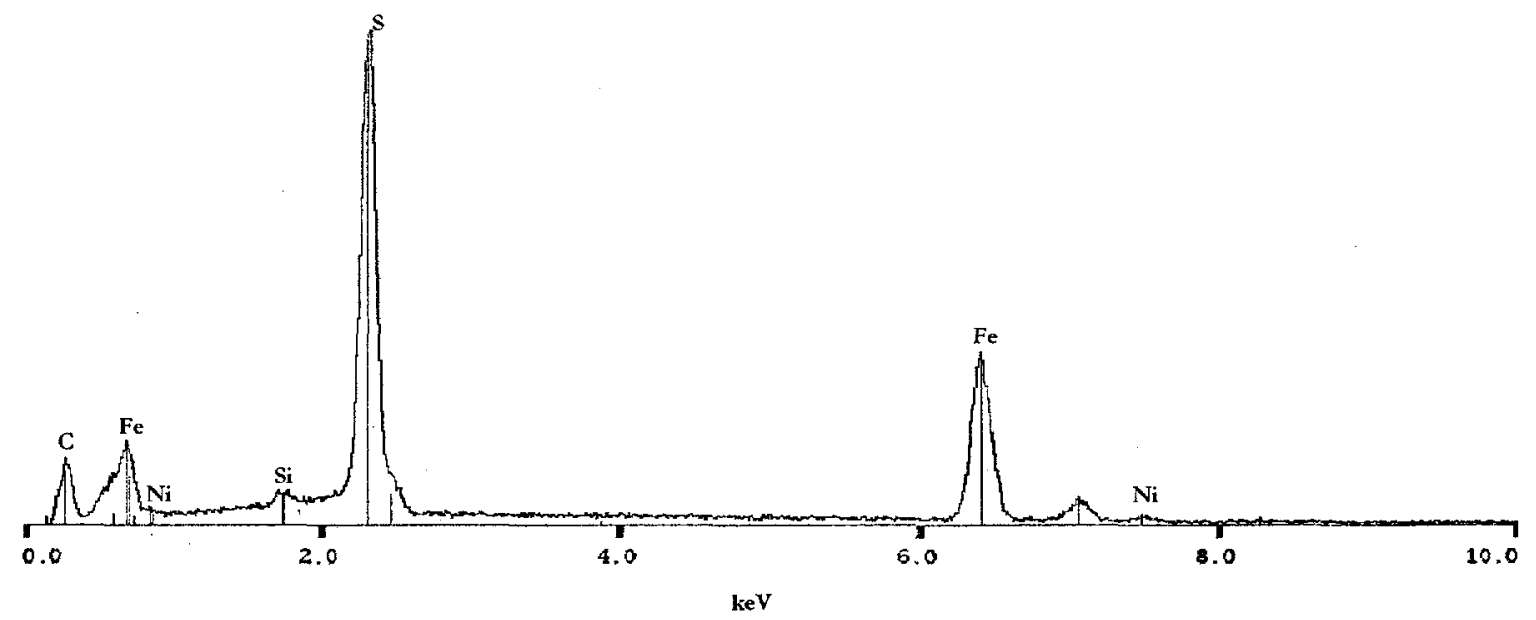

Figure 88: Partial field spectrum of upstream edge in Figure 86. High sulfur and iron. Strong indication of iron sulfides. 


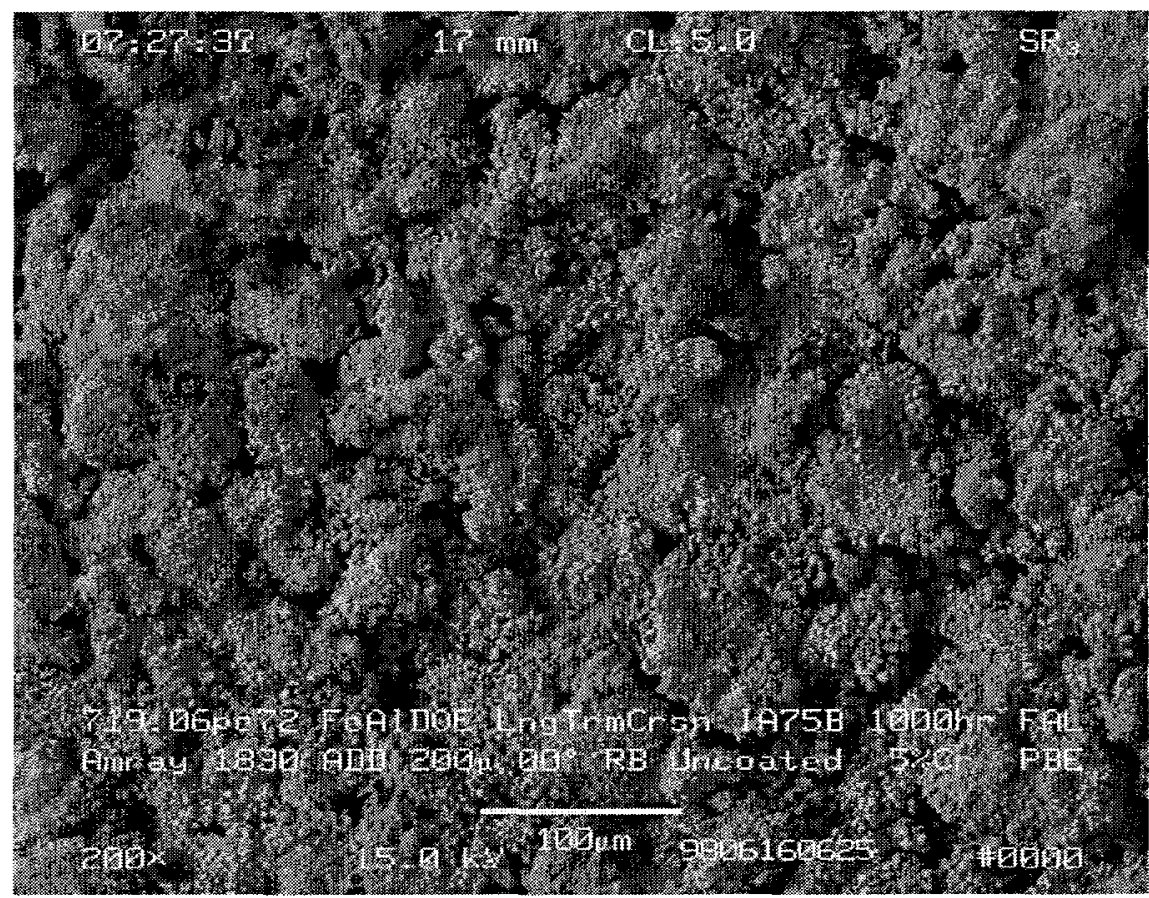

Figure 89: Upstream surface of FAL sample exposed for 1000 hours.

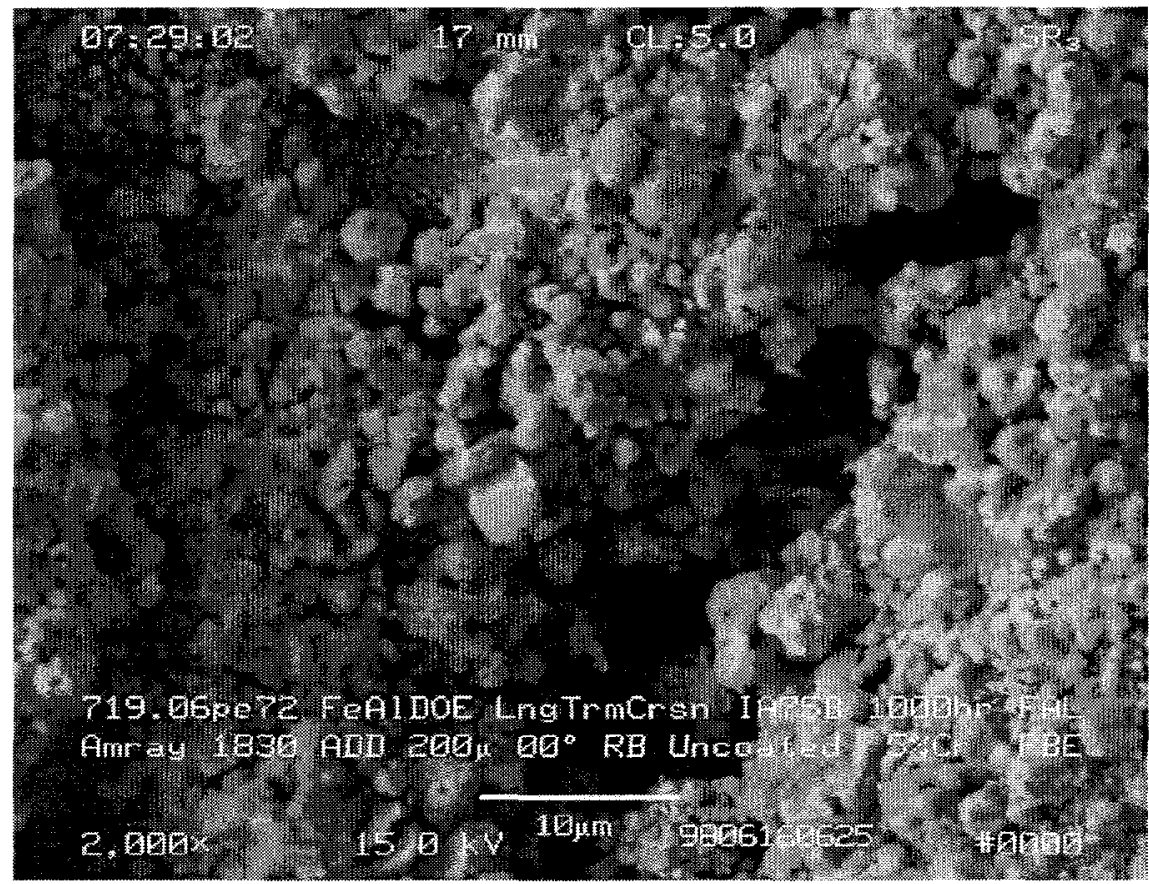

Figure 90: Upstream surface of FAL sample exposed for 1000 hours. Samples surface is covered with iron sulfide crystals. 


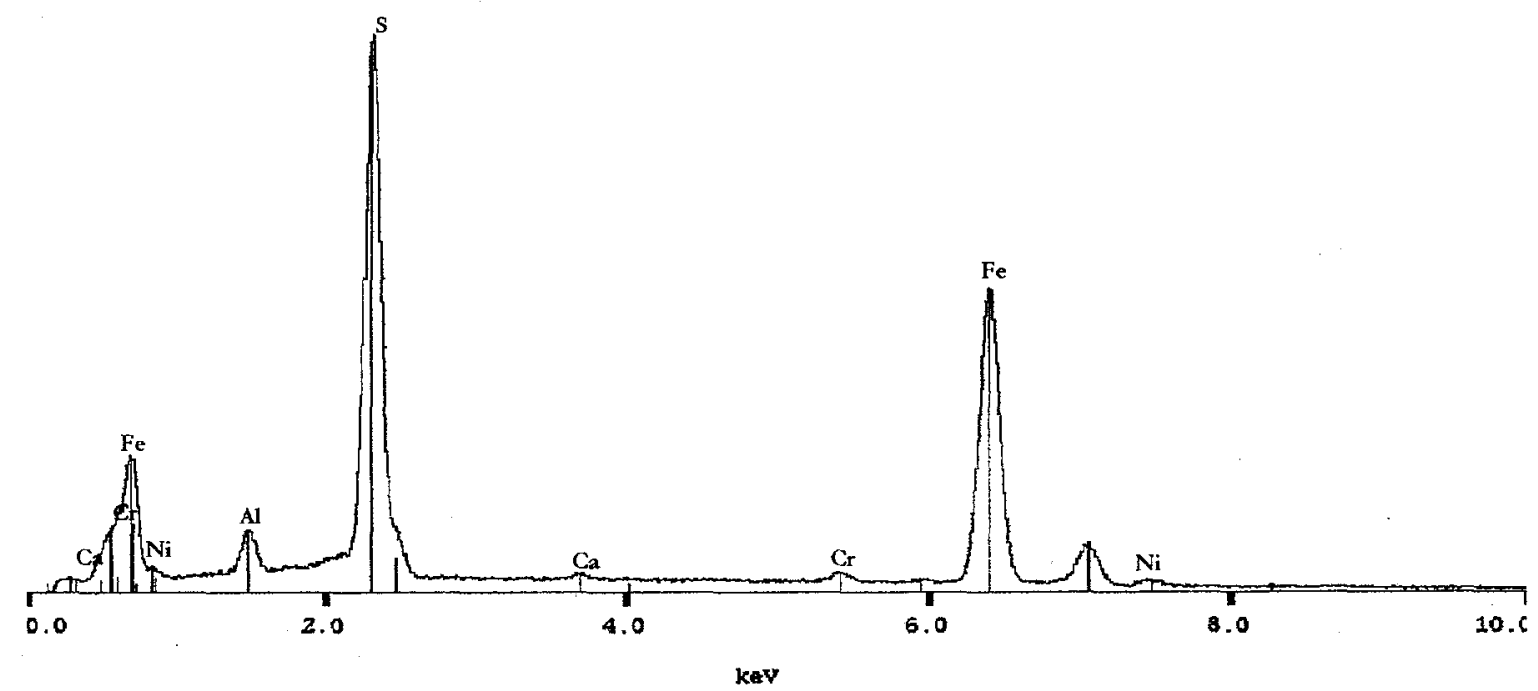

Figure 91: Full screen spectra of Figure 90. The crystals on the upstream surface are most likely iron sulfides.

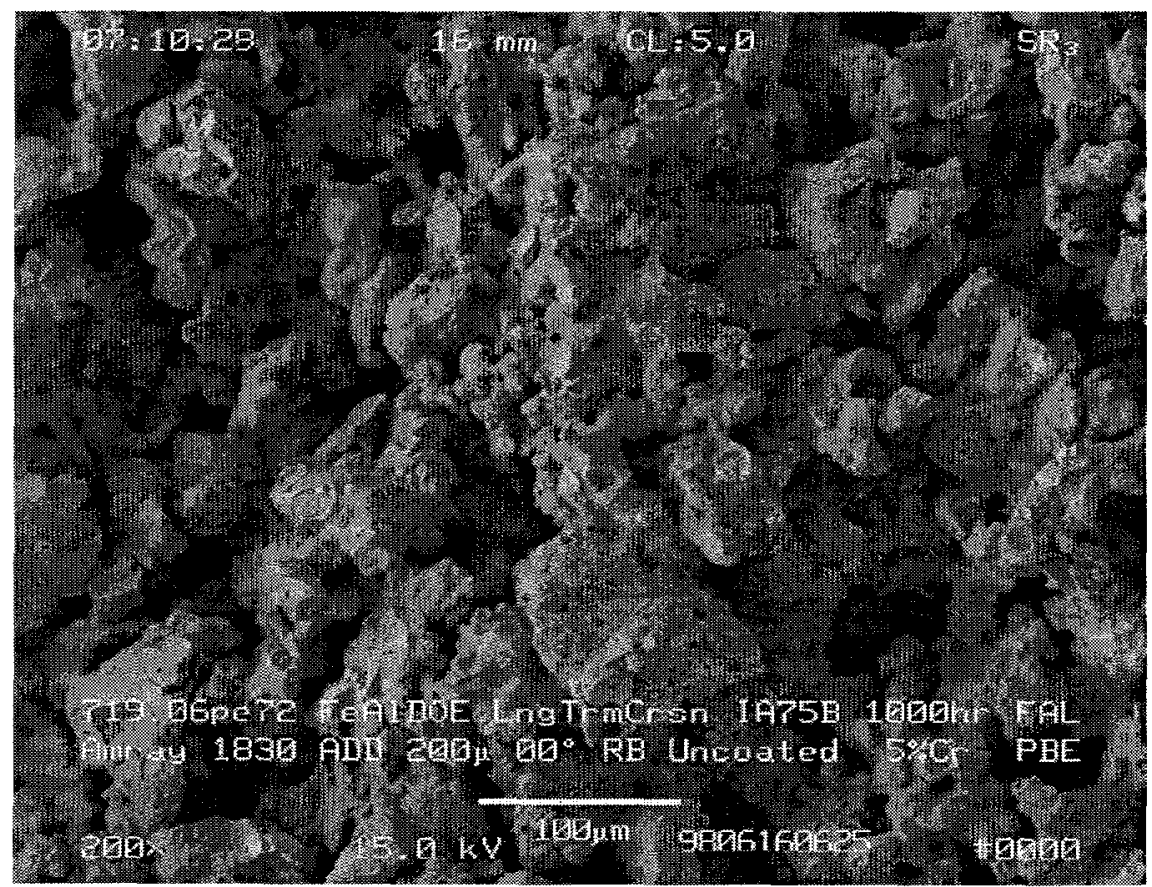

Figure 92: Fracture surface of FAL sample exposed for 1000 hours. 


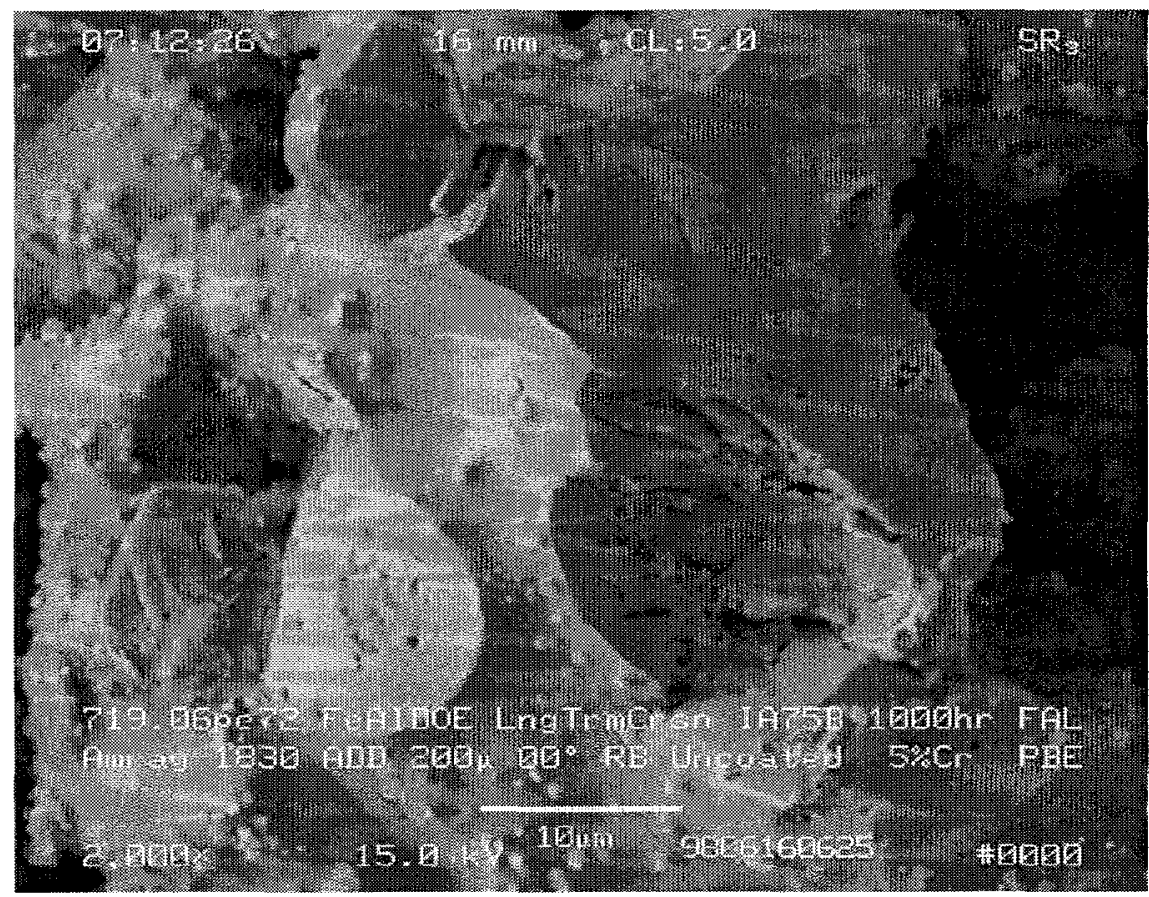

Figure 93: Fracture surface of FAL sample exposed for 1000 hours. Multiple brittle fracture surfaces with some porosity. Zirconium/zirconia nodules on particle surfaces.

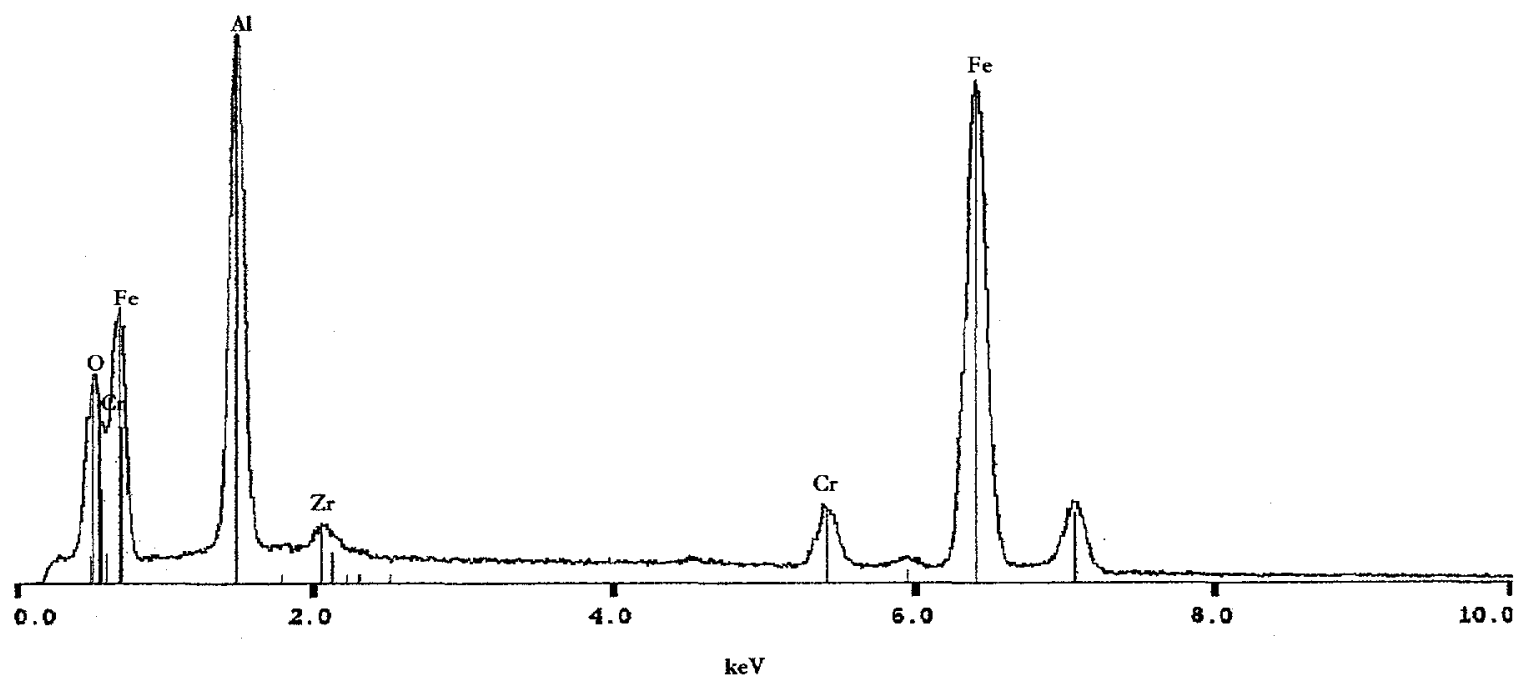

Figure 94: Full screen spectrum of Figure 93. Typical iron aluminide signature. 


\section{SEM Images \\ FAL Sample Exposed for 1500 Hours \\ (FAL Sample \#3)}




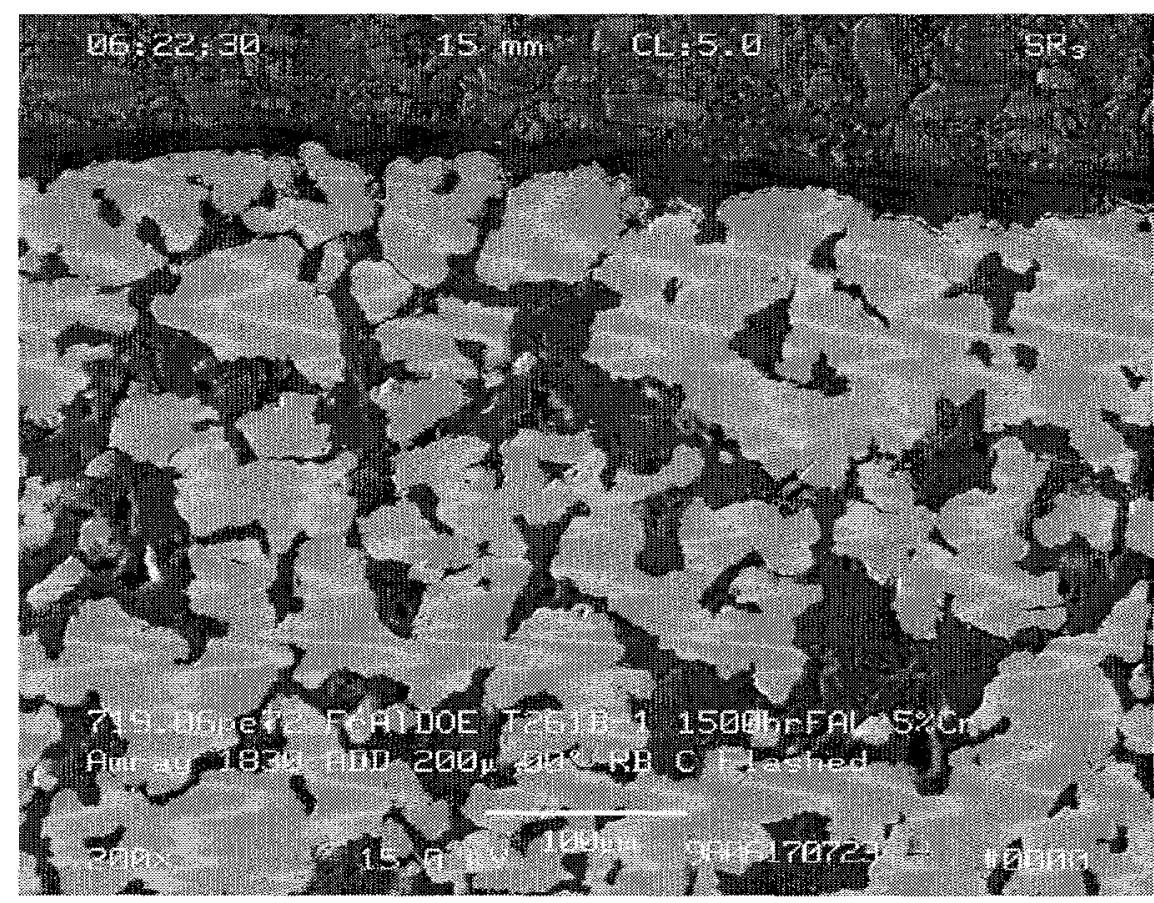

Figure 95: FAL cross-section. Upstream edge shown. Exposed for 1500 hours.

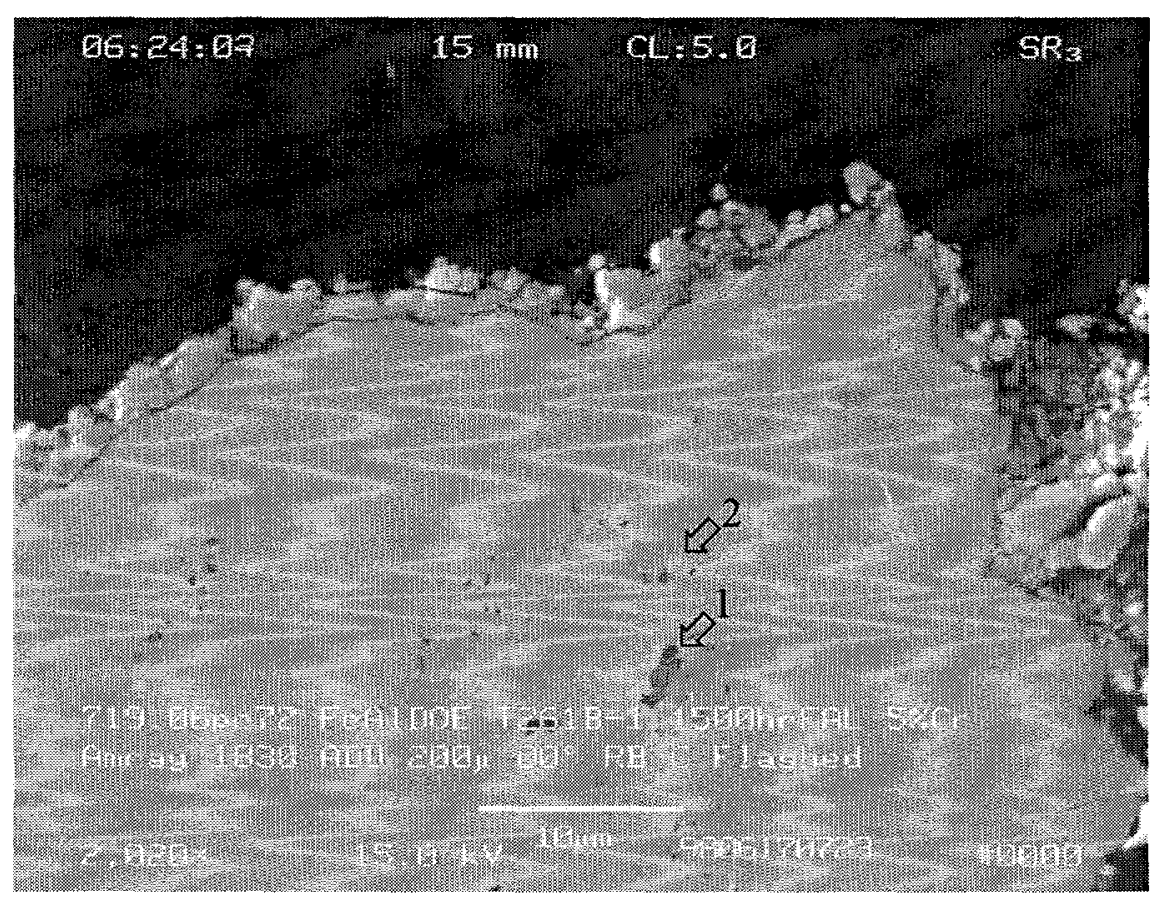

Figure 96: FAL cross-section. Upstream edge shown. Exposed for 1500 hours. Uniform layer of iron sulfide crystals on the upstream surface. Spectrum of areas (1) and (2) presented in the following figures. 


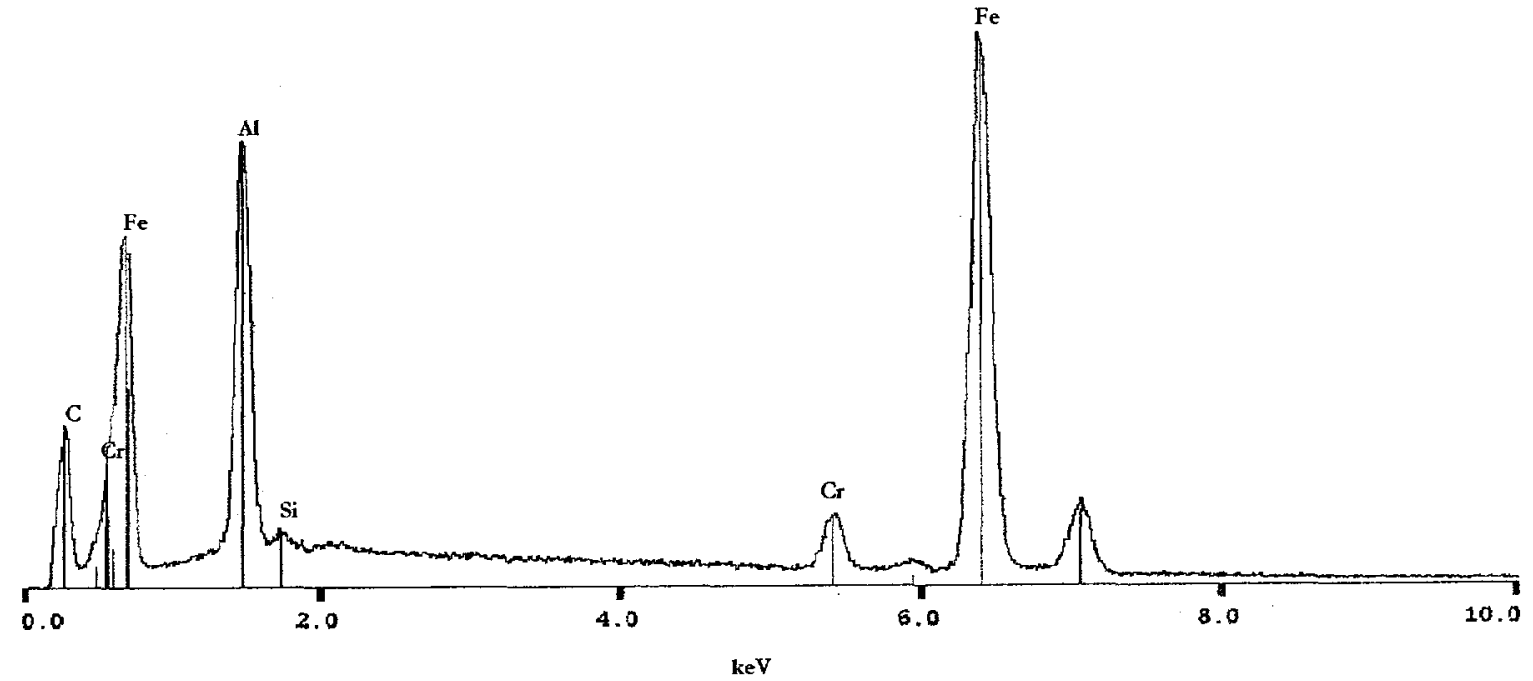

Figure 97: Partial field spectrum of the base metal of Figure 96. Typical iron aluminide signature.

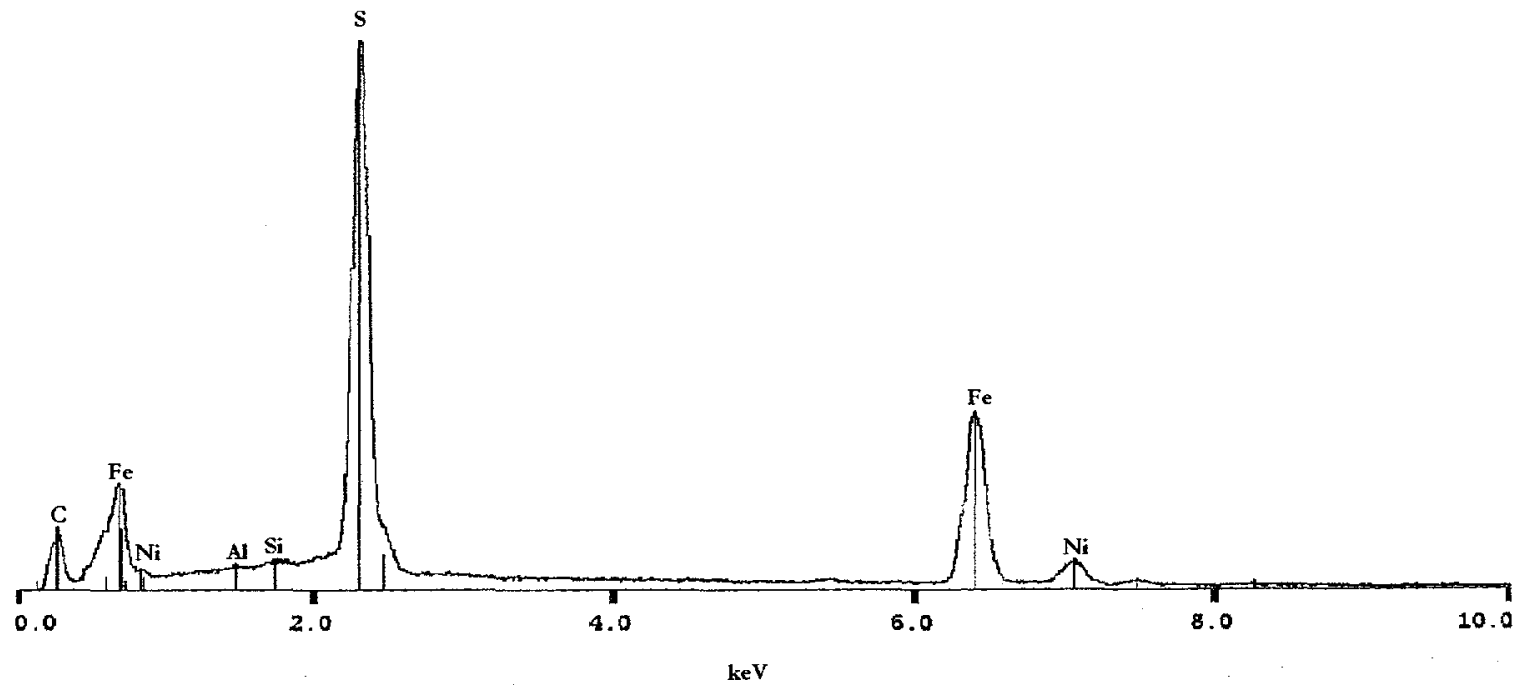

Figure 98: Upstream edge of the filter media of Figure 96. High sulfur and iron. Strong indication of iron sulfides. 


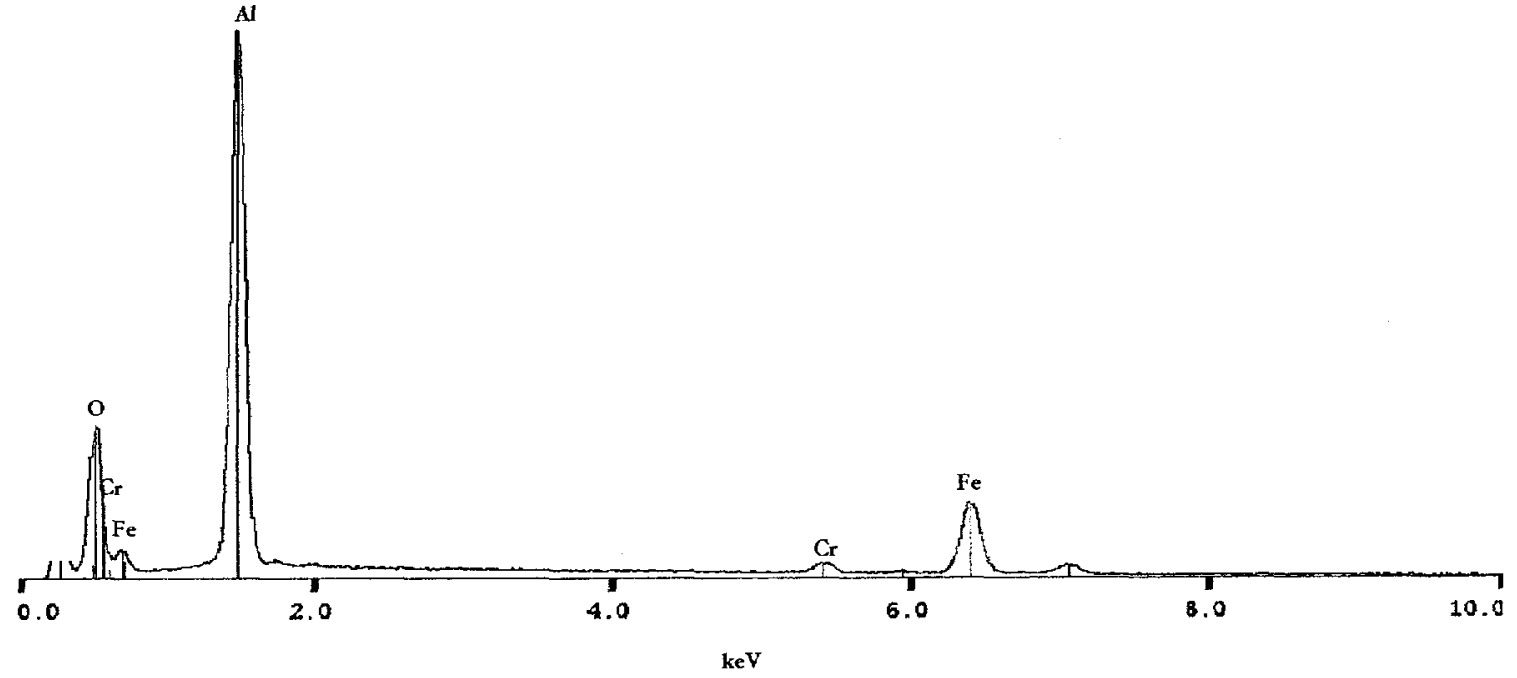

Figure 99: Spot spectrum of dark inclusions (1) in Figure 96. Alumina inclusion from the water atomization of the powdered metal.

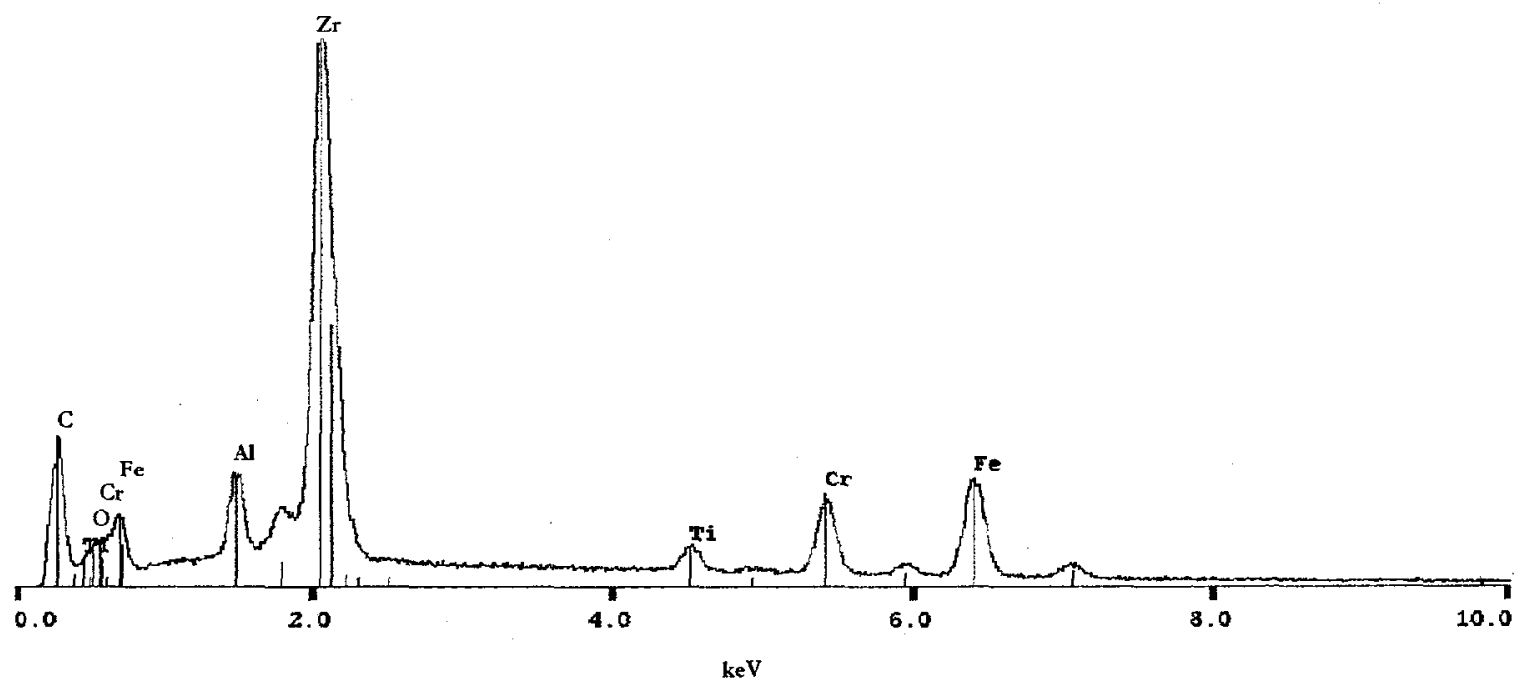

Figure 100: Spot spectrum of light inclusion (2) of Figure 96. Appears to be a zirconia inclusion. 


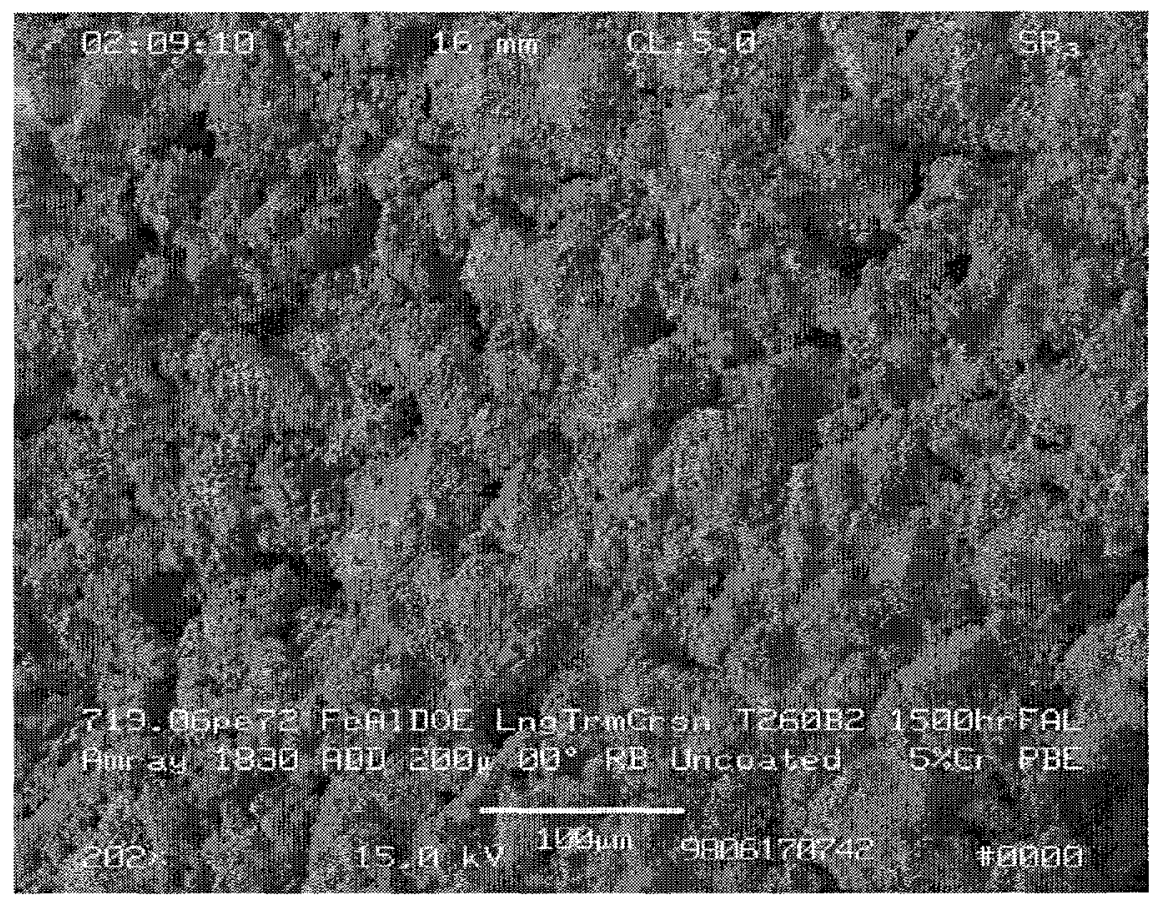

Figure 101: FAL upstream surface. Exposed for 1500 hours. Covered in a layer of crystals.

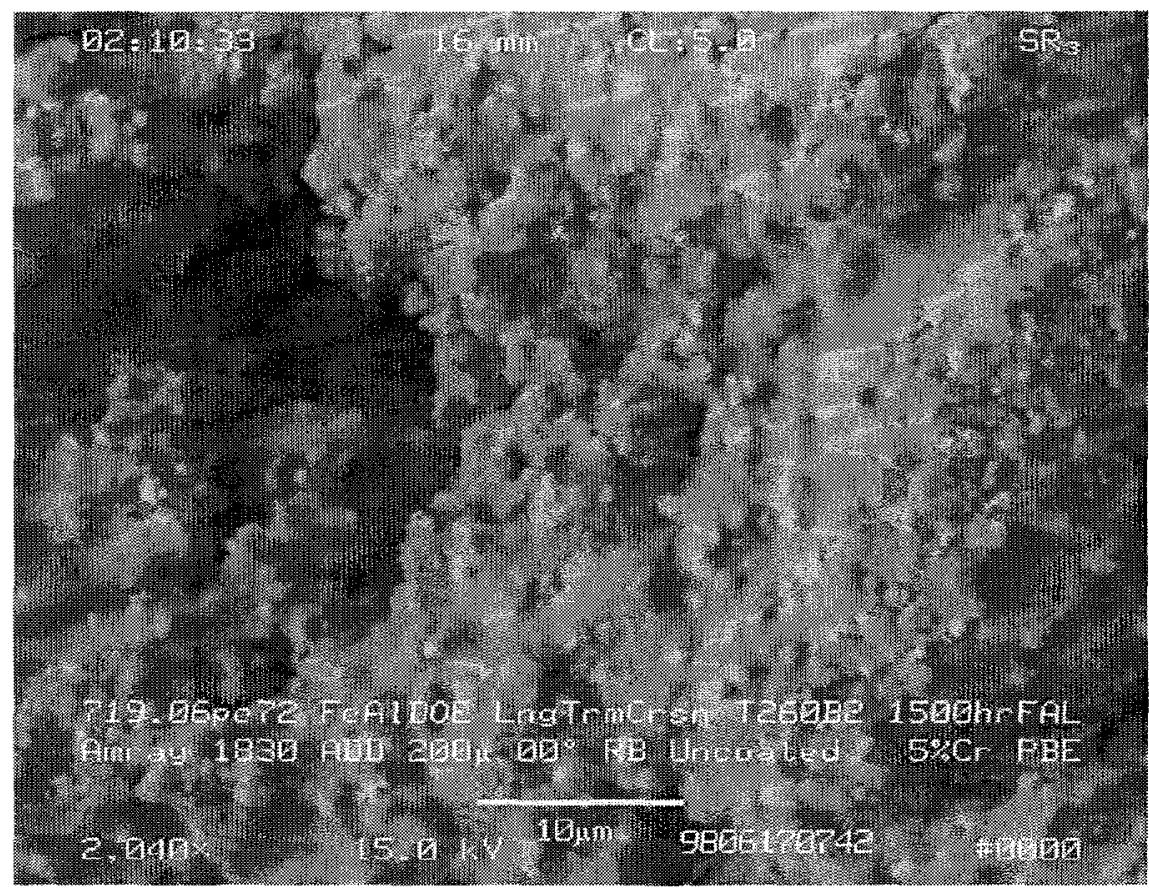

Figure 102: FAL upstream surface. Exposed for 1500 hours. 


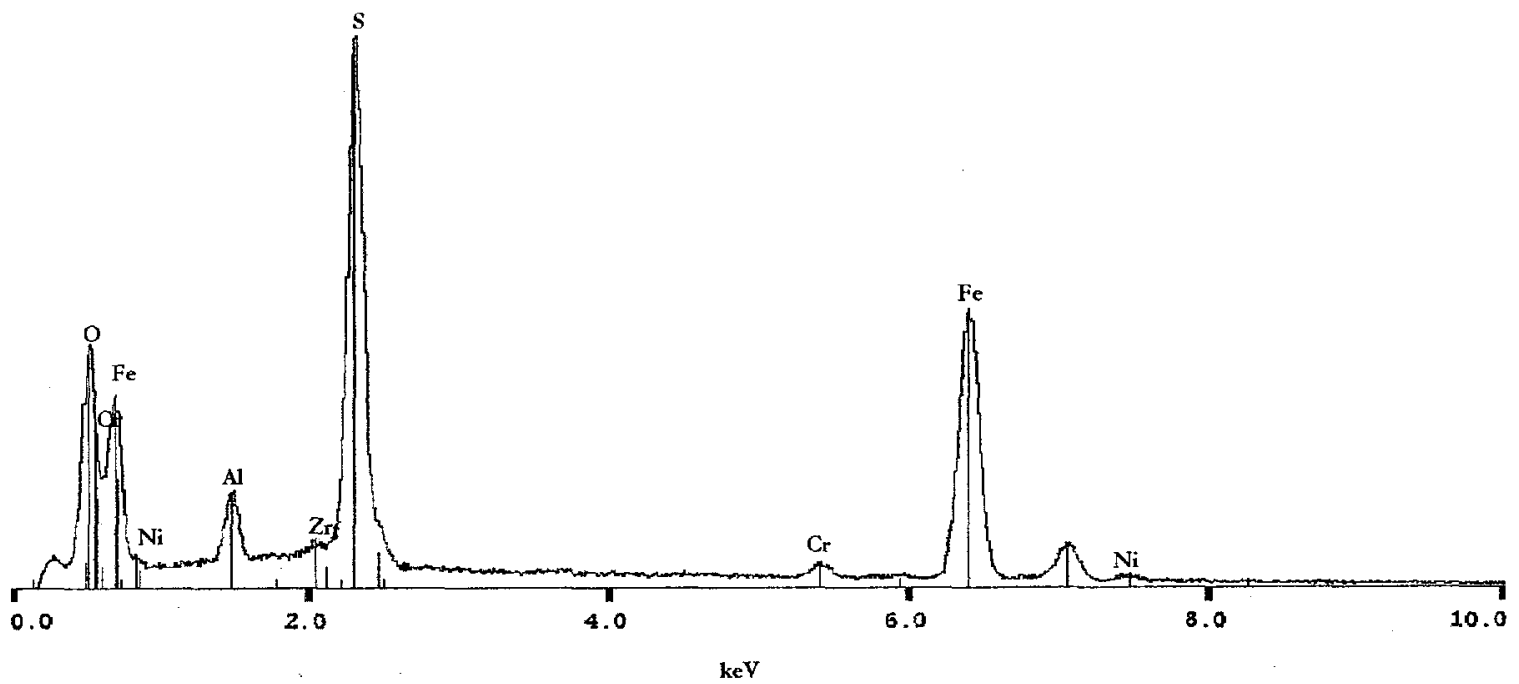

Figure 103: Full screen spectrum of Figure 102. Upstream surface of FAL sample exposed for 1,500 hours at 2000X. High sulfur and iron. Indication of iron sulfides.

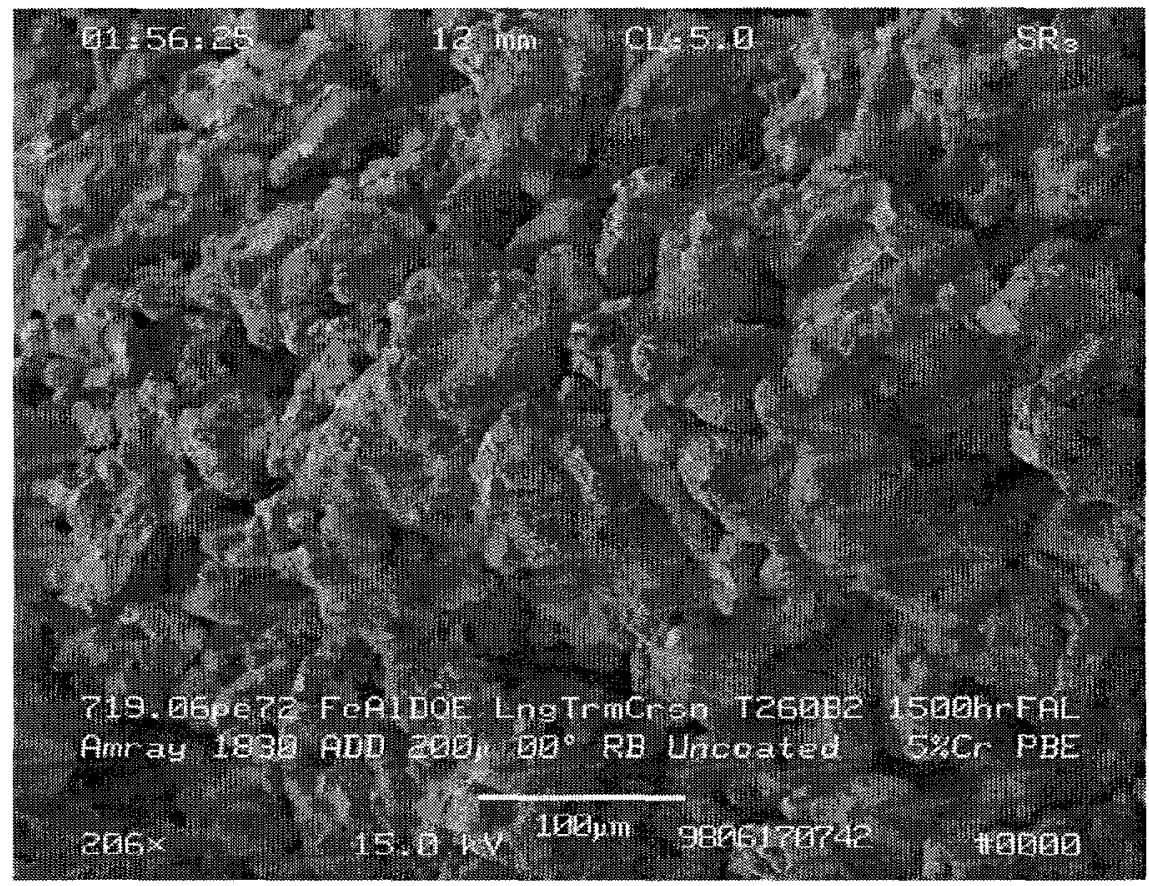

Figure 104: FAL fracture surface. Exposed for 1500 hours. 


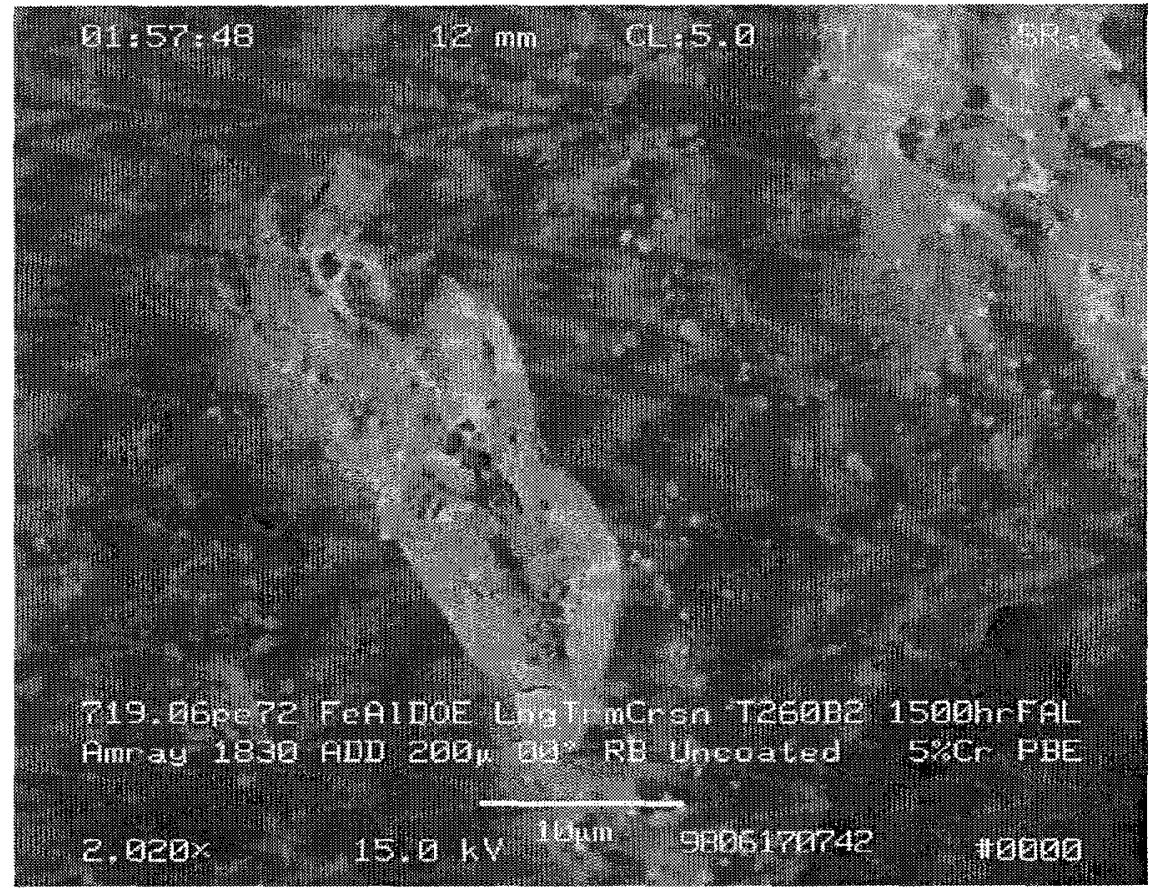

Figure 105: FAL fracture surface. Exposed for 1500 hours.

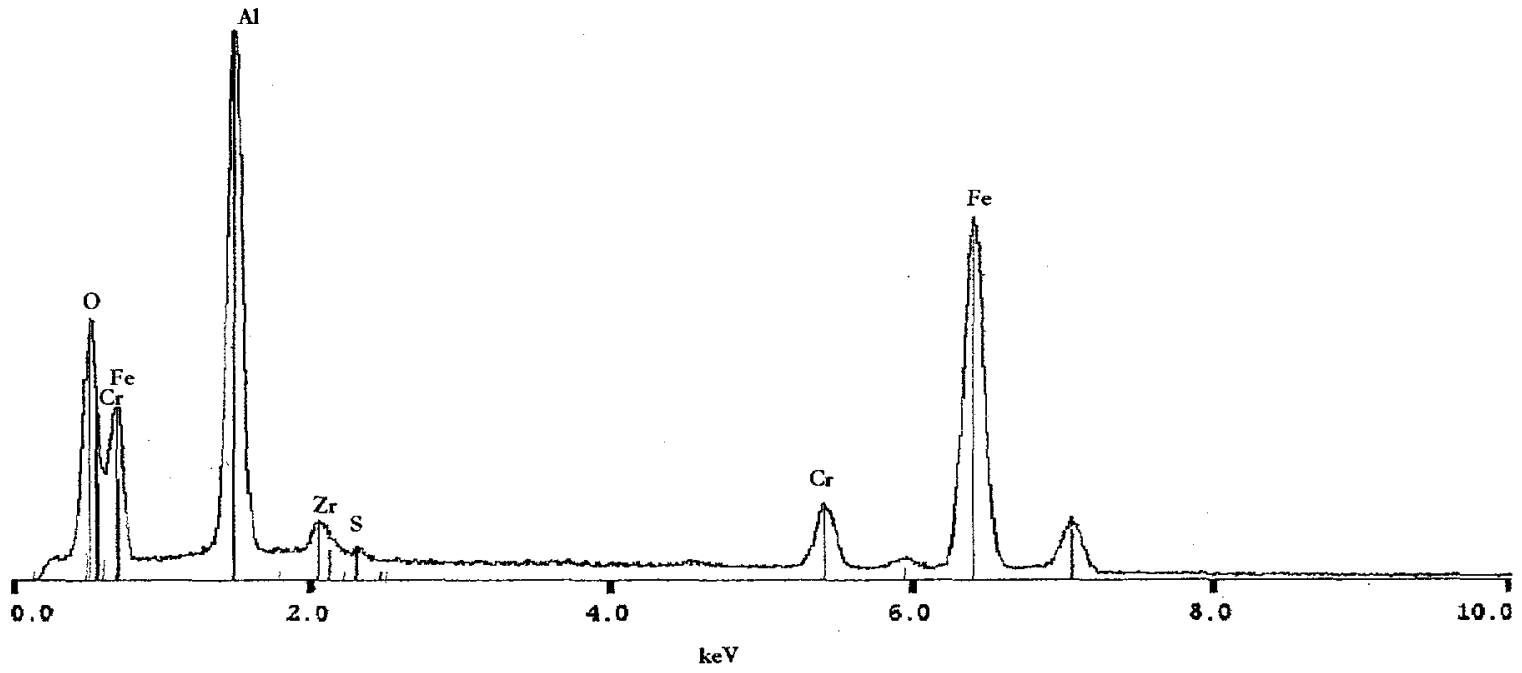

Figure 106: Full screen spectrum of Figure 105. Fracture surface of FAL sample exposed for 1,500 hours at $2000 X$. 


\section{APPENDIX IIV}

\section{RAW NON-DESTRUCTIVE DATA}


Table 4: Mass (grams) of Iron Aluminide Filters (Raw Data)

\begin{tabular}{r|cccccc}
\multicolumn{1}{c|}{ Time (hours) } & FAS sample \#1 & FAS sample \#3 & FAS sample \#2 & FAL sample \#1 & FAL sample \#3 & FAL sample \#2 \\
\hline 0 & 139.0473 & 139.3366 & 137.9868 & 143.7777 & 143.5160 \\
31 & 139.0808 & 139.3725 & & 144.0290 & 143.5578 \\
62 & 139.1097 & 139.4025 & & 144.0505 & 143.5758 \\
125 & 139.1352 & 139.4298 & & 144.0723 & 143.6066 \\
250 & 139.2219 & 139.5179 & & 144.1511 & 143.6911 \\
500 & 139.4493 & 139.7652 & & 144.3741 & 143.9308 \\
750 & & 139.7903 & 138.1535 & & 143.9650 \\
1000 & & 139.7869 & 138.2042 & & 143.9349 & 141.5879 \\
1250 & & 139.8484 & 138.3036 & & 144.0039 & 141.7374 \\
1500 & & 139.8864 & 138.3593 & & 144.0649 & 141.8279 \\
Cleaned & 139.2686 & 139.7667 & & 144.2034 & 143.9258
\end{tabular}

Table 5: Pressure Drop (in. $\mathrm{H}_{2} \mathrm{O}$ ) of Iron Aluminide Filters (Raw Data)

\begin{tabular}{|c|c|c|c|c|c|c|}
\hline Time (hours) & FAS sample \#1 & FAS sample \#3 & FAS sample \#2 & FAL sample \#1 & FAL sample \#3 & FAL sample \#2 \\
\hline 0 & 15.6 & 15.3 & 19.6 & 15.8 & 15.6 & 19.2 \\
\hline 31 & 16.5 & 16.1 & & 18.0 & 16.4 & \\
\hline 62 & 16.1 & 15.9 & & 17.5 & 16.0 & \\
\hline 125 & 17.1 & 17.0 & & 18.7 & 17.2 & \\
\hline 250 & 18.2 & 18.0 & & 19.9 & 18.2 & \\
\hline 500 & 25.4 & 25.3 & & 27.8 & 25.6 & \\
\hline 750 & & 26.3 & 21.7 & & 26.7 & 21.6 \\
\hline 1000 & & 26.9 & 22.2 & & 26.7 & 22.0 \\
\hline 1250 & & 30.7 & 25.6 & & 31.4 & 25.2 \\
\hline 1500 & & 32.9 & 29.1 & & 33.5 & 26.7 \\
\hline Cleaned & 21.6 & 20.7 & 20.1 & 23.1 & 21.1 & 20.7 \\
\hline
\end{tabular}


Table 6: First Bubble Point (in. $\mathrm{H}_{2} \mathrm{O}$ ) of Iron Aluminide Filters (Raw Data)

\begin{tabular}{r|cccccc}
\multicolumn{1}{c}{ Time (hours) } & FAS sample \#1 & FAS sample \#3 & FAS sample \#2 & FAL sample \#1 & FAL sample \#3 & FAL sample \#2 \\
\hline 0 & 20.5 & 20.5 & 20.5 & 22.5 & 22.0 \\
31 & 18.9 & 19.0 & & 23.0 & 24.1 \\
62 & 19.2 & 19.1 & & 22.1 & 24.0 \\
125 & 20.8 & 18.1 & & 23.6 & 17.8 \\
250 & 20.8 & 19.1 & & 19.2 & 20.8 \\
500 & 12.4 & 21.5 & & 20.0 & 25.3 & 19.9 \\
750 & & 20.6 & 15.1 & & 24.5 & 8.0 \\
1000 & & 22.7 & 21.8 & & 21.2 & 3.3 \\
1250 & & 21.0 & 29.1 & & & 21.7
\end{tabular}

Table 7: Tenth Bubble Point (in. $\mathrm{H}_{2} \mathrm{O}$ ) of Iron Aluminide Filters (Raw Data)

\begin{tabular}{r|cccccc} 
Time (hours) & FAS sample \#1 & FAS sample \#3 & FAS sample \#2 & FAL sample \#1 & FAL sample \#3 & FAL sample \#2 \\
\hline 0 & 21.9 & 21.0 & 21.9 & 23.6 & 22.9 & 22.8 \\
31 & 22.9 & 20.6 & & 23.1 & 23.5 & 24.5 \\
62 & 19.8 & 20.6 & & 24.4 & 23.8 \\
125 & 21.9 & 19.2 & & 23.1 & 23.0 & 26.0 \\
250 & 21.5 & 20.8 & & & 26.0 & 25.8 \\
500 & 24.7 & 21.9 & 20.9 & & 24.3 & 2.5 \\
750 & & 23.0 & 22.6 & & 25.7 & 22.4 \\
1000 & & 23.0 & 23.6 & & & 20.8 \\
1250 & & 21.0 & 20.5 & & & 25.4
\end{tabular}


Table 8: Open Bubble Point (in. $\mathrm{H}_{2} \mathrm{O}$ ) of Iron Aluminide Filter (Raw Data)

\begin{tabular}{r|cccccc} 
Time (hours) & FAS sample \#1 & FAS sample \#3 & FAS sample \#2 & FAL sample \#1 & FAL sample \#3 & FAL sample \#2 \\
\hline 0 & 25.3 & 25.0 & 28.3 & 25.9 & 26.5 & 27.5 \\
31 & 24.2 & 26.9 & & 30.0 & 31.0 & \\
62 & 26.3 & 26.5 & & 30.8 & 29.5 & \\
125 & 26.1 & 25.9 & & 29.2 & 29.0 & \\
250 & 25.8 & 26.6 & & 29.6 & 30.2 & \\
500 & 32.7 & 34.7 & & 36.2 & 36.0 & 30.1 \\
750 & & 36.2 & 29.2 & & 35.0 & 29.3 \\
1000 & & 35.3 & 29.0 & & 36.0 & 30.0 \\
1250 & & 33.0 & 29.1 & & 35.0 & 35.0 \\
1500 & & 39.0 & 33.0 & & 30.2 & 26.1
\end{tabular}

